الوسائل المستحدثة

للفصل في الاعاوى الإدارية خلال مدة معقولة في النظام القانوني الفرنسي ومدى إمكانية تطبيقها أمام محاكم

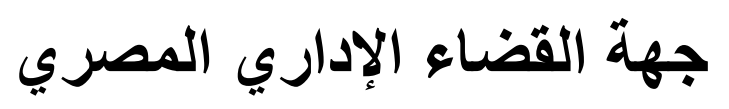

\title{
تأليـف
}

\author{
د / شعبان أحمد رمضان \\ أستاذ القانون العام المساعد \\ كلية الحقوق - جامعة أسيوط
}




$$
\begin{aligned}
& \text { الطبعة الأولى - } 2020 \\
& \text { الناشر دار النهضة العربية } \\
& 32 \text { شارع عبد الخالق ثروت ـ القاهرة }
\end{aligned}
$$

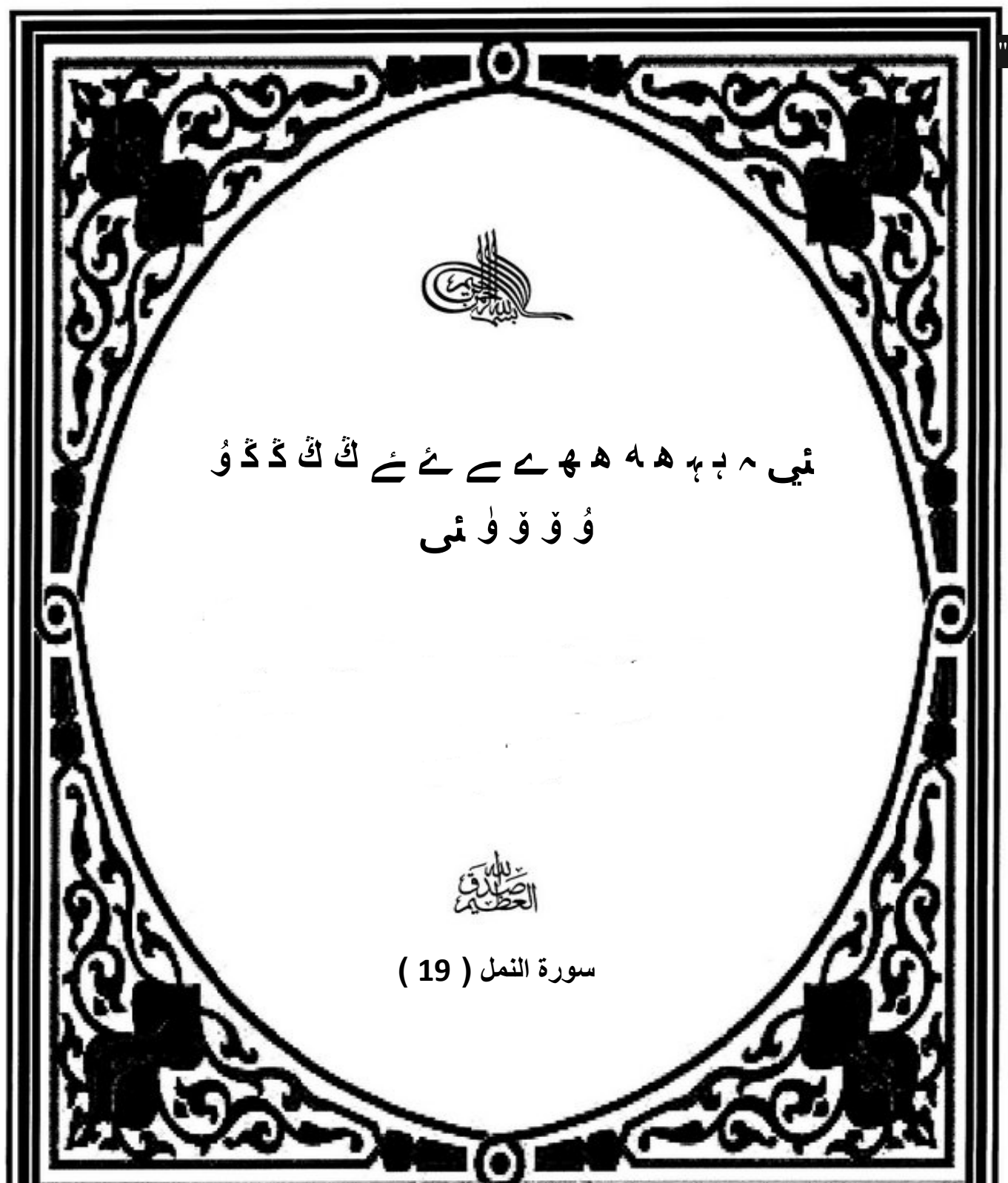




$$
\text { إ }
$$

$$
\text { إلى روح الأخ الفاضل }
$$

الأستاذ الدكتور / عبد المحسن سيد ريان

طيب الله ثراه وأسكنه فسيح جناته 


\section{الوسائل المستحدثة}

للفصل في الدعاوى الإدارية خلال مدة معقولة في النظام القانوني القرنسي خدارة

\section{شعبان أحمد رمضنان}

\section{ملخص البحث}

تتاولت الدراســة الماثلة موضــوع " الوسـائل المسـتحدثة للفصـل في الدعاوى الإدارية خلال مدة معقولة في النظام القانوني الفرسـي ومدى امكانية تطبيقها أمام جهة القضــاء الإداري المصـري " عبر تقسـيمها لثلاثة فصـول عرضنا في الأول منها للفصل في الدعاوى الإدارية خلال مدة معقولة في النظام القانوني الفرنسي من خلال التصدي لتأصيل فكرة العدالة الناجزة في مجال المنازعات الإدارية عبر تحديد الأسـاس القانوني للمدة المعقولة اللازمة للفصل في الدعاوى الإدارية في النظام القانوني الفرنسـي في مبحث أول ، ومضـمون تلك المدة ومعايير تحديدها في مبحث آخر .

وتتاولنا في الفصـل الثاني وسـائل الفصـل في بعض الدعاوى الإدارية خلال مدة معقولة طبقاً لتقنين العدالة الإدارية الفرنسـي وتعديلاته المختلفة بهذا الخصـوص حيث عرضــنا لأبرز تلكم الوسـائل والمتمثلة في إعفاء المقرر

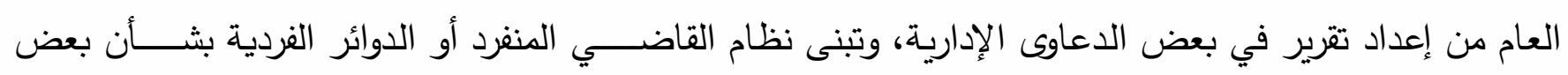

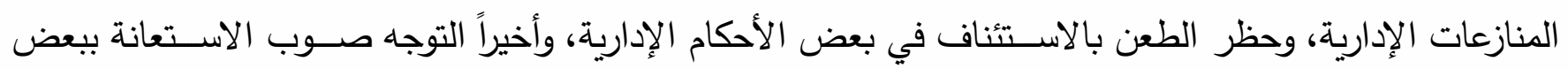
وسائل التقاضي الإكتروني في مجال الدعاوى والطعون الإدارية وذلك في أربعة مباحث على التوالي. وفى الفصـل الثالث والأخير تصدينا لبيان مدى اعتناق القضـاء الإداري المصـري لمبدأ الفصـل في الدعاوى الإدارية خلال مدة معقولة من خلال تقسـيمه لمبحثين عرضــا في أولهما للأسـاس الدسـتوري والقانوني للفصـل في الدعاوى الإدارية خلال مدة معقولة في النظام القانوني المصـري ، وكرســا الآخر لأبرز تطبيقات القضــاء الإداري

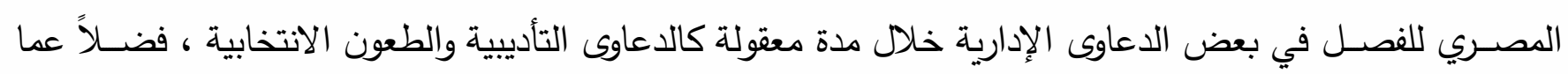
تبنته المحكمة الإدارية العليا بشأن الاكتفاء بإبداء هيئة مفوضي الدولة لرأيها شفاهة في جلسة المرافعة بشأن موضوع الإديه الدعوى دون تطلب تقرير مكتوب بهذا الخصــوص ، وهو الاتجاه الذى باركه واعتنقه المشــرع المصــري في بعض التشريعات بعد صدور الدستور الحالي لعام 2014م وأبرزها قانون مباشرة الحقوق السياسية ، وقانون مجلس النواب، وقانون الهيئة الوطنية للانتخابات .

\section{Summary}




\section{شعبان أحمد رمضنان}

The present study dealt with the topic of "the new means of adjudicating administrative cases within a reasonable period in the Persian legal system and the extent to which they can be applied before the Egyptian administrative judiciary" by dividing it into three chapters. The idea of completed justice in the field of administrative disputes by defining the legal basis for the reasonable period necessary for adjudication of administrative cases in the French legal system in a first section, the content of that .period and the criteria for determining it in another topic

In the second chapter, we dealt with the means of adjudicating some administrative cases within a reasonable period according to the French administrative justice codification and its various amendments in this regard. Administrative, and the prohibition of appealing some administrative rulings, and finally the trend towards the use of some electronic litigation methods in the field of .lawsuits and administrative appeals in four sections, respectively

In the third and final chapter, we addressed the extent to which the Egyptian administrative judiciary embraced the principle of adjudication of administrative cases within a reasonable period by dividing it into two sections. Some administrative cases within a reasonable period, such as disciplinary cases and electoral appeals, as well as what the Supreme Administrative Court has adopted regarding the contentment of the State Commissioners body expressing its opinion orally in the pleading session on the subject matter of the case without requiring a written report in this regard, which is the trend that was blessed and embraced by the Egyptian legislator in some legislations after the issuance of The current constitution for 2014, most notably the law of exercising political rights, the law of the House of

.Representatives, and the law of the National Elections Authority 


\section{الوسائل المستحدثة}

للفصل في الدعاوى الإدارية خلال مدة معقولة في النظام

القانوني الفرنسي

\section{شعبان أحمد رمضنان}

المقدمــة:

شُر عت إجر اءات التقاضي لكفالة حسن سير مرفق القضاء من ناحية ، ولضمان تحقيق العدالة الجيدة من ناحية أخرى ـ بيد أن المُخالاة أو الإفر اط في تلكم الإجر اءات يُعيق على نحو خطير فكرة العدالة الناجزة وما تقتضيه من تيسير إجراءات التقاضي وصولاً للترضية القضائية لرافع الدعوى ـ الأمر الذي يتعين معه السعي لتحقيق العدالة الجيدة و الناجزة في آن و احد. ذللك أن كفالة الحق في التقاضي كأحد أهم الحقوق الدستورية - باعتباره الوسيلة العملية لحماية غيره من الحقوق و الحريات ـ لا تقتصر على مجرد تقريره للقول بوجوده وفاعليته ، و إنما تستوجب التوازن بين سرعة الفصل في الدعاوى تحقيقاً للعدالة الناجزة من ناحية ، و الحصول على ترضية قضائية جيدة ، تو افق صحيح الدستور و القانون و اصول العمل القضائي تكريساً للعدالة الجيدة من ناحية أخرى ـ فالغاية التي يرنو إليها المتقاضون من اللجوء إلى القضاء ـ على حد تعبير المحكمة الدستورية العليا بأحد أحكامها ـ ليس مجرد الحصول على الترضية القضائية فحسب ، بل الحصول عليها في مدة أو أجل معقول بحيث يتعين على المحاكم تقديم تلكم الترضية في وقت ملائم دون تباطؤ متعدد أو غير مبرر ـ. ذلك أن تسويف الفصل في الدعاوى أو تقديم تلك الترضية على نحو منباطئ أو منر اخ من شأنه أن يعطل مقاصد الخصومة ، ويُفقد النزاع جدو اه (1).

ويرى نظر فقهي أن العدالة الناجزة تعني فصل المحاكم في المناز عات المطروحة عليها على نحو سريع وجيد ، أي الفصل فيها خلال أجل معقول دون إخلال بالضمانات الإجر ائية المقررة لحماية حقوق الأفر اد وحرياتهم الأساسية (2) فمعقولية مدة التقاضي لا تعني مطلقاً التسرع في إجر اءات المحاكمة أو اختز الها على نحو يفقدها ضماناتها ، ويُحيل الحكم الصادر فيها إلى قضاء مُبتسر ، و إنما يُقصد بالمعقولية عدم إطالة إجراءات التقاضي على نحو غير مبرر أو بشكل متجاوز فيه(3).

(1) حكم المحكمة الدســورية العليا في الدعوى الدسـتورية رقم 64 لســنة 17 القضــائية ، بجلسـة 7 فبر اير 1998 ، مجموعة

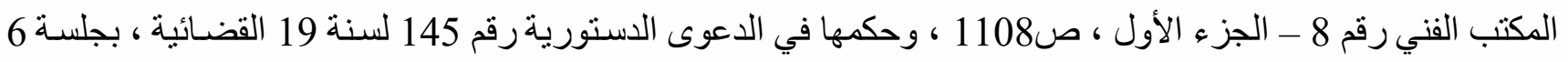

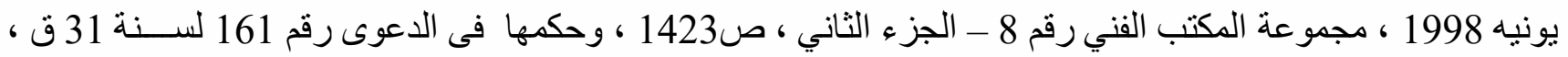

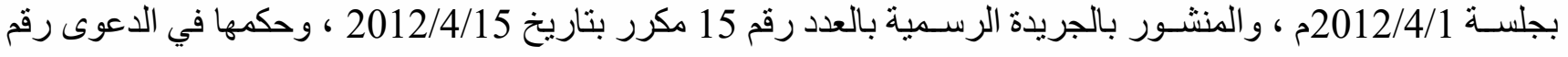

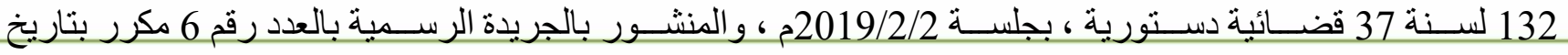
2019/2/11

(2) د. شريف سيد كامل ، الحق في سرعة الإجر اءات الجنائية ، دار النهضة العربية ـ طبعة سنة 2005 ، ص2 صو وما بعدها. (3) د. أحمد فتحي سرور ، الحماية الدستورية للحقوق والحريات ، دار الثروق - طبعة سنة 2000 ، ص ص 2002 ـ 755 وما بعدها .

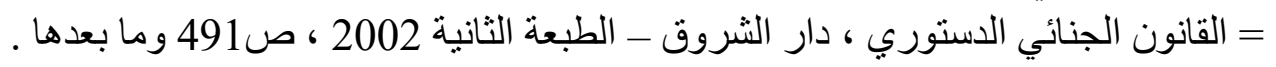




\section{الوسائل المستحدثة}

للفصل في الاعاوى الإدارية خلال مدة معقولة في النظام

القانوني القرنسي
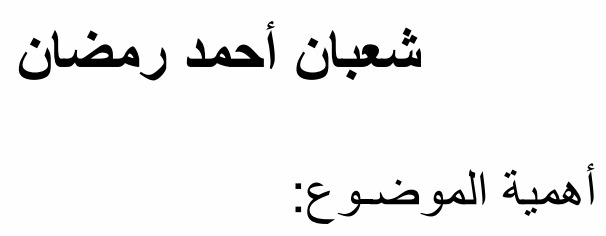

إذا كان الفصل في الدعوى خلال مدة معقو لة ـ كأحد مرتكز ات العدالة الناجزة الجيدة ـ يُشكل أحد دعائم ومعالم

القضاء الجنائي، نظر اً لتعلقه بالحرية الثخصية للمتهمين و المحبوسين احتياطياً على ذمة قضايا جنائية وحقهم في إنهاء

محاكمتهم على نحو سريع للحد من مدة الحبس الاحتياطي ، وكفالة حق الدفاع، على النحو الذي أكدته المادة الخامسة

من الاتفاقية الأوربية لحقوق الإنسان(4)، لما قد يترتب على تباطؤ الإجر اءات القضائية من زو ال أدلة النفي أو اختفاء

الشهود و اختلاط ذاكرتهم(5) فضلاً عن تحقيقه لفكرتي الردع العام والخاص وضمان حق المجتمع في الكثف عن

(4) L'article 5 de la convention européenne des droits de l'Homme consacre le Droit à la liberté et à la sûreté. En ce sens, il énonce que : «1- Toute personne a droit à la liberté et à la sûreté. Nul ne peut être privé de sa liberté, sauf dans les cas suivants et selon les voies légales : a) s'il est détenu régulièrement après condamnation par un tribunal compétent ; b) s'il a fait l'objet d'une arrestation ou d'une détention régulières pour insoumission à une ordonnance rendue, conformément à la loi, par un tribunal ou en vue de garantir l'exécution d'une obligation prescrite par la loi; c) s'il a été arrêté et détenu en vue d'être conduit devant l'autorité judiciaire compétente, lorsqu'il y a des raisons plausibles de soupçonner qu'il a commis une infraction ou qu'il y a des motifs raisonnables de croire à la nécessité de l'empêcher = = de commettre une infraction ou de s'enfuir après l'accomplissement de celle-ci ; d) s'il s'agit de la détention régulière d'un mineur, décidée pour son éducation surveillée ou de sa détention régulière, afin de le traduire devant l'autorité compétente ; e) s'il s'agit de la détention régulière d'une personne susceptible de propager une maladie contagieuse, d'un aliéné, d'un alcoolique, d'un toxicomane ou d'un vagabond ; f) s'il s'agit de l'arrestation ou de la détention régulières d'une personne pour l'empêcher de pénétrer irrégulièrement dans le territoire, ou contre laquelle une procédure d'expulsion ou d'extradition est en cours.

2-Toute personne arrêtée doit être informée, dans le plus court délai et dans une langue qu'elle comprend, des raisons de son arrestation et de toute accusation portée contre elle.

3- Toute personne arrêtée ou détenue, dans les conditions prévues au paragraphe 1.c du présent article, doit être aussitôt traduite devant un juge ou un autre magistrat habilité par la loi à exercer des fonctions judiciaires et a le droit d'être jugée dans un délai raisonnable, ou libérée pendant la procédure. La mise en liberté peut être subordonnée à une garantie assurant la comparution de l'intéressé à l'audience.

4-Toute personne privée de sa liberté par arrestation ou détention a le droit d'introduire un recours devant un tribunal, afin qu'il statue à bref délai sur la légalité de sa détention et ordonne sa libération si la détention est illégale.

5- Toute personne victime d'une arrestation ou d'une détention dans des conditions contraires aux dispositions de cet article a droit à réparation. »

(5) Boka Janos; Chapter 6 " to Delay justice is injustice " ; Acompaarative analysis of (UN) Reasonable

Delay, 27 IUS Gentium, 2014; p. 152.

= د. فتحية محمد قواري ، ضو ابط المحاكمة الجنائية خلال مدة معقولة - در اسة مقارنة ، مجلة الاجتهاد القضائي - جامعة 


\section{الوسائل المستحدثة}

للفصل في الدعاوى الإدارية خلال مدة معقولة في النظام

القانوني الفرنسي

\section{شعبان أحمد رمضنان}

الجر ائم ومحاسبة مرتكبيها(6) ، فإنه لا يقل أهمية أمام القضاء الإداري خاصة مع ما تتسم به إجراءات التقاضي في الدعاوى الإدارية من بُطء نسبي يحول دون تحقيق العدالة الناجزة في حسم المنازعات الإدارية نظر آ لالتزام القضاء الإداري بمر اعاة مجمو عة من المبادئ التي تتطلب قدراً أطول من الوقت للفصل في النزاع كمبدأ التحضير الإلزامي للمناز عة الإدارية من قِبِلْ هيئة المفوضين ، ومبدأ الكتابة و غياب المر افعة الثفهية ، ومبدأ التقاضي على درجتين ، و مبدأ التشكيل المتعدد لهيئة الحكم ، و هو ما حدا بالمشرع الفرنسي أن بفتتح بتلكم المبادئ تقنين العدالة الإدارية Code de justice Administrative

بمعرفة أشخاص متعددين (7).

: مشكلة الموضـوع :

إذا كانت المبادئ السابقة تُعد بمثابة الأسس العامة لإجر اءات التقاضي أمام جهة القضاء الإداري تحقيقًا لغاية العدالة الجيدة ، فإن التمسك بها على إطلاقه قد يُفضي لإطالة أمد التقاضي و عدم الحصول على الترضية القضائية لر افع الدعوى خلال مدة معقولة بما يتعارض وفكرة العدالة الناجزة ـ و إز اء هذا الوضع اتجه المشرع الفرنسي صوب إيجاد مجموعة من الوسائل التي ثُككن القضاء الإداري من سرعة الفصل في المنازعات الإدارية ، مثل تبني نظام القاضي المنفرد " الدو ائر الفردية " ، وحظر الطعن بالاستئناف في بعض الأحكام الإدارية ، و إعفاء المقرر العام من إعداد تقرير في الدعوى في بعض الدعاوى ، وتبني بعض وسائل التقاضي الالكتروني على النحو الذي يسهم في تحقيق العدالة الناجزة ، وبما لا يُخل بالعدالة الجيدة لاسيما مع ما تُلقيه الفقرة الأولى من المادة السادسة من الاتفاقية الأوربية لحقوق الإنسان على عاتق الدول الأوربية من التزام جهاتها القضائية بالفصل في المنازعات في وقت معقول بوصفه مُفترضيًا أوليًا للمحاكمة العادلة حيث نصت تلك الفقرة على حق كل فرد - عند الفصل في حقوقه المدنية والتز اماته ، أو في اتهام جنائي موجه له - في محاكمة علنية و عادلة خلال مدة زمنية معقولة أمام محكمة مستقلة غير منحازة ومشكلة طبقاً للقانون ، و التي جاءت صباغتها بالفرنسية على النحو الآتي : «L'article 6 de la convention européenne des droits de l'Homme consacre le droit à un procès équitable. A ce propos il dispose que : « 1 . Toute personne a droit à ce que sa cause soit entendue équitablement, publiquement et dans un délai raisonnable, par un tribunal

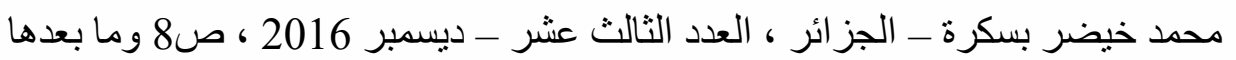

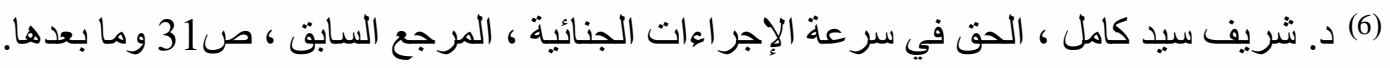

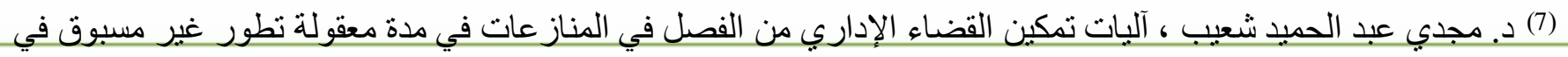

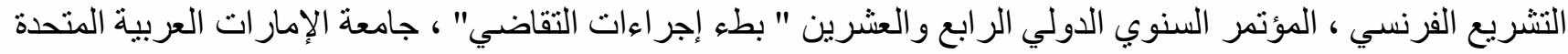

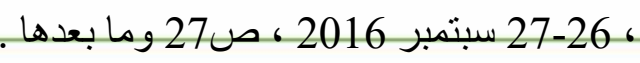




\section{الوسائل المستحدثة}

للفصل في الاعاوى الإدارية خلال مدة معقولة في النظام

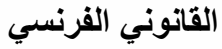

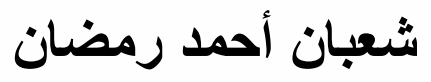

indépendant et impartial, établi par la loi, qui décidera, soit des contestations sur ses droits et obligations de caractère civil, soit du bien-fondé de toute accusation en matière pénale dirigée contre elle. Le jugement doit être rendu publiquement, mais l'accès de la salle d'audience peut être interdit à la presse et au public pendant la totalité ou une partie du procès dans l'intérêt de la moralité, de l'ordre public ou de la sécurité nationale dans une société démocratique, lorsque les intérêts des mineurs ou la protection de la vie privée des parties au procès l'exigent, ou dans la mesure jugée strictement nécessaire par le tribunal, lorsque dans des circonstances spéciales la publicité serait de nature à porter atteinte aux intérêts de la justice. 2. Toute personne accusée d'une infraction est présumée innocente jusqu'à ce que sa culpabilité ait été légalement établie. 3. Tout accusé a droit notamment à

a. être informé, dans le plus court délai, dans une langue qu'il comprend et d'une manière détaillée, de la nature et de la cause de l'accusation portée contre lui ; b. disposer du temps et des facilités nécessaires à la préparation de sa défense ; c. se défendre lui-même ou avoir l'assistance d'un défenseur de son choix et, s'il n'a pas les moyens de rémunérer un défenseur, pouvoir être assisté gratuitement par un avocat d'office, lorsque les intérêts de la justice l'exigent; d. interroger ou faire interroger les témoins à charge et obtenir la convocation et l'interrogation des témoins à décharge dans les mêmes conditions que les témoins à charge ; e. se faire assister gratuitement d'un interprète, s'il ne comprend pas ou ne parle pas la langue employée à l'audience ( 8 )».

ورغم ما قد يوحي به ظاهر النص السالف إير اده من اقتصاره على الحقوق و الالتزامات المدنية ، وكذا الاتهام

الجنائي ، إلا أن غايات النص ومقاصده العامة تستغرق، فيما نرى ، كافة أنو اع المناز عات بما فيها المناز عات الإدارية

على نحو ما قضت به المحكة الأوربية لحقوق الإنسان ببعض أحكامها (9).

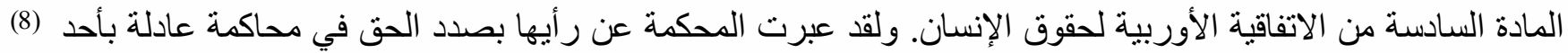

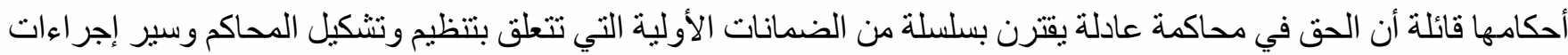

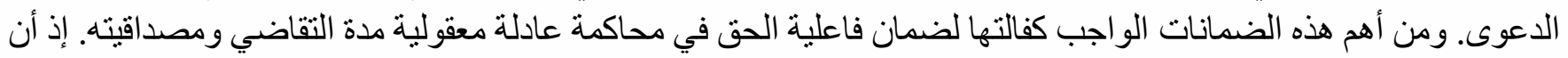

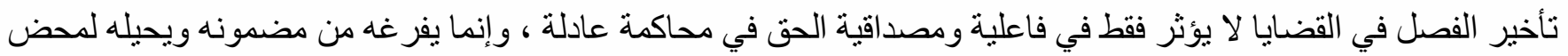
حق نظري.

= ECTHR, Vernillo V.. France, Application No. 11889185, 20 feb. 1991, s 38.

$=$ Frederic Edel; the Iength of civil and criminal proceeding in the case- law of the European court of Human Right, Human Roght files No. 16. Council of Europe publishing. pp. 5-6, Available at http:/www.ech.coeint/library Docs/DG2/HRFILES/OG2-EN-HRFILES.16 (2007).pdf.

(9) ECTHR, Aldo and jean - Baptiste zanatta v. France, Application No. 38042/97,28 Mar. 2000, §§ 22-

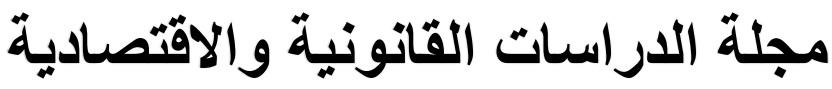




\section{الوسائل المستحدثة}

للفصل في الدعاوى الإدارية خلال مدة معقولة في النظام

القانوني الفرنسي

\section{شعبان أحمد رمضان}

وبهذا الصدد ثُثار جملة تساؤلات تتعلق بكيفية التوفيق بين المبادئ الحاكمة لإجر اءات التقاضي أمام القضاء الإداري بُغية تحقيق العدالة الجيدة ، وما استحدثه المشرع الفرنسي من وسائل لتحقيق العدالة الناجزة ؟ وما هي تلك الوسائل التي تبناها المشرع الفرنسي بتقنين العدالة الإدارية وصو لاً لتحقيق العدالة الناجزة ؟ و إلى أي مدى أفلحت تلكم الوسائل في تيسير إجر اءات التقاضي ومعالجة بُطئها على النحو الذي يحقق العدالة الناجزة و الجيدة على السواء ؟ وللإجابة على التساؤلات المثارة فقد وقع اختيارنا على موضوع الوسائل المستحدثة للفصل في الدعاوى الإدارية خلال مدة معقولة في النظام القانوني الفرنسي عبر تناول بعضًا من تللك الوسائل بالثرح و التحليل لتقييم مدى إسهامها في مُعالجة بطء إجر اءات التقاضي أمام جهة القضاء الإداري ، ومدى نجاحها في تحقيق العدالة الناجزة وبما لا يؤثر سلبًا على فكرة العدالة الجيدة ، ومن ثم مدى إمكانية استفادة النظام القانوني المصري من تلك التجربة لمعالجة بطء إجر اءات التقاضي أمام جهة القضاء الإداري لاسيما مع تبني المشرع الدستوري المصري بدستور 2014 بالمادة 210 فلسفة مفادها سر عة الفصل في بعض المناز عات الإدارية خلال مدة عشرة أيام من تاريخ قيد الطعن أمام المحكمة الإدارية العليا أو محكمة القضاء الإداري وذلك بالنسبة للطعون على قرارات الهيئة الوطنية للانتخابات و المتعلقة بالاستفتاءات و الانتخابات الرئاسية ..... و ونتائجها ، وكذا انتخابات المحليات (10)؛ وهو ما يُعد تكريساً وثتويجاً لما أوردته المادة 97 من الدستور نفسه بشأن سرعة الفصل في القضايا(11).

منهج الدراسة وخطتها: اقتضت طبيعة الدراسة الماتلة بثأن الوسائل المستحدثة للفصل في الدعاوى الإدارية خلال مدة معقولة في النظام القانوني الفرنسي اللجوء للمنهجين التأصبلي لتأصبل فكرة العدالة الناجزة أو المدة المعقولة اللازمة للفصل في المنازعات الإدارية ، و التحليلي الإحصائي عبر تتاول الوسائل التي استحدثها المشرع الفرنسي بالتحليل لمعرفة مدى

26 .

$=$ Frederic Edel; the Ieng of civil and criminal proceedings in the case- law of the European court of

Human Righats, Human Rights files No. 16, council of Europe publishing, 78, Ibid. pp. 7-9. (10) تتص الفقرة الأخيرة من المادة رقم 210 من الدســتور المصـــري لعام 2014 على أنه : " ... وتختص المحكمة الإدارية

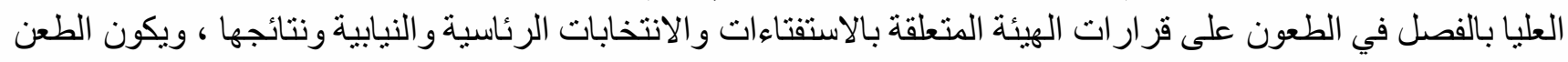

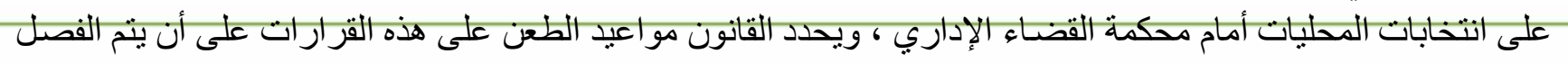

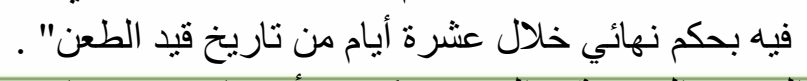

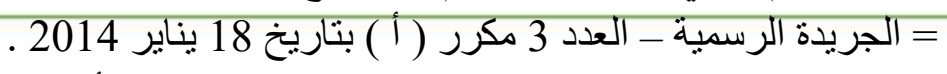
(11) تتص المادة 97 من الدستور المصري لعام 2014 على أن : " التقاضي حق مصون ون ومكفول للكافة . وتلتزم الدولة بتقريب

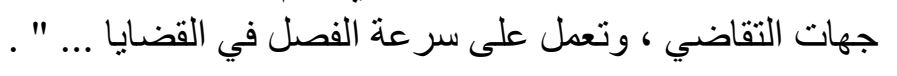


للفصل في الاعاوى الإدارية خلال مدة معقولة في النظام القانوني الفرنسية خلادي مدان

\section{شعبان أحمد رمضنان}

إسهامها في معالجة مشكلة بطء إجر اءات التقاضي أمام جهة القضاء الإداري على ضوء الإحصاءات التي تتضمنها تقارير مجلس الدولة الفرنسي بشأن تقييمه لتلك الوسائل و التي تُشير حسبما سنفصله في موضعه من الدر اسة لدور هاء الفعال في تقصير أمد الفصل في الدعاوى و الطعون الإدارية على النحو الذي يُسههم في تحقيق العدالة الناجزة في مجال

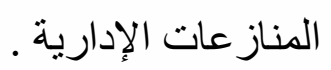

و عليه فقد ارتأينا تقسيم هذه الدر اسة لثلاثة فصول نخصص أولهما لتأصيل فكرة العدالة الناجزة في مجال المنازعات الإدارية عبر تحديد مضمون المدة المعقولة اللازمة للفصل في الدعاوى الإدارية ، وأساسها القانوني ، ومعايير تحديدها ، ونتصدى في الثاني لدر اسة وتحليل وسائل الفصل في الدعاوى الإدارية خلال مدة معقولة طبقا لتقنين

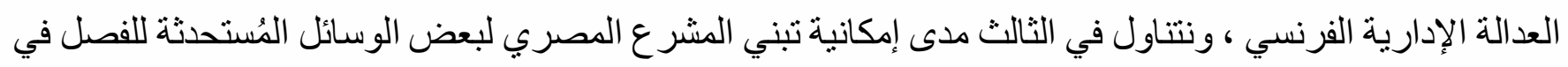

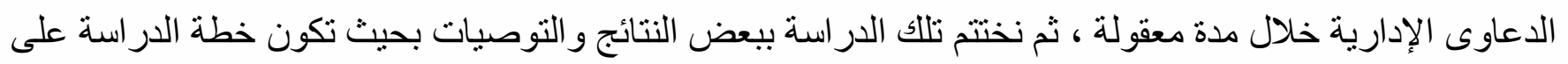
النحو الآتي :

الفصل الأول : الفصل في الدعاوى الإدارية خلال مدة زمنية معقولة في النظام القانوني القرنسي.

الفصل الثاني : وسائل الفصل في الدعاوى الإدارية خلال مدة معقولة طبقاً لتقنين العدالة الإدارية الفرنسي. الفصل الثالث : مدى إمكانية تبني المشرع المصري لبعض الوسائل المُستحدثة للفصل في الدعاوى الإدارية خلال مدة معقولة. 


\section{شعبان أحمد رمضنان}

$$
\begin{aligned}
& \text { الفصل الأول } \\
& \text { الفصل في الدعاوى الإدارية خلال مدة معقولة } \\
& \text { في النظام القانوني الفرنسي }
\end{aligned}
$$


للفصل في الدعاوى الإدارية خلال مدة معقولة في النظام

$$
\text { شعبان أحمد رمضان }
$$




\section{الوسائل المستحدثة}

للفصل في الاعاوى الإدارية خلال مدة معقولة في النظام

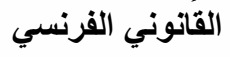

\section{شعبان أحمد رمضنان}

\section{الفصل الأول}

الفصل في الدعاوى الإدارية خلال مدة معقولة

في النظام القانوني الفرنسي

أضحى الفصل في النزاع خلال مدة معقولة حقاً دستوريًا ذي صبغة عالمية حيث حرصت عديد من النظم

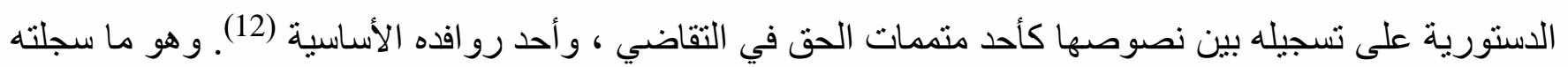

الدساتير المصرية المتعاقبة بنصها على أن تعمل الدولة على سرعة الفصل في القضايا(13).

بيد أن المشرع الدستوري الفرنسي لم بسجل هذا الحق ضمن نصوص الدستور الراهن لعام 1958 ، الأمر

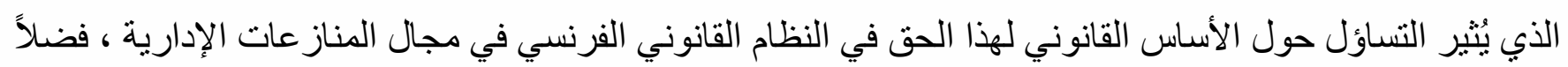

عن تحديد مضمون المدة المعقولة اللازمة للفصل في تللك المناز عات في قضاء مجلس الدولة الفرنسي.

ولإجابة على التساؤل المطروح بثقيه نقسم هذا الفصل لمبحثين نخصص أولهما لتبيان الأساس القانوني

للفصل في الدعاوى الإدارية خلال مدة معقولة في النظام القانوني الفرنسي ـ ونكرِّ الآخر لتحديد مضمون الددة

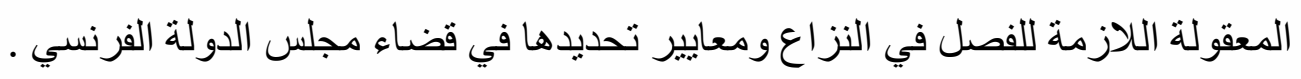

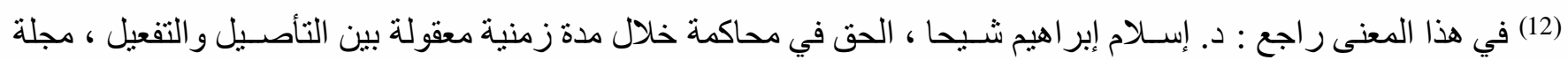

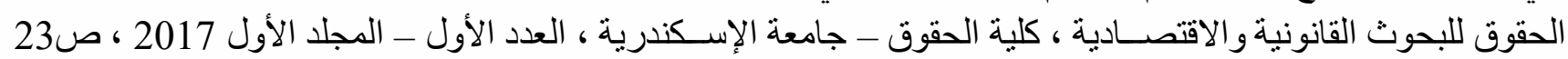

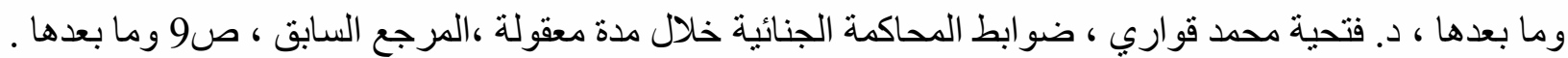

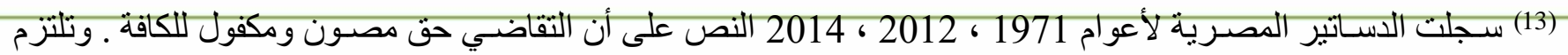

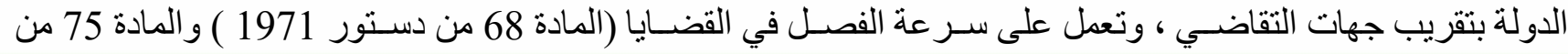
دستور 2012 ، والمادة 97 من دستوير 2014) . 


\section{الوسائل المستحدثة}

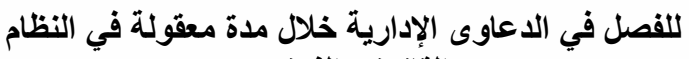

القانوني الفرنسي خلادي

$$
\text { المبحث الأول }
$$

الأساس القانوني للفصل في الدعاوى الإدارية خلال مدة معقولة في النظام القانوني الفرنسي

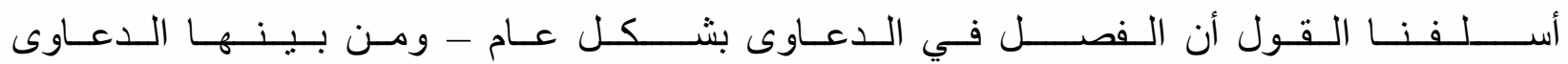
الإدارية ـ خلال مدة معقولة يُعد أحد مرتكزات الحق في التقاضي بُغية تحقيق العدالة الناجزة. وأن المشر ع الدستوري

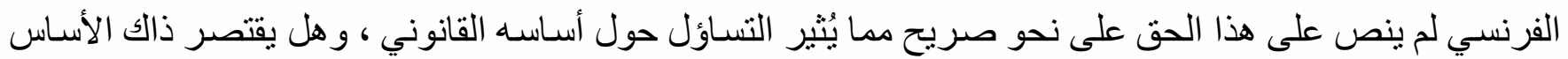
على التشريع الداخلي ؟ أم أنه يمتد ليشمل كذللك بعض النصوص ذات الصبغة الدولية لاسيما الاتفاقيات الدولية المُلزمة

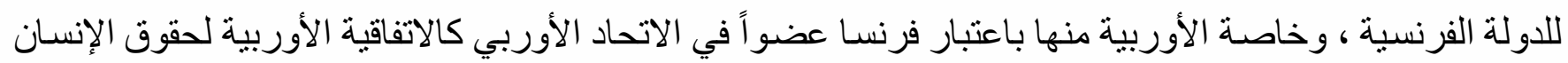

وللإجابة على التساؤل المطروح نقسم هذا المبحث لمطلبين نُعرض في أولهما للفصل في النز اع في مدة معقولة طبقا لأحكام الاتفاقية الأوربية لحقوق الإنسان ـونتناول في الآخر الفصل في النزاع خلال مدة معقولة طبقا لتقنين العدالة الإدارية الفرنسي .

\section{المطلب الأول}

الالتز ام بالقصل في المناز عات الإدارية خلال مدة معقولة طبقاً لأحكام الاتفاقية الأوربية لحقوق الإنسان

المعاهدة الدولية طبقاً لما استقر عليه فقه القانون الدولي هي كل اتفاق ينم إبرامه بين شخصين أو أكثر من الإنيان

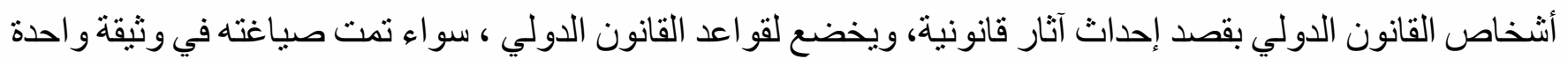
أو أكثر ، و أياً كانت التسمية التي تُطلق عليه (14).

وقد استقر فقه القانون الدولي العام على أن المعاهدة الدولية بمجرد إبرامها أو التصديق عليها من قِبِّلْ أطر افها

(14) Anziloty (D.); Cours de droit international traduction francais par Gidel, paris - 1926, p.66 ; Rousseau (ch); principes géneraux du droit international public, T.1, Paris - 1949, P. 964.

= وراجع في الفقه العربي :

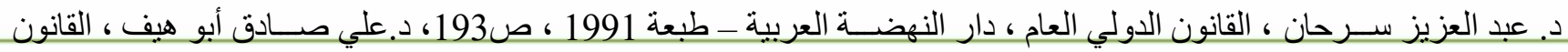

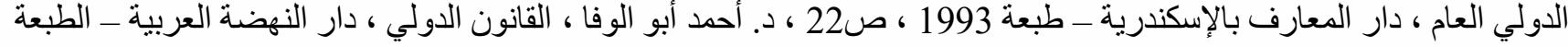

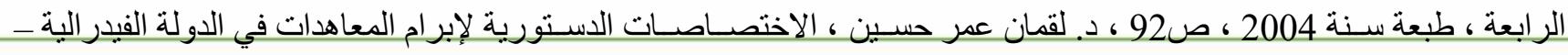

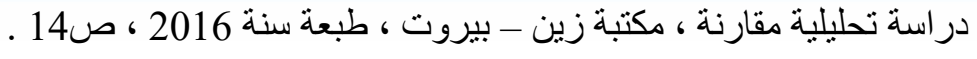




\section{الوسائل المستحدثة}

للفصل في الدعاوى الإدارية خلال مدة معقولة في النظام

القانوني الفرنسي

\section{شُبان أحمد رمضنان}

تصبر لها قوة ملزمة بالنسبة لعاقديها ، و المنضمين إلبها على سو اء فيما اصطلح عليه بمبدأ القوة الملزمة للمعاهدات(15) بحيث يتعين الإذعان لها وتنفيذها بحسن نية(16) سواء بالنسبة لعلاقات الدولة الخارجية مع أطر اف المعاهدة التي تُعد طرفًا فيها ، أو على الصعيد الداخلي من قِبَّل سلطاتها العامة(17) التشريعية و التنفيذية و القضائية .

وتُعد الاتفاقية الأوربية لحقوق الإنسان أحد المرجعيات القانونية للنظام القانوني الفرنسي باعتبار فرنسا عضواً في الاتحاد الأوربي ، وملزمة بتطبيق أحكام تلك الاتفاقية على ضوء ما بعتنقه النظام الدستوري الفرنسي من سمو المعاهدات الدولية ، و القوة الملزمة لها ، على القو انين الداخلية طبقًا لنص المادة (55) من الدستور الفرنسي لعام 1958

ويعنينا في هذا المقام ما أوردته الفقرة الأولى من المادة السادسة من تلكم الاتفاقية من النص على حق الفرد في محاكمة علنية و عادلة خلال مدة معقو لة أمام محكمة مستقلة غير منحازة ومُشكلة طبقا للقانون، أيا كان موضوع النزاع، المنازعة في حقوق أو التز امات مدنية أو اتهامات ذات طابع جنائي موجهة له،....الخ. وذللك على النحو الذي جسدته المادة التي نحن بشأنها(19).

${ }^{(15)}$ Rousseau (ch.); Le droit international public, paris - dalloz, 3ém. éde, 1965, P. 53; Marcel (M.); droit de gens modern, 2ém. éd., 1928 p. 335.

$$
\text { (16) د. محمد مجدي مرجان ، آثار المعاهدات بالنسبة لأطر افها : دار النهضة العربية - طبعة سنة } 1981 \text { ، ص18. } 1852 \text {. }
$$

(17) Delboz (L.); Les principes généraux de droit international public, 3ém. éd., 1964, P. 352.

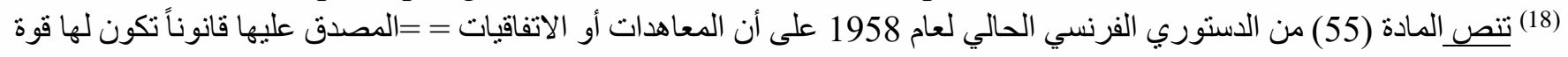

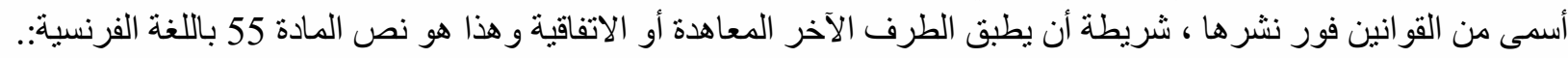

«Les traités ou accords régulièrement ratifiés ou approuvés ont, dès leur publication, une autorité supérieure à celle des lois, sous réserve, pour chaque accord ou traité, de son application par l'autre partie. »

= Duverger (M.); Constitutions et Doeuments politiques, éd., P.U.F., 1987, P. 307.

(19) L'article 6 de la convention européenne des droits de l'Homme consacre le droit à un procès équitable.

A ce propos il dispose que : «1. Toute personne a droit à ce que sa cause soit entendue équitablement, publiquement et dans un délai raisonnable, par un tribunal indépendant et impartial, établi par la loi, qui décidera, soit des contestations sur ses droits et obligations de caractère civil, soit du bien-fondé de toute accusation en matière pénale dirigée contre elle. Le jugement doit être rendu publiquement, mais l'accès de la salle d'audience peut être interdit à la presse et au public pendant la totalité ou une partie du procès dans l'intérêt de la moralité, de l'ordre public ou de la sécurité nationale dans une société démocratique, lorsque les intérêts des mineurs ou la protection de la vie privée des parties au procès l'exigent, ou dans la mesure jugée strictement nécessaire par le tribunal, lorsque dans des circonstances spéciales la publicité serait de nature à porter atteinte aux intérêts de la justice. 2. Toute personne accusée d'une infraction est 


\section{الوسائل المستحدثة}

للفصل في الدعاوى الإدارية خلال مدة معقولة في النظام

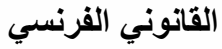

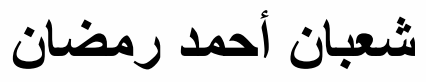

ويلحظ المتفحص لنص المادة السادسة من الاتفاقية الأوربية لحقوق الإنسان أنه يُشكل التز اما على عاتق الدول

أعضاء الاتحاد الأوربي ومن بينها فرنسا بطبيعة الحال التزاماً يقضي بضرورة الفصل في الدعاوى المختلفة المنظورة أمام جهاتها القضائية خلال مدة معقولة باعتبار تللك المدة تُعد من مرتكزات ومتممات الحق في التقاضي. وهو الأمر H. الذي أكدته المحكمة الأوربية لحقوق الإنسان منذ بو اكير أحكامها الصادرة تطبيقاً لهذا النص؛ حيث أعلنت في حكم c/ Francece بما لايجعلها تتأخر في إصدار الأحكام ويما لا يؤثر على فاعليتها ومصداقيتها(20). وترى المحكمة أن الحق في محاكمة عادلة خلال مدة زمنية معقو لة يُعد مفترضًا أوليًا لضمان فاعلية ومصداقية المحاكمة العادلة من ناحية، وكفالة حسن سير العدالة من ناحية أخرى، و هو ما عبرت عنه المحكمة في حكم Vernillo قائلة: V. France

«En exigeant le respect du "délai raisonnable", la Convention souligne l'importance qui s'attache à ce que la justice ne soit pas administrée avec des retards propres à en compromettre l'efficacité et la crédibilité (21)».

وقد خلصت المحكمة إلى وجود التز ام على عاتق الدول الأوربية بتهيئة نظمها القانونية الداخلية على نحو يكفل حق الأفر اد في محاكمة خلال مدة معقولة وذلك بحكمها في قضية Ekin V. France و الذي جاءت عبارته بالفرنسية

présumée innocente jusqu'à ce que sa culpabilité ait été légalement établie. 3. Tout accusé a droit notamment à :

a. être informé, dans le plus court délai, dans une langue qu'il comprend et d'une manière détaillée, de la nature et de la cause de l'accusation portée contre lui ; b. disposer du temps et des facilités nécessaires à la préparation de sa défense ; c. se défendre lui-même ou avoir l'assistance d'un défenseur de son choix et, s'il n'a pas les moyens de rémunérer un défenseur, pouvoir $==$ être assisté gratuitement par un avocat d'office, lorsque les intérêts de la justice l'exigent; $d$. interroger ou faire interroger les témoins à charge et obtenir la convocation et l'interrogation des témoins à décharge dans les mêmes conditions que les témoins à charge ; e. se faire assister gratuitement d'un interprète, s'il ne comprend pas ou ne parle pas la langue employée à l'audience. »

(20) CEDH 24 oct. 1969, n 10073/82, H. c/ France, § 58. En effet, la CEDH perçoit dans ce principe un moyen de veiller «à ce que la justice ne soit pas rendue avec des retards propres à en compromettre l'efficacité et la crédibilité ».v. également ; CEDH 31 mars 1992, affaire numéro 18020/91, X. c/ France, série A, n 236 ; CEDH 26 avril 1994, affaire numéro 22121/93, Vallée c/ France, série A, n 289-A ; CEDH 26 avril 1994, affaire numéro 22800/93, Karakaya c/ France, série A, n 289-B.

(21) Arrêt 20 février 1991, affaire Vernillo c. France, Requête no11889/85, \$38. 


\section{الوسائل المستحدثة}

للفصل في الاعاوى الإدارية خلال مدة معقولة في النظام

القانوني القرنسي خلاني

\section{شعبان أحمد رمضنان}

كما يلي : (22).

« Il incombe aux Etats contractants d'organiser leur système judiciaire de telle sorte que leurs juridictions puissent garantir à chacun le droit d'obtenir une décision définitive sur les contestations relatives à ses droits et obligations de caractère civil dans un délai raisonnable. Elle estime que l'on ne saurait considérer comme « raisonnable » la durée globale de la procédure, plus de neuf ans, alors même que l'enjeu du litige revêtait une importance particulière ».

و هو ما أعادت المحكمة الأوربية التأكيد عليه مجددا في عديد من الأحكام المتواترة في هذا الثـأن23).

و إذا كان ظاهر نص الفقرة الأولى من المادة السادسة من الاتفاقية الأوربية لحقوق الإنسان يوحي باقتصار

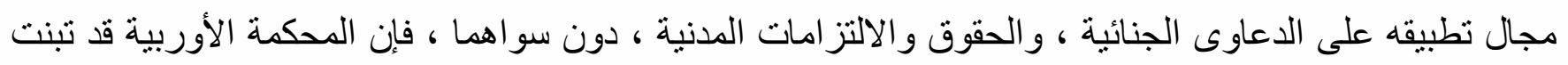

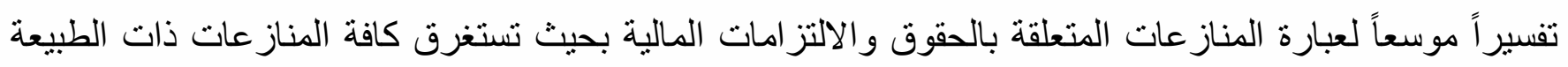

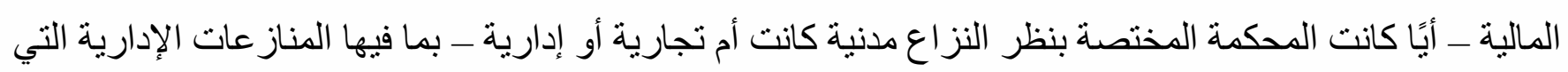

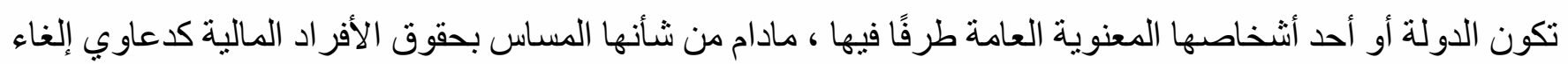
القرار ات الإدارية المتعلقة بنزع الملكية للمنفعة العامة(24) وتلك المتعلقة بتر اخيص البناء ، و الحقوق المالية للموظفين

وصفوة القول أن ما ورد بالمادة ( 1-6 ) من الاتفاقية الأوربية لحقوق الإنسان بشأن الفصل في النزاع خلال

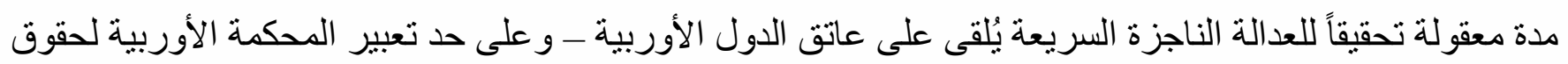

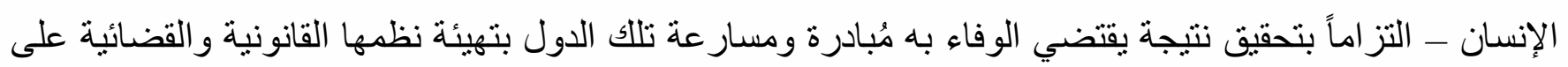

(22) Arrêt 17 octobre 2001, affaire Association Ekin c. France, Requête no 39288/98 \$73.

(23) Cour EDH 26 avril 1994, affaire numéro 22121/93, vallée c/ france, série A. no 289 - A ; CEDH, 7 dec. 1999. Bouilly c/ france, no 38952/97, ş 17 ; CEDH, 28 nov. 2000, leclery c/ france, no 38398/97, ş 26 et 29 -31 ; CEDH. 19 juin 2001, AAU; CEDH, 27 juin 2000. Frydlender. ; CEDH. 11 Fev. 2010, malet c/ France, requête no 24997/07.

$=$ Cassia (P.), " Délai raisonnable de jugement" in les Grands Arrêts du contentieux Administrative, 3ém. éd., 2011, pp. 111 - 113

(24) ECTHR, Aldo and jean - Baptiste zanatta V. France, Application No. 38042/97, 28 Mar. 2000, şs 22 $-26$.

$$
\text { (25) د. إسلام إبراهيم شيحا ، الحق في محاكمة خلال مدة زمنية معقولة .... ، المرجع السابق ، ص46 وما بعدها . }
$$




\section{الوسائل المستحدثة}

للفصل في الدعاوى الإدارية خلال مدة معقولة في النظام

القانوني الفرنسي خلارل مداري

\section{شعبان أحمد رمضان}

النحو الذي يضمن حق الأفر اد بهذا الخصوص تجنباً لإثارة مسئوليتها حال الإخلال به (26). الأمر الذي ننتهي معه للقول بأن نص تللك المادة يُعد أساسًا قانونيًا بالتز ام فرنسا - باعتبار ها إحدى الدول الأوربية الموقعة على الاتفاقية بتهيئة نظمها القانونية و القضائية ، ومن بينها تقنين العدالة الإدارية ، وكذا جهة القضاء الإداري على النحو الذي يكفل سرعة الفصل في الدعاوى الإدارية خلال مدة معقولة باعتباره أحد متممات الحق في التقاضي كأحد أهم الحقوق الاستورية تحقيقاً لمبدأ العدالة الناجزة .

ولعل هذا الاعتقاد الر اسخ بضرورة مر اعاة الالتز ام بالفصل في المنازعات في مدة معقولة تطبيقا لما أوردته

« déni de justice المادة السادسة التي نحن بصددها، جعلت بعض الفقه يرى أن الخروج عليها يثكل جريمة » processuel انكار ا للعدالة على المستوى الاجر ائي الأمر الذي يقتضي تقرير مسؤلية الدولة عن هذا الخلل(27). و هذا الاتجاه يضاهي المسلك الذي اتبعته محاكم جهة القانون الخاص التي لجأت لمفهوم إنكار العدالة لتأسيس مسؤلية الدولة عن تأخر مرفق القضاء في الفصل في المنازعات في مدة معقولة (28).

$$
\begin{aligned}
& \text { المطلب الثاني - اني } \\
& \text { الفصل في الدعاوى الإدارية خلال مدة معقولة } \\
& \text { طبقاً لتقنين العدالة الإدارية }
\end{aligned}
$$

الفصل في النزاع خلال مدة زمنية معقولة لا يُعد من الحقوق الدستورية التي كفلها الدستور الفرنسي لعام 1958 ، أو إعلان حقوق الإنسان والمواطن الصادر عن الثورة الفرنسية عام 1789 على نحو صريح ـ كما أن المجلس الدستوري الفرنسي لم يعده من قبيل الحقوق الأساسية ذات الصبغة الدستورية ، أو أحد الضمانات اللازمة لكفالة

(26) Cour EDH, 28 nov. 2000, Leclercq c/ france, no 38398/97, ş 30 ; CEDH, Grande chambre, 1 juin 2001, Kress c/ france no 39594/98 ; CEDH , 17 juill - 2001, ASSOC. Ekin c/ france, no 39288/98, AJDA 52, not. F. julin ( La fferière ) ; D. 2002. Somm. 2770, obs. T. Massis; CEDH Grand chmbre , 12 avr. 2006, Martini c/ France, no 58675/00 ; voire, GAJA, no 104, 19 ém. éd., Dalloz., p. 794.

(27) «Le profond ancrage de ce principe conduit certains auteurs à voir dans un dépassement de ce délai un « déni de justice processuel». L. Savadogo, Déni de justice et responsabilité internationale de l'État pour les aetes de ses juridietions, JDI (Clunet), 03/2016, p. 827 s., cité par B. Nieaud, Délai raisonnable et droit européen, AJ pénal 2017. 163.

(28) Cette solution est à rapprocher de celle déjà mise en œuvre par les juridictions civiles qui fonde la responsabilité étatique pour violation du délai raisonnable sur le déni de justice (TGI Paris, 6 juillet 1994, C. et A. de Jaeger c. Agent judiciaire du Trésor public, Gaz. Pal., 1994 II 589, note Petit et TGI Paris, 5 novembre 1997, Gauthier c/ Ministre de la justice et autres). 


\section{الوسائل المستحدثة}

للفصل في الدعاوى الإدارية خلال مدة معقولة في النظام

القانوني الفرنسي خلارل مداري

\section{شُبان أحمد رمضنان}

الحق في محاكمة عادلة حتى وقت قريب وهو ما كان مثنارًا لانتقاد جانب من الفقه الفرنسي (29). بيد أن المجلس

الدستوري اعتنق فيما بعد سياسة قضائية مفادها إضفاء الصفة الدستورية على هذا الحق على إثر جملة عو امل ،

وكان ذلك بموجب قر ارهر رقم 510-2004 بتاريخ 20 بناير 2005 مستنداً في ذلك لما تضمنته المادة 16 من إعلان حقوق الإنسان و المواطن لعام 1789 بشأن ضرورة اتخاذ القاضي الإجر اء المناسب للفضل في الدعوى وكان ذللك بمناسبة حكمه في مدى دستورية القانون المتعلق باختصاص المحاكم الجزئية ذات الولاية المحلية وكذلك الابتدائية و الذي جاء بأحد أسبابه : "ولما كان القانون محل الطعن بسمح للأشخاص المعنوية برفع الأمر للمحكمة ذات الولاية المحلية فإن الأشخاص المعنوية مخولين من قبل ذلك بالتدخل للافاع أمام تلك المحاكم وأن الصلاحية الجديدة لن تؤثر على عمل القاضي و لا تُشكل اعتداءً على حقوق الدفاع أو الحق في محاكمة عادلة الذي جسدته المادة (16) من إعلان حقوق الإنسان و المو اطن الصادر عام 1789 (30) " .

وقد أكد المجلس الدستوري قضاءه السابق بقر ارهرقم 595 - 2009 بتاريخ 3 ديسمبر 2009 (31) بشأن مدى دستورية القانون الأساسي الصادر بالتطبيق لنص المادة 1-61 من الدستور الفرنسي المتعلقة باختصاص المجلس الدستوري بالقصل فيما يحيله إليه مجلس الدولة أو محكمة النقض من مناز عات متعلقة بمخالفة أحد النصوص التشريعية

(29) Patrice SPINOSI; Quel regard sur la jurisprudence du conseil constitutionnel sur le procès équitable, Nouveaux cahiers du conseil constitutionnel no 44 (Le conseil constitutionnel et le procès équitable ) - Juin 2014.

(30) «Considérant, par ailleurs, que, si la loi déférée permet aux personnes morales de saisir la juridiction de proximité, ces personnes pouvaient déjà intervenir devant elle en défense ; que cette faculté nouvelle n'affecte pas l'office du juge de proximité et ne porte atteinte ne aux droits de la défense, ni au principe de procès équitable garanti par l'article 16 de la Déclaration des droits de l'homme et du citoyen de 1789 ». CC., DC. No 2004-510, 20 janvier 2005, Loi relative aux compétence du tribunal d'instance, de la juridiction de proximité et du tribunal de grand instance.

$=\mathrm{http}: / / \mathrm{www} \cdot$ conseilconstitutionnel/Fr

(31) CC., Dc. No 2009-595, 3 déc. 2009. Loi organique rélative à l'application de l'article 61-1 de la constitution.

= Gaia (P.), Ghevontian (R.) Melin - Soucramanien (F.), olive (E.), Roux (A.) ; Les Grandes Decision du conseil constitutionnel, ouvrage cree par favoreu (L.) et Philip (L.), 17 ém. éd. 2013, pp. 584 -603 ; V. lascombe (V.), michel et vandendriessche, Xavier, code constitutionnel et Des Droits Fondamentaux, 5 ém. éd., Dalloz - 2016, p. 300-02. 


\section{الوسائل المستحدثة}

للفصل في الدعاوى الإدارية خلال مدة معقولة في النظام

القانوني الفرنسي خلارك معاري

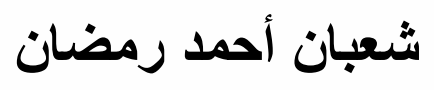

لما يكفله الدستور من حقوق وحريات(32) خلال مدة زمنية محددة(33).

و على صعيد التنظيم التشريعي لقو انين مجلس الدولة الفرنسي المتعاقبة فقد تناول المشرع الفرنسي تنظيم جهة القضاء الإداري بتشريعات عدة أهمها تلك التي ركزت على إدخال تعديلات و إصلاحات جوهرية أبرز ها ما بتعلق بإنشاء المحاكم الإدارية عام 1953 لتصبح عقب هذا التاريخ مختصة بنظر المناز عات الإدارية كمحكمة أول درجة(34) بحيث يتم الطعن على أحكامها أمام مجلس الدولة باعتبار هاضي ثاني درجة . وتلا ذلك إنشاء محاكم الاستنئاف الإدارية عام 1987(35) وما ترتب عليه من تحول مجلس الدولة كقاعدة عامة لمحكمة نقض إداري بالنسبة للأحكام التي تصدر ها المحاكم الإدارية ، أو كمحكمة استئناف بالنسبة للأحكام الصادرة من محاكم الاستئناف الإدارية كمحكمة أول درجة(36). بيد أن التشريعات المتعاقبة لتظيم جهة القضاء الإداري في فرنسا لم تتضمن إلى ما قبل عام 2005 ثمة إلز ام بالفصل في الدعاوى الإدارية خلال مدة زمنية معقولة إلى أن حدث تحول جذري بهذا الخصوص على إثر إدخال تعديل جو هري على تقنين العدالة الإدارية Code de justice Administrative في 28 مايو 2005 بموجب المرسوم رقم 911 - 2005 خوَّل المتقاضين الحق في مطالبة الدولة قضائًا بتعويض الأضرار التي ألمت بهم جراء عدم فصل محاكم جهة القضاء الإداري في مناز عاتهم خلال مدة معقولة مع منح مجلس الدولة اختصاصاً منفرداً بالفصل في تلكم الدعاوى ـ دعاوى التعويض عن تأخر الفصل في الدعاوى خلال مدة معقولة ـ باعتبار ه محكمة أول و آخر درجة عبر نصه في المادة ( R311-1 ) على أن : يختص مجلس الدولة كمحكمة أول وآخر درجة بالفصل في الدعاوى التالية : ...... 5 - دعاوى التعويض عن مسئولية الدولة الناجمة عن تأخر فصل المحاكم الإدارية في الدعاوى المرفوعة أمامها خلال مدة معقولة. وقد جاء نص تللك الفقرة بالفرنسية على النحو الآتي :

« Le conseil d'Etat est compétent pour connaitre en premier et dernier ressort : ...

(32) Lévy (D.) ; Devand que soulever la question prioritaire de constitutionnalité, la question prioritaire de constitutionnalité, sous la Direction de Dominique Rousseau, Gazett du palais, lextenso éd. 2010, p. 21.

(33) CC., DC. no 2009-595,3 déc. 2009, loi organique relative à l'application de l'article 61-1 delà constitution, Magnom (X.); la Question prioritaire de constitutionnalité pratique et contentieux, A jour au ler nov. 2010 , p. 207.

(34) Décret no 53-934 du 30 sep. 1953 portant réforme du Contentieux = administratif.

(35) Loi no 87-1127 du 311987 portant réforme du Contentieux administratif.

راجع في ذلك د. مجدي عبد الحميد شعيب ، آليات تمكين القضاء الإداري من الفصل في المنازعات في مدة معقولة ، المرجع (36)

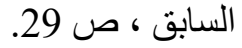




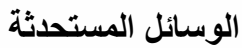

للفصل في الدعاوى الإدارية خلال مدة معقولة في النظام

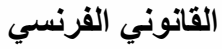

\section{شعبان أحمد رمضنان}

5- Des actions en responsabilité dirigées contre L'Etat pour durée excessive de la procédure devant la juridiction administrative $\mathrm{e}^{(37)} »$.

ويستخلص من استقراء النص عاليه وجود التزام قانوني على محاكم القضاء الإداري بالفصل في الدعاوى

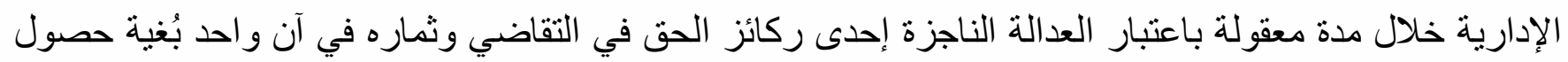

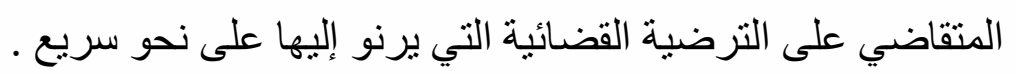

ولعل تدخل المشرع الفرنسي بإجر اء تعديلات عدة على تقنين العدالة الإدارية بهدف تيسير إجر اءات التقاضي

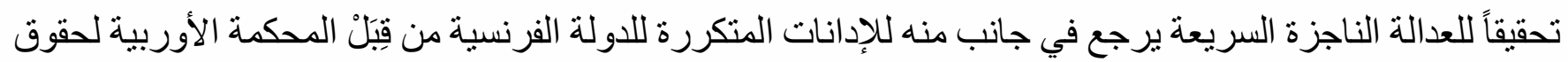
الإنسان بشأن انتهاك محاكم جهة القضاء الإداري لحق الأفر اد في الفصل في مناز عاتهم خلال مدة معقولة (38) إعمالاً لنص الفقرة الأولى من المادة السادسة من الاتفاقية الأوربية لحقوق الإنسان من ناحية ، ولتحول قضاء مجلس الدولة

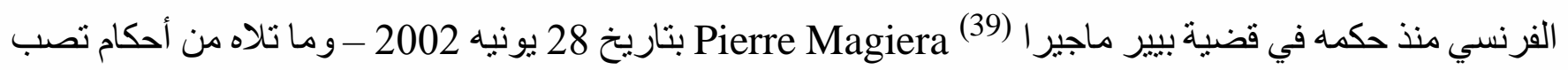
في معينه - صوب إقرار مسؤولية الدولة عن عدم فصل المحاكم الإدارية في المنازعات المطروحة عليها خلال مدة معقولة من ناحية أخرى حيث أكد المجلس بهذا الحكم أن هذا الحق ـ الفصل في النز اع خلال مدة معقولة - لا يستند في وجوده فقط إلى نص المادة 1-6 من الاتفاقية الأوربية لحقوق الإنسان ، و إنما يرتكز كذللك على المبادئ العامة التي لهي تحكم سير مرفق القضاء الإداري معتبر اً أن عدم الفصل في الدعوى خلال مدة معقولة يُعد خطاً في تسيير مرفق القضاء الإداري تتعقد مسؤولية الدولة عن تعويض المتضرر بسببه(40) . الأمر الذي حدا بالمشر ع الفرنسي للنص على ضرورة

(37) Décret no 2005-911 du 28 juillet 2005 modifiant le partie réglementaire du code de justice administrative , Ant. R11-1.

(38) CEDH. 11 Fev. 2010, malet c/ France, requête no 24997/07. no 289 - CEDH, 28 nov. 2000, leclery c/ france, no 38398/97, ş 26 et 29 -31 ; A ; CEDH, 7 dec. 1999. Bouilly c/ france, no 38952/97, ş 17 ; CEDH. 19 juin 2001, AAU; CEDH, 27 juin 2000. Frydlender. ; Cour EDH 26 avril 1994, affaire numéro 22121/93, vallée c/ france, série A.

= Cassia (P.), " Délai raisonnable de jugement" in les Grands Arrêts du contentieux Administrative, 3ém. éd., 2011, pp. $111-113$

(39) CE, ASS., 28 Jein 2002, Grand des sceaux, ministre de la justice c/magiera ; ( Lebon 248 ; AJDA 2002, 596, chron. F. donnat et D. Cassas ; D. 2003, not. V. Holderbaeh-Martin, RFDA 2002. 756 , concl. F. Lamy ; LPA 2 oct 2002. 15, concl. et obs. M. Vialettes ; LPA 5 nov. 2002. 17, not. M. C. Rouault ; LPA 11 avril. 2003, g. art. M. C. Gergerés ; Drodm. 10/2002. 167, comm. M. L'ombard ; Gaz.pal. 2002. 1444, not. O. Guillaumont ; JCP 2003, 11. 10151, not. J. J. Menuret ; Dradm. 10/2006. 17. étude D. Dero- Bugny.

(40) Lombard (M.) ; Responsabilité de l'Etat pour la durée excessive des procès administratif, Droit 
الفصل في الدعاوى الإدارية خلال مدة معقولة طبقًا للتعديل الذي أدخله على تقنين العدالة الإدارية بموجب المرسوم رقم 2005-211 بتاريخ 28 مايو 2005 و الذي يُعد الأساس القانوني لهذا الالتز ام باعتباره من متمدات ومرتكزات الحق في التقاضي .

Administratif no 10, octobre 2002, comm. 167, p. 3 ; cassia (p.) ; les "Délai raisonnable de jugement" in les Garauds arrêts du contentieux administrative, op. cit., pp. 110- 113. 


\title{
الوسائل المستحدثة
}

للفصل في الاعاوى الإدارية خلال مدة معقولة في النظام

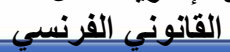

\section{شعبان أحمد رمضان}

$$
\text { المبحث الثاني }
$$

مدلول المدة المعقولة ومعايير تحديدها

في قضاء مجلس الدولة الفرنسي

اقتصر المسلك التشريعي لنص الفقرة الأولى من المادة السادسة من الاتفاقية الأوربية لحقوق الإنسان على

وضع التزام على عاتق الدول الأعضاء بضرورة الفصل في الدعاوى القضائية خلال مدة زمنية معقولة ، دون تبيان لماهية تلكم المدة ـ و هو المسلك نفسه الذي انتهجه المشرع الفرنسي فيما أدخله من تعديل على تقنين العدالة الإدارية

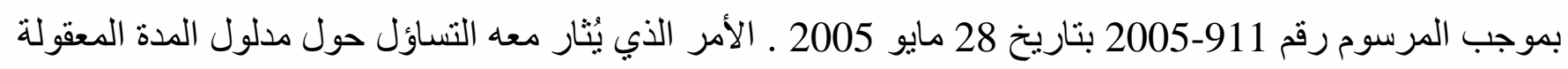

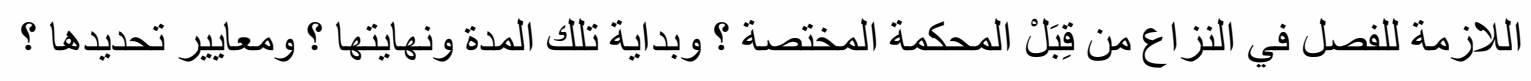
ونظر اً لعدم تصدي المشرع لوضع تعريف محددة للمدة المعقولة ومعايير تحديدها ، فقد اجتهد الفقه عبر استقر ائه و تحليله للأحكام القضائية الصادرة بهذا الخصوص - سواء على صعيد لهيد أحكام المحكمة الأوربية لحقوق الإنسان

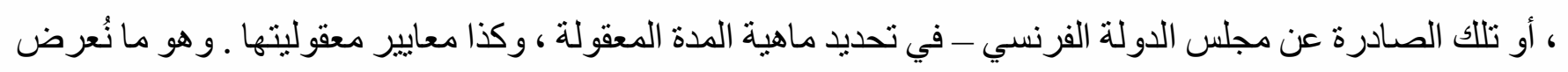
له في مطلبين على التو الي .

\author{
المطلب الأول \\ ماهية المدة المعقولة ومعايير تحديدها \\ في قضاء المحكمة الأوربية لحقوق الإنسان
}

نتناول في نقطتين تحديد المقصود بالمدة المعقولة اللازمة للفصل في الدعوى، ومعايير أو ضو ابط معقولية تلك المدة .

أولاً - ماهية المدة المعقولة اللازمة للفصل في الدعوى : 


\section{الوسائل المستحدثة}

للفصل في الدعاوى الإدارية خلال مدة معقولة في النظام القانوني الفرنسي

\section{شُبان أحمد رمضنان}

يرجع لفقه القانون الجنائي قصب السبق في تصديه لتحديد مدلول المدة المعقولة التي يتعين إنهاء المحاكمة الجنائية خلالها(41) و التي تعني طبقاً لنظر فقهي إنجاز السلطات القضائية ما يوكل إليها من منازعات للفصل فيها في أجل معقول ، دون إخلال بالضمانات الإجرائية المقررة لحماية حقوق الأفر اد وحرياتهم الأساسية (42). في حين برى

نظر آخر أنها - أي المدة المعقولة - عدم إطالة إجر اعات التقاضي على نحو غير مبرر أو بشكل متجاوز فيه (43). ويخلص جانب من فقه القانون الجنائي إلى أن حق المتهم في المحاكمة خلال مدة معقولة هو حق شخصي ذو بُعد اجتماعي Proit individual الشخصية للمتهم المتعلقة بالحرية و الأمن و الإنصاف ـ كما يُتيح للمجتمع في الوقت نفسه تحقيق العدالة و الردع ، و إعادة دمج المحكوم عليهم بالبر اعة في الحياة الاجتماعية ، فضلاً عن حيازة الأحكام القضائية المُتسمة بالسرعة المناسبة ، وكذلك أجززة القضاء ، على ثقة ودعم أفر اد المجتمع (44).

ثانياً : معابير معقولية المدة اللازمة للفصل في النزاع في قضاء المحكمة الأوربية لحقوق الإنسان : يُثار التساؤل حول بداية المدة المعقولة اللازمة للفصل في الدعاوى الإدارية أمام جهة القضاء الإداري ، ومعايير معقولية تلك المدة في قضاء المحكمة الأوربية لحقوق الإنسان ؟ وللإجابة على التساؤل المطروح في شقه الأول بتضح من استقر اء بعض أحكام المحكمة الأوربية لحقوق الإنسان الصـادرة بهذا الخصوص أن بداية مدة التقاضي لا تبدأ بالضرورة من تاريخ رفع الدعوى أمام القضاء ، بل تبدأ

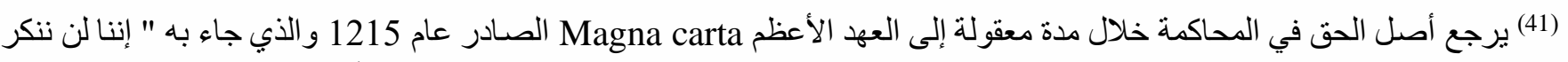
على إنسان حقه في العدالة ولن نؤجل النظر في القضايا" كما تضمنه إعلان الحقوق لو لاية فرجينيا الأمريكية سنة 1776 الناء ، ثم دسنور و لاية ماساسوتش عام 1780 . 178

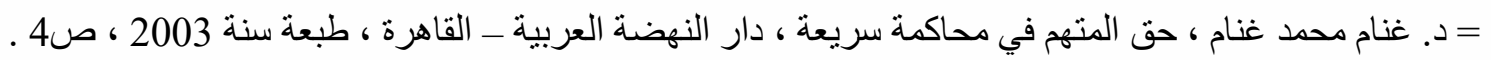

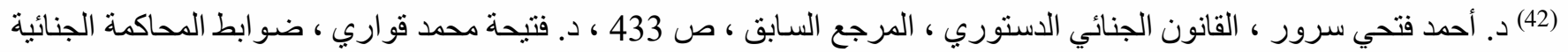

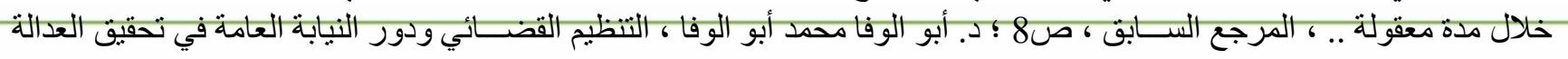

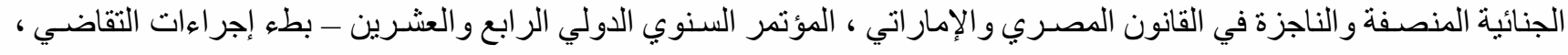

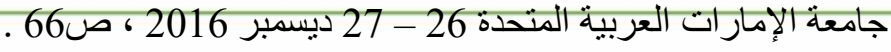

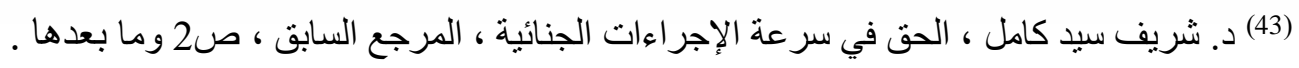

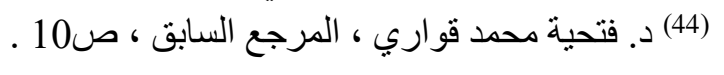




\section{الوسائل المستحدثة}

للفصل في الاعاوى الإدارية خلال مدة معقولة في النظام

القانوني الفرنسي خلارل مداري

\section{شُبان أحمد رمضنان}

من تاريخ تقديم تظلم للجهة الإدارية(45) متى كان التظلم وجوبياً (46) ، وأن تلك المدة تستغرق جميع مر احل التقاضي حتى إصدار حكم بات في موضوع الدعوى ، بل وإجر اءات تنفيذ الحكم كذللك(47) و إن كان ذلك لا يحول دون تقدير معقولية تلك المدة خلال مرحلة بذاتها من مر احل التقاضي.

ويمكن القول أن مدة التقاضي طبقاً لما أرسته المحكمة الأوربية لحقوق الإنسان تبدأ في السريان في أحوال التظلم الوجوبي من تاريخ تقديم هذا التظلم لجهة الإدارة ، بينما تبدأ بمفهوم المخالفة في حالات التظلم الاختياري من تاريخ رفع الدعوى أمام المحكمة المختصة وتتتهي بصدور حكم بات في موضوعها ، أو بتاريخ تتفيذ الحكم متى كان تنفيذه يتطلب اتخاذ الإدارة إجر اءات محددة لذلك .

\section{معايير معقولية المدة اللازمة للفصل في الدعوى :}

أرست المحكمة الأوربية لحقوق الإنسان بأحكامها المتو اترة بشأن تفسير ها للفقرة الأولى من المادة السادسة من

الاتفاقية الأوربية لحقوق الإنسان وحرياته الأساسية قاعدة عامة مفادها أن معقولية المدة اللازمة للفصل في الدعاوى المختلفة يُعد من المسائل النسبية التي تختلف بحسب ظروف وملابسات كل دعوى على حدة ـ بيد أنها وضعت رغم ذللك جملة ضوابط ومعايير يُمكن الاستهاء بها لتقدير مدى معقولية أو عدم معقولية المدة التي استغرقتها المحكمة المختصة للفصل في الدعوى .

ويلحظ المتفصص لقضاء المحكمة الأوربية لحقوق الإنسان أن لها أحكام متو اترة تكفلت فيها بالنص على معايير يستهدى بها لتحديد ما إذا كانت المدة تعد مقولة من عدمه. ويدخل في عداد هذه المعايير تلك التي أوردتها في حكمها

${ }^{(45)}$ Cour EDH, 31 mars 1992. X C/ France. No 18020/91 ş 31. " La période à considérer a débuté le ler décembre 1989, date de la demande préalable d'indemnisation au ministre de la solidarité, de la santé et de la protection sociale .... Elle n'a pas encore pris fin, $x$ ayant introduit un recours devant la cour administrative d'appel de paris le 20 janvier 1992 ... Elle s'entend donc déjà a sur plus de deux ans" ; Voir également : Cour EDH 26 avril 1994, affaire numéro 22121/93, vallée c/ france, série A. no 289 - A ; CEDH, 7 dec. 1999. Bouilly c/ france, no 38952/97, ş 17 ; CEDH, $28=$ =nov. 2000, leclery c/ france, no 38398/97, s 26 et 29 -31; CEDH. 19 juin 2001, AAU; CEDH, 27 juin 2000. Frydlender. ; CEDH, Grand chamber , 7 juin 2001 , kress c/ france, no 39594198 ; CEDH, Grand chambre 12 avril. 2006, martinie c/ france no 58675100 ; voir, GAJA, no 104, 19 ém. éd., Dalloz., p. 794. CEDH. 11

Fev. 2010, malet c/ France, requête no 24997/07.

(46) د. مجدي عبد الحميد شعيب ، آليات تمكين القضاء الإداري من الفصل في المنازعات في مدة معقولة ، المرجع السابق ، ص54.

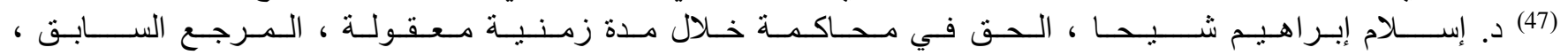
ص44 - 45. 


\section{الوسائل المستحدثة}

للفصل في الدعاوى الإدارية خلال مدة معقولة في النظام

القانوني الفرنسي

\section{شعبان أحمد رمضنان}

الصادر في 25 مارس عام Pélissier et Sassi c/ France وتتمثل في مدى صعوبة القضية و المشاكل

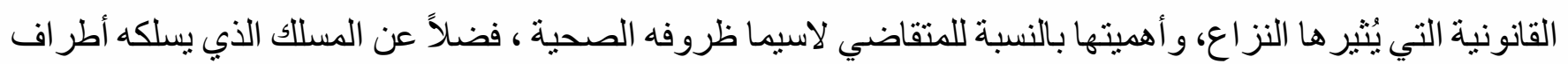
الدعوى أثناء سير الخصومة (48) .

وهو ما أعادت المحكمة التأكيد عليه في حكمها في قضية Frydlender c/ France بتاريخ 25 يونيه 2000 بونة موضحة أن تقدير مدى معقولية المدة من عدمة يعتمد على أمور عدة يدخل في عدادها صعوبة القضية و المشاكل

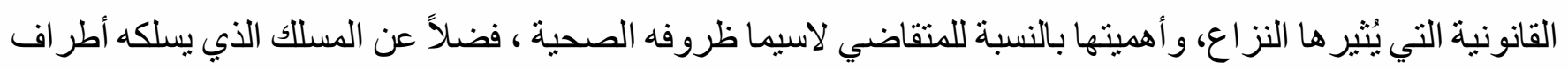
الدعوى أثناء سير الخصومة (49." . . ل

ولقد اضطردت المحكمة على التعبير عن المعايير التي تستهدى بها لتحديد معقولية المدة من عدمه في أغلب أحكامها قائلة:

" La durée "raisonnable" d'une procédure doit s'apprécier suivant les circonstances de la couse et à l'aide de critères suivant : la complexité de l'affaire, le comportement du requérant et celui des autorités compétentes ainsi que l'enjeu du litige pour l'intéressé".

ويُعد من أمثلة صعوبة القضية و المشاكل القانونية التي يُثير ها النزاع تعدد و اقعات الدعوى - كتعدد التهم في

${ }^{(48)}$ CEDH 25 mars 1999, Pélissier et Sassi c. France, n 25444/94, § 67, D. 2000. 357, note D. Roets ; CEDH 15 juill. 1982, n ${ }^{\circ}$ 8130/78, Eckle c/Allemagne, § 73, CEDH 27 nov. 1991, Kemmache c. France, $\mathrm{n}^{\text {os }} 12325 / 86$ et 14992/89, § 60, D. 1992. 329, obs. J.-F. Renucci ; RSC 1992. 143, obs. L.-E. Pettiti; CEDH 31 mars 1992, X c. France, n 18020/91, § 32, AJDA 1992. 416, chron. J.-F. Flauss; D. 1992. 334, obs. J.-F. Renucci ; ibid. 1993. 67, chron. Y. Lambert-Faivre ;, D. 2000. 357 , note D, Roets, CEDH 25 juin 2000, Frydlender C. France, affaire no 30979/96, ş 43 ; CEDH, 1 juin 2001, kress c. France no 39594/98 ; CEDH 12 avril, 2006, Martinie C. France, no 58675/00; CEDH 6 mai 1981, n 7759/77, Buchholz c Allemagne.

(49) voir à ce propos, CEDH 12 avril, 2006, Martinie C. France, no 58675/00; CEDH 6 mai 1981, n 7759/77, Buchholz c Allemagne. ; CEDH 15 juill. 1982, $\mathrm{n}^{\circ}$ 8130/78, Eckle c/ Allemagne, § 73, CEDH 27 nov. 1991, Kemmache $c$. France, n $^{\text {os }} 12325 / 86$ et 14992/89, § 60, D. 1992. 329, obs. J.-F. Renucci ; RSC 1992. 143, obs. L.-E. Pettiti ; CEDH 25 mars 1999, Pélissier et Sassi c. France, n 25444/94, § 67, D. 2000. 357, note D. Roets ; CEDH 31 mars 1992, X c. France, n 18020/91, § 32, AJDA 1992. $==416$, chron. J.-F. Flauss; D. 1992. 334, obs. J.-F. Renucci ; ibid. 1993. 67, chron. Y. Lambert-Faivre ;, D. 2000. 357 , note D, Roets, CEDH 25 juin 2000, Frydlender C. France, affaire no 30979/96, ş 43 ; CEDH, 1 juin 2001, kress c. France no 39594/98 ; CEDH, 25 juin 2000, Frydlender C. France, affaire no 30979/96, ş 43 ; CEDH, 1 juin 2001, kress c. France no 39594/98; CEDH, Grande chambre, 12 avril, 2006, Martinie C. France, no 58675/00.

\section{مجلة الدراسات القانونية والاقتصادية}




\section{الوسائل المستحدثة}

للفصل في الاعاوى الإدارية خلال مدة معقولة في النظام

القانوني الفرنسي خلارل مداري

\section{شعبان أحمد رمضان}

المجال الجنائي ، أو تعلق الدعوى بجر ائم معقدة كغسل الأموال - أو صعوبة المسائل المتعلقة بالإثبات ـ وغموض النصوص و اجبة التطبيق ، أو وجود تنازع على الاختصاص ، أو توقف الفصل في الدعوى على الفصل في مسألة أولية كتفسير معاهدة دولية أو الفصل في مدى دستورية النص الذي يحكم النزاع (50)، أو تعدد أطر اف الدعوى ونحو ذللك ـ كما يُعد من قبيل مسلك أطر اف الدعوى أثناء سير الخصومة على النحو الذي قد بطيل أمد الفصل في الدعوى(51) تعدد الطلبات أو الدفوع المقدمة من الخصوم بقصد التعطيل و المماطلة ، أو تعدد طلبات تأجيل الجلسات أو تمديد الآجال المحددة لتقديم المذكر ات و الرد عليها(52) وهو ما أكدت المحكمة الأوروبية عدم اتخاذه ذريعة لتأخير الفصل في الدعوى حيث أوجبت ضرورة تدخل المحكمة المختصة في توجيه إجر اءات الدعوى للحد من تلك السلوكيات و إلا تحملت الدولة المسئولية نتيجة تأخر محاكمها في الفصل في الدعوى خلال مدة معقولة.

و على صعيد أهمية القضية بالنسبة للمتقاضي كأحد أهم معايير معقولية المدة اللازمة للفصل في الدعوى طبقاً لما أرسته المحكمة الأوربية لحقوق الإنسان تأتي نوعية القضايا التي تحتاج لعناية خاصة كالقضايا المتعلقة بالمستقبل الوظيفي ، وقضايا مكافآت التقاعد والمعاش خاصة إذا كان رافعها من ذوي الاحتياجات الخاصة. كذلك حالة تقدم المتقاضي في السن وصعوبة ظروفه الصحية(53) حيث قضت المحكمة في أحد أحكامها بأن استغراق المحكمة مدة عامين للفصل في موضوع الدعوى يُعد مخالفة وخروجاً عن حدود المدة المعقولة نظر اً للظروف الصحية للمدعي و التي يُستخلص منها أن بقاءه على قيد الحياة قد لا يستمر فترة طويلة الأمر الذي كان يتعين معه على المحكمة مر اعاة هذا الظرف و الفصل في الدعوى خلال مدة معقولة ، وقد جاء ببعض فقر ات هذا الحكم بهذا الصدد :

" .... Dans un mémoire complémentaire du 29 octobre 1990 (le requérant ) insista sur l'urgence de son cas :

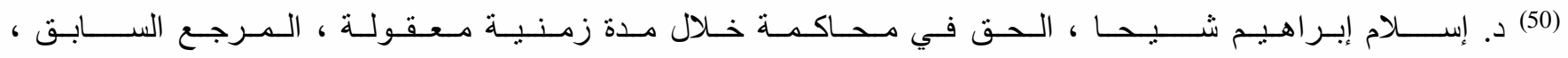
ص52 ، 53.

(51) CEDH Clinique Mozart S.A.R.L contre France du 09/06/2004 Hudoc 5119 requête 46098/99 ; CEDH Arrêt Marschner contre France du 28/09/2004 requête 51360/99 ; CEDH Pelissier et Sassi contre France du 25 mars 1999 Hudoc 966 requête n²5444/94; CEDH Richard Dubarry contre France du 01/06/2004 Hudoc 5108 requête 52929/00 ; CEDH Debbasch contre France du 03/12/2002 Hudoc 4003 requête 49392/99;==CEDH Arrêt Portington contre Grèce du 27/09/1998 Hudoc 955 requête 28523/95 ; CEDH Clinique Mozart S.A.R.L contre France du 09/06/2004 Hudoc 5119 requête 46098/99 ; CEDH Arrêt Marschner contre France du 28/09/2004 requête 51360/99 .

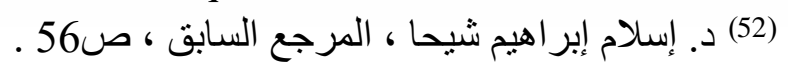

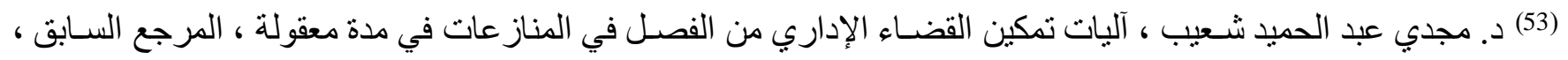




\section{الوسائل المستحدثة}

للفصل في الاعاوى الإدارية خلال مدة معقولة في النظام

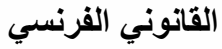

\section{شعبان أحمد رمضنان}

( ... ) l'état de santé de l'exposant s'est aggravé depuis le mois de septembre 1990 comme en atteste le certificat médical produit ..... cette mise eu demeure permettra que soit respecté le droit du requérant à ce que la cause soit entendue dans un délai raisonnable selon les termes de l'article 6 (art.6) de la convention européenne des Droits de l'Homme... $"(54)$

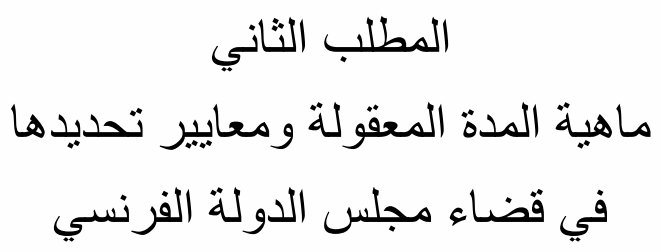

يُعد حكم مجلس الدولة الفرنسي في قضية بيير ماجير|(55) Pierre magiera نقطة تحول في قضاء المجلس صوب اعتناق مبدأ الفصل في الدعاوى الإدارية خلال مدة زمنية معقولة ، و إقرار مسئولية الدولة حال الإخلال بذلك ،

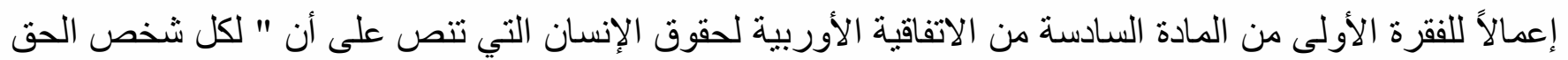
في محاكمة منصفة ، وأن تُسمع دعو اه بصورة علنية وخلال مدة معقولة". و إعمالا لما تقضي به المادة 13 من الإتفاقية الأوربية لحقوق الإنسان وذلك على النحو الذي أفصح عنه المجلس في الحكم الذي نحن بصدده |(56).

(54) Cour EDH, 31 mars 1992, affaire X. c France X. c/ France, Requête no 18020/91; com. No 14 ; voir également : rapports du 9 octobre 1982 sur la requête no 8261178, koffer c Italie . Décisions et rapports no 30, pp. 13-14. Paras 16-17, et du 13 janvier. 1992 sur la requête no 12973/87, Mathes c Autriche, paras 18-20. ; CEDH 12 avril, 2006, Martinie C. France, no 58675/00; CEDH 6 mai 1981, n 7759/77, Buchholz c Allemagne ; CEDH 31 mars 1992, X c. France, $\mathrm{n}^{\circ}$ 18020/91, AJDA 1992. 416, chron. J.F. Flauss; D. 1992. 334, obs. J.-F. Renucci ; ibid. 1993. 67, chron. Y. Lambert-Faivre ;, D. 2000. 357 , note D, Roets, CEDH 25 juin 2000, Frydlender C. France, affaire no 30979/96.

${ }^{(55)}$ CE.,ASS., 28 juin 2002, Gard des sceaux, ministre de la justice c/ magiera, Rec. lebon p. 248 ; AJDA 2002, p. 596, chron. F. donnat et D.casas; D. 2003, not. V. Holderbach - martin ; RFDA 2002. 756. Comcl. F. lamy. LPA 2 oct. 2002. 15, comel. Et obs. M. vialettes ; LPA 5 nov. 2002. 17, not. M.-C Rouault, LAP 11 avr. 2003.9. art. M. C. Gergerès ; Dr. adm. 10/2002.167, comm. M. Lombard; Gaz. Pal. 2002. 1444. Not. O. Guillaumont ; JCP 2003. 11. 10151, not. J-J. Mevuret ; Dr. adm. 10/2006. 17, étudc D. Dero-Bugny.

(56) En ce sens le conseil d'état a déclaré que : «Considérant qu'aux termes de l'article 6, paragraphe 1 de la convention européenne de sauvegarde des droits de l'homme et des libertés fondamentales : "toute personne a droit à ce que sa cause soit entendue équitablement, publiquement et dans un délai raisonnable par un tribunal (.) qui décidera (.) des contestations sur ses droits et obligations de caractère civil (.)"; qu'aux termes de l'article 13 de la même convention : "toute personne dont les droits et libertés reconnus

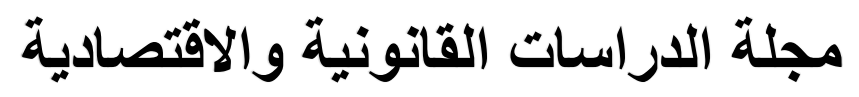




\section{الوسائل المستحدثة}

للفصل في الدعاوى الإدارية خلال مدة معقولة في النظام

القانوني الفرنسي

\section{شعبان أحمد رمضنان}

وكذللك استنادًا للمبادئ العامة التي تحكم سير مرفق القضاء الإداري ، وأن النتيجة المنطقية المترتبة على

الإخلال بهذا الحق بتمثل في التزام الدولة بجبر وتعويض الأضرار التي ألمت بالتقاضي جراء استطالة أمد التقاضي

و عدم الفصل في الدعوى خلال مدة معقولة . وهو الحكم الذي تلته أحكاماً أخرى تصب في معينه على النحو الذي يُعد

تحولًا في السياسة القضائية لمجلس الدولة الفرنسي صوب إقر ار مسئولية الدولة عن سوء إدارة مرفق العدالة (57) أو

بمعنى آخر أن مسؤوليته الدولة عن تعويض الإضرار الناجمة عن طول مدة التقاضي وعدم الفصل في النزاع خلال مدة معقولة لا تستند فحسب - طبقاً لهذا الاتجاه القضائي - على نص الفقرة الأولى في المادة السادسة للاتفاقية الأوربية لحقوق الإنسان ، و إنما ترتكز كذلك على مخالفة المبادئ العامة الحاكمة لتسبير مرفق القضاء الإداري بحيث تستخرق عديد من المنازعات الإدارية التي يختص بها القضاء الإداري الفرنسي بقطع النظر عما إذا كانت تتدرج في عداد المناز عات التي تشملها ضمانة المدة المعقولة الواردة بالمادة المذكورة (58).

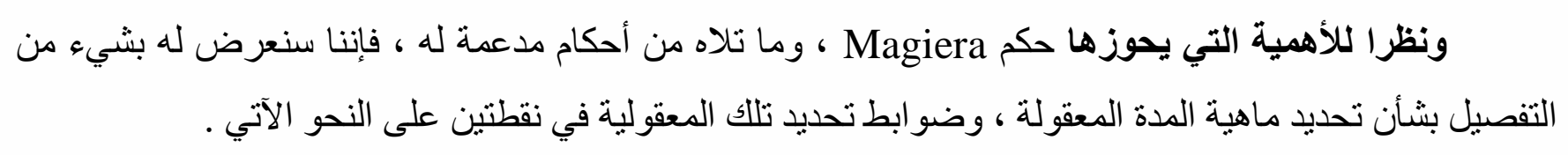

dans la présente convention, ont été violés a droit à l'octroi d'un recours effectif devant une instance nationale, alors même que la violation aurait été commise par des personnes agissant dans l'exercice de leurs fonctions officielles"; Considérant qu'il résulte de ces stipulations, lorsque le litige entre dans leur champ d'application, ainsi que, dans tous les cas, des principes généraux qui gouvernent le fonctionnement des juridictions administratives, que les justiciables ont droit à ce que leurs requêtes soient jugées dans un délai raisonnable ; Considérant que si la méconnaissance de cette obligation est sans incidence sur la validité de la décision juridictionnelle prise à l'issue de la procédure, les justiciables doivent néanmoins pouvoir en faire assurer le respect ; qu'ainsi lorsque la méconnaissance du droit à un délai raisonnable de jugement leur a causé un préjudice, ils peuvent obtenir la réparation du dommage ainsi causé par le fonctionnement défectueux du service public de la justice ;»

${ }^{(57)}$ Garrido (L.); " La responsabilisation des acteurs du procès administratif : remède aux délais excessifs de jugement ou avatar ? ", Droit Administratif - Rev. Mensuelle lexisnexis jurisclasseur, no 5, mai 2011, étude 9. P.6. L'affaire saral potchou.

${ }^{(58)}$ Cassia (P.) ; " Délai raisonnable de jugement " in les grands arrêts du contentieux administratif ..., op.cit., p.131.

= CE., 17 juill, 2009, Ville de Brest, no 295653, Rec. Lebon; AJDA 2009, 1605, chron. S.- J. Liebre et D. Botteghi, Dr. adm. 10/2009, comm. F. Melleray. No 141 ; JCP 2009, 317, ş 4 , chron. B. plessix ; JCP adm. 2010. 2006, not. N. Albert ; RFDA 2010, 405, not. S. Givernaud: " Le droit à réparation des conséquences de la darée excessive de jugement est fondée sur les seuls " Principes généraux que gouvernement le fonctionnement des juridictions administratives" ; dans le même sens, fondant le droit à un délai raisonnable de jugement sur un principe général de droit européen ; AJDA 2009, P. 2216.

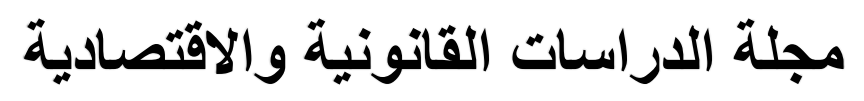




\section{الوسائل المستحدثة}

للفصل في الاعاوى الإدارية خلال مدة معقولة في النظام

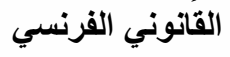

\section{شعبان أحمد رمضنان}

\section{أولاً - ماهية المدة المعقولة في قضاء مجلس الدولة الفرنسي :}

يُستخلص من استقر اء حكم مجلس الدولة الفرنسي في قضية بيير ماجيرا أن المدة المعقولة التي يتعين على

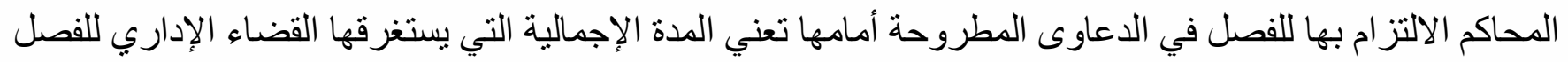
في النزاع بحكم نهائي عبر مر احل الطعن المختلفة فيما يُعرف بالمعيار الثمولي Moniére Globale جملة عناصر أبرز ها مدى صعو بة القضية أو تعقد المسائل التي شُثيرها ، وسلوك المتقاضين أثناء إجراءات سبر الدعوى

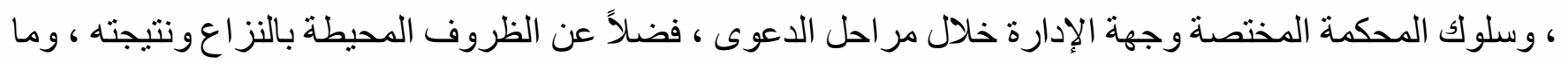
إذا كان يتعين الفصل فيه على نحو سريع من عدمه (60). ويرى نظر فقهي أن مجلس الدولة الفرنسي عبر حكمه في قضية Magiera نفسه ، قد أقام قرينة نسبية على أن الددة المعقولة يتعين ألا تتجاوز ثماني سنو ات أمام جميع مر احل التقاضي في الدعاوى الإدارية ، كما يجب ألا تتجاوز العامين ونصف أمام كل مرحلة من تلاك المر احل (62). غير أن تلكم المدد لا تُعد مدداً

${ }^{(59)}$ C.E., 6 mars 2009, Le Helloco, no 312625, 4 ém.et 5ème. Sous-sections réunies, du 28 mars 2012, La SOCITE EIFFAGETP, no 342015, 4ème. Sous - section jugeant seule, Rec. Lebon, publiés sur www.Legifrance.fr.

(60) à ce propos le conseil d'état d déclaré que « Considérant que le caractère raisonnable du délai de jugement d'une affaire doit s'apprécier de manière à la fois globale - compte tenu, notamment, de l'exercice des voies de recours - et concrète, en prenant en compte sa complexité, les conditions de déroulement de la procédure et, en particulier, le comportement des parties tout au long de celle-ci, mais aussi, dans la mesure où la juridiction saisie a connaissance de tels éléments, l'intérêt qu'il peut y avoir, pour l'une ou l'autre, compte tenu de sa situation particulière, des circonstances propres au litige et, le cas échéant, de sa nature même, à ce qu'il soit tranché rapidement ». C.E., ASS., 28 juin 2002, Garde des sceaux, ministre de la justice C/ Magiena, Rec.Lebon, PP. 248 et suv.

(61) CE.,ASS., 28 juin 2002, Gard des sceaux, ministre de la justice c/ magiera, Rec. lebon p. 248 ; AJDA 2002, p. 596, chron. F. donnat et D.casas; D. 2003, not. V. Holderbach - martin ; RFDA 2002. 756. Comcl. F. lamy. = =LPA 2 oct. 2002. 15, comel. Et obs. M. vialettes ; LPA 5 nov. 2002. 17, not. M.-C Rouault, LAP 11 avr. 2003.9. art. M. C. Gergerès ; Dr. adm. 10/2002.167, comm. M. Lombard; Gaz. Pal. 2002. 1444. Not. O. Guillaumont ; JCP 2003. 11. 10151, not. J-J. Mevuret ; Dr. adm. 10/2006. 17, étudc D. Dero-Bugny.

${ }^{(62)}$ Cassia (P.) ; Délai raisonnable du jugement in les grands arrêts du contentieux administratif .., op.cit. pp. 112-113. 


\section{شعبان أحمد رمضنان}

جامدة ، و إنما تختلف بحسب ظروف كل دعوى وملابساتها ، وهو ما يُمكن استخلاصه من أحكام المجلس التالية لحكم Magiera ومنها حكمه بتاريخ 19 يو نيه 2006 و الذي قضى فيه بأن انقضاء مدة تتجاوز أربع سنوات من تاريخ تقديم

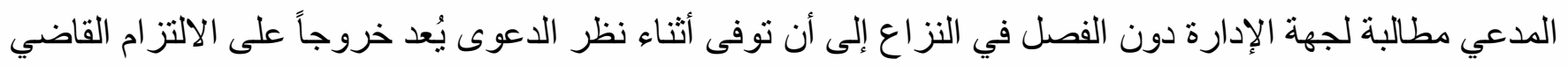
بضرورة الفصل في الدعوى خلال مدة معقولة(63).

ولقد أعاد المجلس التأكيد على المبادئ التي ضمنها حكم Magiera وذلك في حكم مدينة بريست الذي أصدره عام 2009 ففي هذا الحكم حرص المجلس بداية على التأكيد على حق المتقاضين في أن يفصل في مناز عاتهم في مدة معقولة، منو ها بعد ذلك إلى أنه في حالة عدم مر اعاة ذلك من جانب مرفق القضـاء فإن ذلك يعد خرقا للمبادئ التي تحكم عمل القضاء ومن ثم يحق للمنقاضي المطالبة بتعويضه عن الأضر ار المادية و المعنوية المباشرة و المؤكدة التي اصابته جر اء ذللك(64)، وهي نفس المبادي التي سبق وجسدها مجلس الدولة في حكم Magiera (65).

${ }^{(63)}$ C.E., 19 juin 2006, no 286459, M. A et Mme B: Juris-Data no 2006-070334 ; voir également, C.E., du 26 mai 2010. M. Michel. A C/ le Gard de sceaux. Ministre de la justice, no 316292.

راجع ايضـا؛ د. مجدي عبد الحميد شـعيب ، آليات تمكين القضــاء الإداري في الفصـل في المنازعات في مدة معقولة ، المرجع

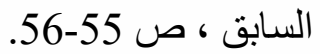

(64) En ce sens ; le conseil d'état a déclaré que » Considérant qu'il résulte des= =principes généraux qui gouvernent le fonctionnement des juridictions administratives que les justiciables ont droit à ce que les requêtes soient jugées dans un délai raisonnable ; que, si la méconnaissance de cette obligation est sans incidence sur la validité de la décision juridictionnelle prise à l'issue de la procédure, les justiciables doivent néanmoins pouvoir en faire assurer le respect ; qu'il en résulte que, lorsque leur droit à un délai raisonnable de jugement a été méconnu, ils peuvent obtenir la réparation de l'ensemble des préjudices tant matériels que moraux, directs et certains, causés par ce fonctionnement défectueux du service de la justice et se rapportant à la période excédant le délai raisonnable ». C.E., sect., 17 Juill. 2009, ville de Brest, no 295635, Rec. Lebon, AJDA2009. 1605, chron. S.-L. liéber et D. Botteghi ; Dr. adm. 10/ 2009 , comm. F. Melleray, no 141 ; JCP 2009. 317, ş 4 , chro. B. plessix ; JCP Adm. 2010. 2006, not. N. albert; RFDA 2010. 405, not. S.Givernoud.

(65) Considérant que l'action en responsabilité engagée par le justiciable dont la requête n'a pas été jugée dans un délai raisonnable doit permettre la réparation de l'ensemble des dommages tant matériels que moraux, directs et certains, qui ont pu lui être causés et dont la réparation ne se trouve pas assurée par la décision rendue sur le litige principal ; que peut ainsi, notamment, trouver réparation le préjudice causé par la perte d'un avantage ou d'une chance ou encore par la reconnaissance tardive d'un droit ; que peuvent aussi donner lieu à réparation les désagréments provoqués par ${ }^{\text {la }}$ durée abusivement longue d'une procédure lorsque ceux-ci ont un caractère réel et vont au-delà des préoccupations habituellement causées par un procès, compte tenu notamment de la situation personnelle de l'intéressé ». C.E., ASS., 28 juin 2002, Garde des sceaux, ministre de la justice C/ Magiena, Rec.Lebon, PP. 248 et suv. 


\section{الوسائل المستحدثة}

للفصل في الاعاوى الإدارية خلال مدة معقولة في النظام

القانوني الفرنسي

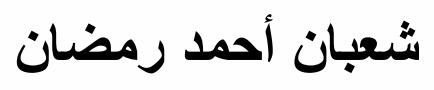

ويعد ذلك أثـار المجلس في للكيفية التي يتم على هديها بيان مدى معقولية مدة الفصل في النزاع من عدمه،

حيث أكد على وجوب الأخذ في الاعتبار المدة الإجمالية التي يستغرقها الفصل في الدعوى لتقدير مدى معقوليتها من عدمه ، دون إغفال المدة التي اسغرقتها الدعوى أمام كل درجة من درجات التقاضي على حده قائلا: "يتعين لتقدير معقولية مدى الفصل في الدعوى أن ينظر ابتداءً للمدة الإجمالية للنز اع عبر درجات التقاضي المختلفة بحيث إذا قدَّر معقو ليتها انتقل لتقدير كل درجة على حدة من درجات التقاضي لتقدير مدى معقوليتها(66)." وهو ما عاد المجلس وأكده مجدداً بحكمه الصادر بتاريخ 23 يونيو 2014(67).

ويرى الباحث من استقر اء أحكام مجلس الدولة الفرنسي بصدد مدلول المدة المعقولة اللازمة للفصل في الدعاوى الإدارية أنها تعني ضرورة الفصل في تللك الدعاوى على نحو سريع ، دون إخلال بحقوق الدفاع ، وبمر اعاة ظروف و ملابسات كل دعوى على حدة ؛ وأن تقدير معقولية المدة يخضع لسلطة محكمة الموضوع تحت رقابة المحكمة الأعلى

ويلحظ المتفحص لأحكام مجلس الدولة بشأن معرفة منى يبدأ حساب مدة التقاضي لتقدير معقوليتها من عدمه أنه سار على ذات النهج الذي سارت عليه المحكمة الأوربية لحقوق الإنسان إذ أقر بحساب هذه المدة قبل رفع الدعوى أمام القضاء لاسيما في حالات التظلم الوجوبي في بعض صور المنازعات الإدارية حيث أكد المجلس في عديد من أحكامه أن المدة المعقولة الإجمالية تبدأ من تاريخ تقديم التظلم الوجوبي لجهة الإدارة(68) وتتتهي بصدور حكم بات في

(66) A ce propos le conseil d'état a jugé que « le caractère raisonnable du délai doit, pour une affaire, s'apprécier de manière globale -compte tenu notamment de l'exercice des voies de recours- et concrète en prenant en compte sa complexité, les conditions de déroulement de la procédure, de même que le comportement des parties tout au long de celle-ci, et aussi, dans la mesure où le juge a connaissance de tels éléments, l'intérêt qu'il peut y avoir pour l'une ou l'autre, compte tenu de sa situation particulière, des circonstances propres au litige et, le cas échéant, de sa nature même, à ce qu'il soit tranché rapidement ; que lorsque la durée globale de jugement n'a pas dépassé le délai raisonnable, la responsabilité de l'Etat est néanmoins susceptible d'être engagée si la durée de l'une des instances a, par elle-même, revêtu une durée excessive ». C.E., sect., 17 Juill. 2009, ville de Brest, no 295635 , Rec. Lebon, AJDA2009. 1605, chron. S.-L. liéber et D. Botteghi ; Dr. adm. 10/ 2009 , comm. F. Melleray , no 141 ; JCP 2009. 317, ş 4 , chro. B. plessix ; JCP Adm. 2010. 2006, not. N. albert; RFDA 2010. 405, not. S.Givernoud.

(67) L' arrêt du conseil d' Etat, 4 éme 15 éme SSR, 23/6/2014, no 369946. Recueil lebon, publiés sur . www.legifrance.fr.

${ }^{(68)}$ C.E., 31 mars 2006, Mme Kirikkant, no 285962, Rec. Lebon, P. 1067 ; JCP Adm. 2006 1268, obs, Guttier (C.) 


\section{الوسائل المستحدثة}

للفصل في الاعاوى الإدارية خلال مدة معقولة في النظام

القانوني الفرنسي

\section{شعبان أحمد رمضنان}

موضو عها، أو تنفيذه بالفعل منى كانت جهة الإدارة ملتزمة باتخاذ إجر اءات معينة لتنفيذ هذا الحكم(69).

ورغبة من المشرع الفرنسي في تبسيط إجراءات تعامل المواطنين مع إدارات الدولة فقد أدخل تعديلاً على

Coode des relations entre les agents et leurs تقنين العلاقة بين الإدارة و المتعاملين معها administrations على التظلمات المقدمة لها يُعد قبو لاً لتلك التظلمات ، وليس رفضاً لها على نحو ما كان يجري عليه العمل قبل ذلك حيث تم تطبيق تللك المادة و العمل بموجبها بالنسبة للنظلمات المقدمة لإدار ات الدولة ومؤسساتها العامة ابتداءً من 12 نوفمبر 2014 ، في حين نم تطبيقها على الإدارات المحلية وإدارات الضمان الاجتماعي وبقية الجهات التي تقوم على إدارة مرفق عام اعتبار اً من 12 نوفمبر 2015 (71) و لاشك أن هذا الاتجاه من قِبَّل المشرع الفرنسي يصب في صالح تحقيق العدالة الناجزة بحسم النزاع الإداري

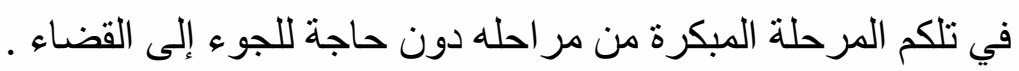

ثانياً - معايير معقولية المدة اللازمة للفصل في الدعوى في قضاء مجلس الدولة الفرنسي :

اعتنق مجلس الدولة الفرنسي في حكمه بقضية بيير ماجير ا Pierre Magiera و الأحكام التي تلته وتصبُ في

معينه ، المعايير نفسها التي أرستها المحكمة الأوربية لحقوق الإنسان بصدد تحديد معقولية المدة اللازمة للفصل في

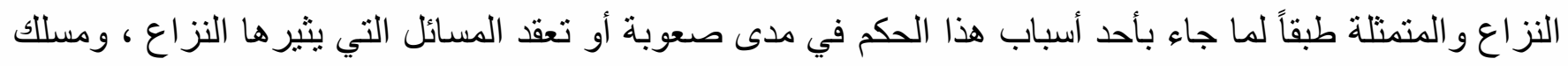
أطر اف الدعوى أثناء سير الخصومة ، فضلاً عن الأهمية التي تمثلها الدعوى بالنسبة للمدعي (72).

${ }^{(69)}$ C.E., 18 juin 2008, Gesta , no 295831, à publier au l'ebon ; RFDA 2008. 755, congl. C. de salins et 1178, not. D. pouyoud ; AJDA 2008. 1237 ; JCP adm. 2008. 2187, obs. J. Moreau; JCP 2008. 1.191, ş chron. B. plessix. qui juge que " Le terme final du délai à prendre en considération, après épuisement des procédures, est le moment où le justiciable Recoit satisfaction à titre définitif " .

(70) Article L 231-1, ( Créé par ordonnance no 2015 - 1341 du 23 octobre 2015) : Le silence gardé pendant deux mois par L'administration sur une demande vaut décision d'acceptation .

(71) د. مجدي عبد الحميد شعيب ، آليات تمكين القضاء الإداري في الفصل في المناز عات في مدة معقولة ، المرجع السابق ، ص52 ، 53

(1) CE 28 juin 2002, $\mathrm{n}^{\circ}$ 239575, Garde des sceaux, ministre de la justice c/ Magiera, Lebon 248 avec les concl. ; AJDA 2002. 596, chron. F. Donnat et D. Casas ; D. 2003. 23, note V. Holderbach-Martin ; RFDA 2002. 756, concl. F. Lamy; ibid. 2003. 85, étude J. Andriantsimbazovina. 
وبالنظر إلى الأهمية التي يحوز ها حكم Magiera فيما نحن بصدده فإننا سنورد بعضاً من أسبابه المتعلقة بضرورة الفصل في النز اع خلال مدة معقولة ومعايير تلك المعقولية، ومسؤولية الدولة حال الإخلال بالفصل في الدعاوى الإدارية

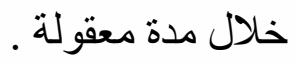

تخلص و اقعات حكم بيير ماجيرا في إقامته دعوى أمام المحكمة الإدارية بباريس للمطالبة بتعويضه عن

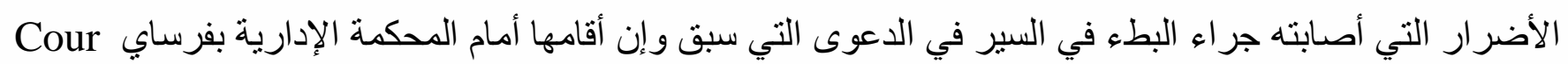
administrative du Versailles ، فقضت المحكمة الإدارية بباريس برفض الدعوى ، فقام السيد Magiera بالطعن على هذا الحكم أمام المحكمة الإدارية الاستئنافية بباريس و التي قضت بإلغاء حكم محكمة أول درجة ـ المحكمة الإدارية

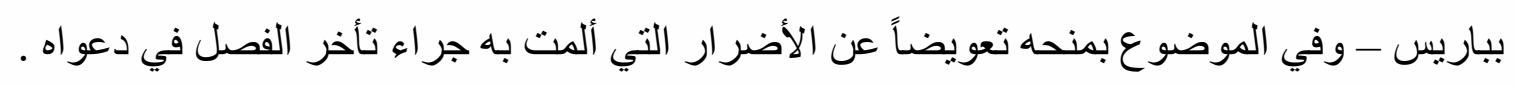

ولما لم يلق هذا الحكم قبو لاً لدى وزارة العدل الفرنسية فقد بادر وزير العدل بالطعن على ذلك الحكم أمام مجلس الدولة الفرنسي الذي انتهى إلى رفض الطعن المقام من وزير العدل وتأييد حكم المحكمة الإدارية الاستئنافية بباريس فيما قررته من تعويض السيد P. Magiera عن الأضرار التي لحقت به حيث أرسى مجلس الدولة الفرنسي عبر هذا ولائ

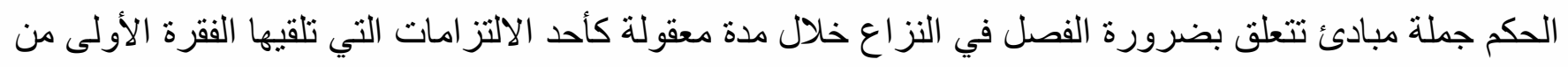

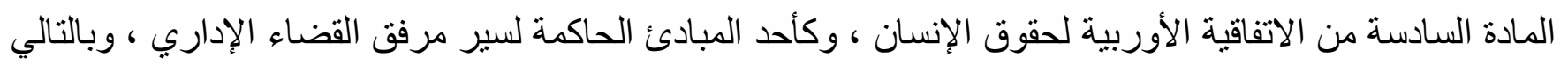
قيام مسؤولية الدولة حال الإخلال بهذا الالتزام وتعويضها للإضرار التي تصيب المتقاضين جراء عدم الفصل في لهي الدعاوى خلال مدة معقولة.

وفي معرض الفصل في الطعن المعروض عليه حرص مجلس الدولة على التأكيد على حق المتقاضي الذي يُقٍِّر أن مرفق العدالة قد أخل تجاهه بمر اعاة الالتز ام القاضي بضرورة الفصل في النزاع في مدة معقولة في تقرير

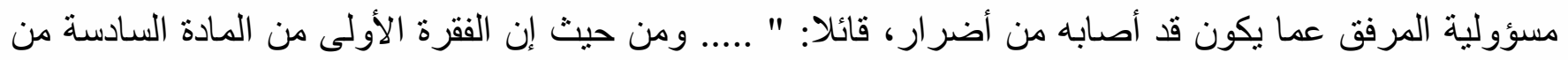
الاتفاقية الأوربية لحقوق الإنسان و الحريات الأساسية قد نصت على أن " لكل شخص الحق في دعوى مُنصفة ، وأن

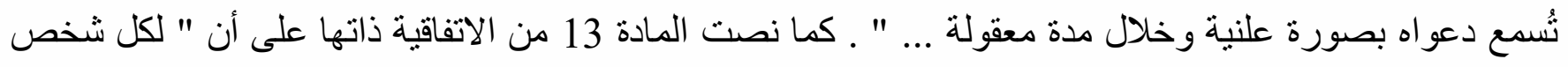
انتُكِكت إحدى الحريات أو الحقوق المكفولة له بموجب هذه الاتفاقية الحق في إقامة دعوى فاعله أمام إحدى المحاكم الوطنية ، ولو كان الانتهاك قد حصل من أشخاص أثناء ممارستهم لوظائفهم الرسمية (73).

(73) " ..... Considérant qu'aux termes de l'article 6. Paragraphe 1 de la convention européenne de sauvegarde des droits de l'homme et des libertés fondamentales : " toute personne a droit à ce que sa cause soit entendue équitablement, publiquement et dans un délai raisonnable par un tribunal ...." 


\section{الوسائل المستحدثة}

للفصل في الاعاوى الإدارية خلال مدة معقولة في النظام

القانوني الفرنسي

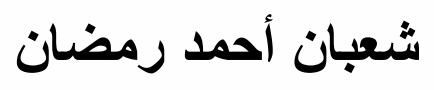

وتابع المجلس قائلاً : ومن حيث إن البيّن من تلك الأحكام القانونية ، ومن القو اعد العامة التي تحكم سير العمل

بالقضاء الإداري ، أن لكل متقاضي الحق في أن يتم الفصل في دعو اه خلال مدة معقولة . ومن حيث إن صدور الحكم خلال مُدة تتجاوز تللك المدة المعقولة ، و إن كان لا يؤثر على صحة الحكم الصـادر ، إلا أنه لا يُخل بحق المُتقاضين في مُقاضاة الدولة لإلز امها باحتر ام تلك المدة، وبالمطالبة بالتعويض الجابر للأضر ار التي حاقت بهم نتيجة سوء الأداء بمرفق العدالة (74).

و أكد المجلس في الحكم الذي نحن بصدده أن مسلك المحكمة الإدارية الاستئنافية بباريس القاضي بتقرير مسئولية

الدولة لتجاوز المدة المعقولة للفصل في الدعوى التي سبق وأن أقامها السيد بيير ماجير ا هو مسلك يتفق مع صحيح القانون (75).

وفيما يتعلق بكيفية حساب المدة وما إذا كانت تتم على أساس المدة الإجمالية أم تقدر بحسب كل درجة من درجات التقاضي منفصلة أعلن المجلس عن اعتماده التقدير الإجمالي أو الثامل من حيث المبدأ دون إغفال التقدير المنفرد لمر احل النزاع. وبعبارة أكثر تفصيلا أعلن المجلس عن أنه لتحديد ما إذا كانت المدة التي استغرقتها المنازعة أمام القضاء قد تجاوزت الحد المعقول من عدمه يتعين أن تتم بصورة شاملة - مع الأخذ في الاعتبار ما إذا كان ثمة طعن قد أقيم على الحكم الصادر من محكمة أول درجة أم لا.

qu'aux termes de l'article 13 de la même convention : " toute personne dont les droits et libertés reconnus dans la présente convention, ont été violés a droit à l'octroi d'un recours effectif devant une instance nationale, alors même que la violation aurait été commise par des personnes agissant dans l'exercice de leurs fonctions officielles. C.E., Ass., 28 juin 2002, Gardes des sceaux. Ministr de la justice c/ magiera, Rec. L. pp. 248 et suv

(74) «Considérant qu'il résulte de ces stipulations, lorsque le litige entre dans leur champ d'application, ainsi que, dans tous les cas, des principes généraux qui gouvernent le fonctionnement des juridictions administratives, que les justiciables ont droit à ce que leurs requêtes soient jugées dans un délai raisonnable ; Considérant que si la méconnaissance de cette obligation est sans incidence sur la validité de la décision juridictionnelle prise à l'issue de la procédure, les justiciables doivent néanmoins pouvoir en faire assurer le respect : qu'ainsi lorsque la raisonnable de jugement leur a causé un préjudice ils peuvent obtenir la réparation du dommage ainsi causé par le fonctionnement défectueux du service public de la justice ». C.E., Ass., 28 juin 2002, Gardes des sceaux. Ministr de la justice c/ magiera, Rec.

L. pp. 248 et suv

(75) «Considérant qu' après avoir énoncé que la durée de la procédure avait été excessive, la cour administrative d'appel en a déduit que la responsabilité de l' Etat était engagée vis -à-vis de M.X...; que , Ce faisant, loin de violer les textes et les principes sus rappelés, elle en a fait une exacte application ». C. E., Ass., 28 juin 2002, Gardes des sceaux. Ministre de la justice C/ Magiera, Rec. L., PP. 248 et suv. 


\section{الوسائل المستحدثة}

للفصل في الدعاوى الإدارية خلال مدة معقولة في النظام

القانوني الفرنسي

\section{شعبان أحمد رمضان}

هذا ولم يغفل المجلس بيان المعايير التي يهتدى بها لتقرير مدى معقولية المدة من عدمه معلنا جملة من المعايير لا تختلف عن تلاك التي تعتمدها المحكمة الأوربية لحقوق الإنسان. و أشار المجلس في هذا الثأن إلى أن تلك المعايير تتمثل في درجة التعقيد التي تنطوي عليها المنازعة و الظروف المحيطة بتسييرها، وعلى وجه الخصوص مُتابعة طرفي الدعوى لدعو اهم ومُبادرتهم بتقديم المستندات و المذكر ات طيلة المدة التي استغرقتها تلكم الإجراءات.

وفي ذات الساق أوضح المجلس أن الظروف الخاصة بالمدعي والطبيعة التي تتميز بها الدعوى ومدى أهميتها بالنسبة له وما إذا كانت الظروف التي تحيط به تستوجب البت فيها على وجه السرعة من عدمة ينبغي أن تكون محل اعتبار عند تقدير ما إذا كانت المدة التي استغرقها النزاع تتسم بالمعقولية من عدمه(76).

وبتطبيق المعايير آنفة الذكر أيد المجلس في الحكم الذي نحن بصدده ما قررته المحكمة الإدارية الاستئنافية بباريس من أن دعوى السبد ... Mageera X. التي أقامها أمام المحكمة الإدارية بفيرساي لا تثير مشاكل قانونية معقدة تجعلها تستغرق مدة سبع سنوات وستة أثنهر للفصل فيها، الأمر الأي بقطع بصحة ما قضت به محكمة الاستنئاف من أن النزاع تجاوز الفصل فيه حدود المدة المعقولة ومن ثم يضحى زعم الوزير بأن المحكمة أخطأت في تطبيق القانون زعم لا أساس لله (77).

ويلحظ المتفحص لأحكام مجلس الدولة التالية لحكم Magiera بشأن تقدير معقولية مدة الفصل في النزاع من عدمه، أن قضاء المجلس لم يطر أ عليه تغيير ا يذكر؛ سو اء فيما يتعلق بتحديد مو عد سريان المدة أو بخصوص المعايير التي يستهدي بها. ويمكن الإشارة في هذا الشأن للحكم الذي أصدره في الطعن رقم 286459 بتاريخ 19 يونيه 2006

(76) « le caractère raisonnable du délai de jugement d'une affaire doit s'apprécier de manière à la fois globale - compte tenu, notamment, de l'exercice des voies de recours - et concrète, en prenant en compte sa complexité, les conditions de déroulement de la procédure et, en particulier, le comportement des parties tout au long de celle-ci, mais aussi, dans la mesure où la juridiction saisie a connaissance de tels éléments, l' intérêt qu'il peut y avoir, pour l'une ou l'autre, compte tenu de sa situation particulière , des circonstances propres au litige et, le cas échéant, de sa nature même, à ce qu'il sait tranché rapidement ». CE 28 juin 2002, $\mathrm{n}^{\circ}$ 239575, Garde des sceaux, ministre de la justice c/ Magiera, Lebon 248 avec les concl. ; AJDA 2002. 596, chron. F. Donnat et D. Casas ; D. 2003. 23, note V. HolderbachMartin ; RFDA 2002. 756, concl. F. Lamy.

(77) «Considérant que pour regarder comme excessif le délai de jugement du recours de M. X..., la cour administrative d'appel de Paris énonce que la durée d'examen de l'affaire devant le tribunal administratif de Versailles a été de 7 ans et 6 mois pour "une requête qui ne présentait pas de difficulté particulière" ; qu'en statuant ainsi, la cour, contrairement à ce que soutient le ministre, a fait une exacte application des principes rappelés ci-dessus ». C.E., ASS., 28 juin 2002 , Gardes des sceaux. Ministre de la justice c/ magiera, Rec. L., pp. 248 et suv. 


\section{الوسائل المستحدثة}

للفصل في الاعاوى الإدارية خلال مدة معقولة في النظام

القانوني الفرنسي

\section{شعبان أحمد رمضان}

(78). وكذللك لحكم Ville de Brest الصار في 17 يوليه 2009 (79). وهو ذات المسلك الذي أعاد التأكيد عليه بحلاء في الطعن رقم 369946 بتاريخ 26 يونيه 2014 ففي هذا الحكم أعلن المجلس أنه يهتدي بجملة معايير تتعلق بطبيعة المناز عة من حيث بساطتها أو تعقد المشاكل التي تثيرها ، ومسلك الطاعن ، وكذا مسلك السلطتين الإدارية والقضائية ، فضلاً عن الأهمية التي تُمثلها الدعوى بالنسبة للطاعن ، و على وجه الخصوص ظروفه الصحية ومدى تقدمه في العمر وظروفه الخاصة التي قد تقتضي عدم التر اخي في الفصل في النزاع(80) .

وصفوة القول طبقاً لما استقر عليه قضاء المحكمة الأوربية لحقوق الإنسان، وقضاء مجلس الدولة الفرنسي أن تقدير معقولية أو عدم معقولية مدة التقاضي يدخل في حسابها عناصر شتى على نحو ما أسلفنا ـ كما أن معيار المدة المعقولة يختلف من حالة لأخرى حسب ظروف وملابسات كل دعوى على النحو الذي يجعل تلك المدة أمر نسبي يختلف من حالة لأخرى حيث خلصت المحكمة الأوربية لحقوق الإنسان في بعض أحكامها إلى أن انقضاء مدة تزيد على أربعة أعو ام للفصل في الدعوى يُعد مدة معقولة ، في حين خلصت في حكم آخر إلى أن استغر اق الدعوى مدة عامين للفصل فيها من جانب المحكمة المختصة يُعد مدة غير معقولة بالنظر إلى الظروف الصحية للمدعي و التي تشي بأن بقاءه على قيد الحياة قد لا يطول كثيرًا (81). الأمر الذي كان يتعين معه على المحكمة المختصة مر اعاة ظروفه المرضية ، وبالتالي فصلها في دعو اه خلال مدة معقولة(82) . وهو المسلك نفسه الذي اعتنقه مجلس الدولة الفرنسي في عديد من أحكامه حيث قدَّر عدم معقولية مدة الفصل في بعض المنازعات تأسيساً على جملة عناصر من بينها تقدم سن المدعي وحالته الصحية (83). و أن تللك المدة المعقولة تختلف من دعوى لأخرى طبقا لظروفها وملابساتها .

${ }^{(78)}$ C.E., 19 juin 2006, no 286459.

= CASSIA (P.); " Délai raisonnable de jugement ". in les grands arrêst du contentieux administratif, op.cit., pp. 118 ct suv.

(79) C.E., sect., 17 juill 2009, ville de Brest, no 295653; AJDA 2009, 1605, chron. S-L. Liéber et D. Botteghi ; Dr adm. 10/2009 . comm. F. Melleray, no 141; JCP 2009, 317, ş 4, chron. B. plessix ; JCP Adm. 2010. 2006, not N. Albert ; RFDA 2010. 405, not. S. Givernaud.

${ }^{(80)}$ L' arrêt du conseil d'Etat, 4 ème 15 ème SSR, 23 juin 2014, no 369946, Rec. L. ebon, publiés sur Www.legifrance.fr.

${ }^{(81)}$ CEDH, Les arrêst vocaturo C. Italie du 24 mai 1991. Série A no 206- C. P. 29, par. 2, G. C/ Italie du 27 fev. 1992, Série A no 228- F.P. 65. Par. 2, et pandolfelli et plaunbo c/ Italie du 27 fev 1992, série A no 231 - B, P. 16, par 2.

${ }^{(82)}$ CEDH, 31 mars 1992, affaire X. C. France, Requête, No 18020/91. Com. No 26.

${ }^{(83)}$ C.E., 4ème. et 5 èmm . sous - sections réunies 19 juin 2006, no 286459. 
للفصل في الدعاوى الإدارية خلال مدة معقولة في النظام

$$
\text { شعبان أحمد رمضان }
$$


للفصل في الدعاوى الإدارية خلال مدة معقولة في النظام

$$
\text { شعبان أحمد رمضان }
$$


للفصل في الدعاوى الإدارية خلال مدة معقولة في النظام

\section{شعبان أحمد رمضنان}

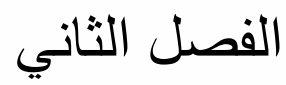

وسائل الفصل في الدعاوى الإدارية خلال مدة معقولة

طبقاً لتقنين العدالة الإدارية الفرنسي 
للفصل في الدعاوى الإدارية خلال مدة معقولة في النظام

$$
\text { شعبان أحمد رمضان }
$$




\section{الوسائل المستحدثة}

للفصل في الاعاوى الإدارية خلال مدة معقولة في النظام

القانوني الفرنسي

\section{شعبان أحمد رمضنان}

الفصل الثاني

وسائل الفصل في الدعاوى الإدارية خلال مدة معقولة

طبقاً لتقنين العدالة الإدارية الفرارية خلي الإنسي

يسعى المشرع في النظم القانونية على اختلاف مشاربها - وهو بصدد تنظيم الحق في التقاضي ـ نحو الموازنة بين تحقيق العدالة الجيدة عبر تقييده للقضاء باتباع إجر اءات محددة تضمن دقة تمحيص الخصومة القضائية وكفالة

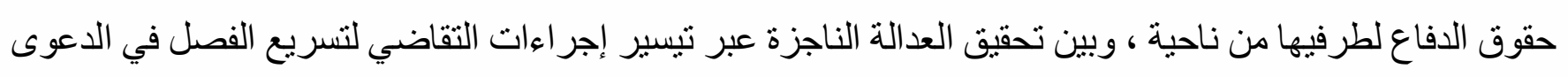

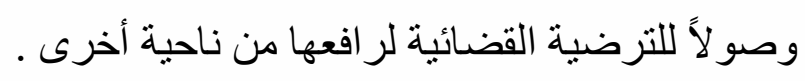

ونظراً لتقييد القضاء الإداري بعديد من المبادئ التي نستوجب قدراً أطول من الوقت للفصل في الدعاوى الإدارية كمبدأ التحضير الإلز امي للمناز عة الإدارية قبل الفصل في موضو عها ـ ومبدأ الكتابة و غياب المر افعة الثفهية

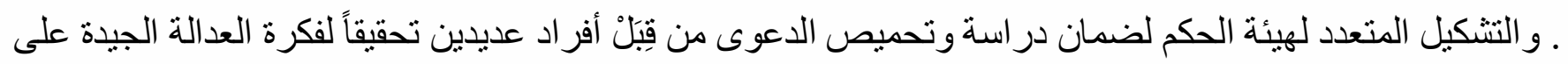

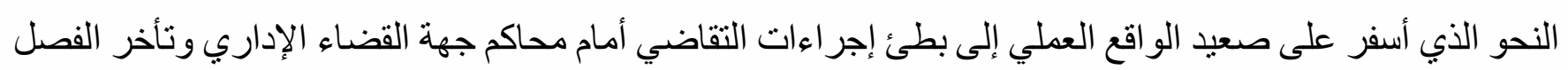

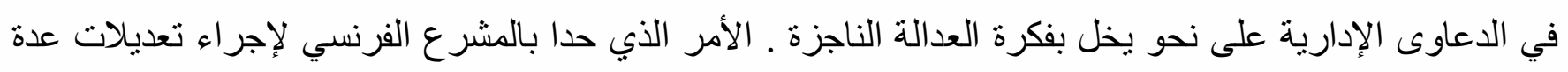

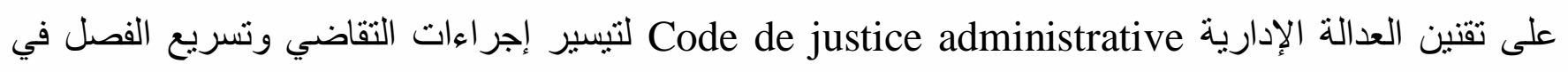
الدعاوى الإدارية خلال مدد معقو لة تحقيقا للعدالة الناجزة وذلك كنتيجة لعديد من الأحكام التي أصدرتها المحكمة الأوربية لحقوق الإنسان ضد فرنسا بتعويض المتضررين من تأخر محاكمها في الفصل في مناز عاتهم خلال مدة معقولة طبقاً

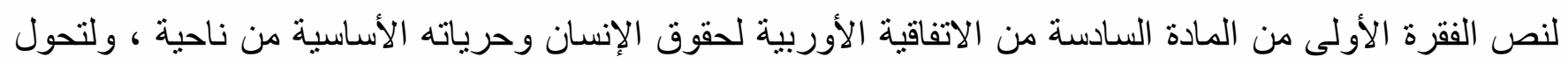
قضاء مجلس الدولة الفرنسي صوب إقرار مبدأ الفصل في الدعاوى الإدارية خلال مدة معقولة - ومسئولية الدولة حال

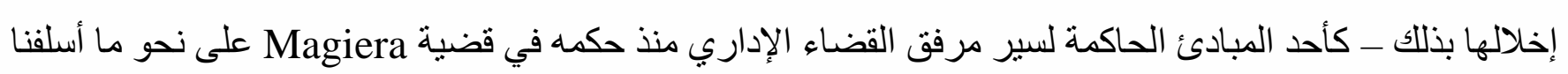
في الفصل الأول من ناحية أخرى .

ويُعد من أبرز الوسائل التي تبناها المشرع الفرنسي للفصل في الدعاوى الإدارية خلال مدة معقولة إعفاء

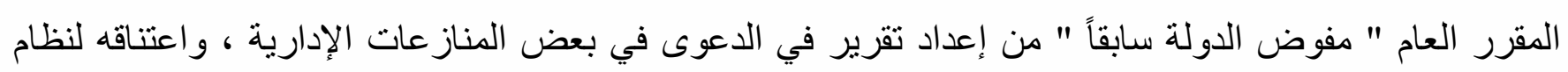
القاضي المنفرد أو الدو ائر الفردية لنظر بعض المناز عات ، وحظر الطعن بالاستئناف في بعض الأحكام الإدارية. فضلاً عن توجهه صوب إقرار بعض وسائل التقاضي الإليكتروني أو الدعوى الإدارية الإليكترونية(84).

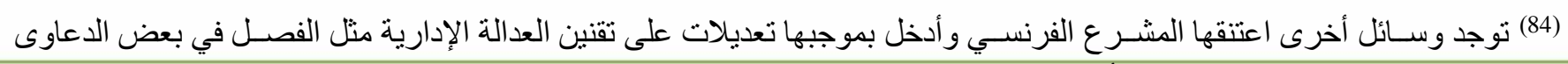
بمرسـوم ، وتحديد مو اعيد ملزمة و أخرى توجيهية للفصـل في بعض اعلد الدعاوى ـ راجع في ذللك : د. مجدي عبد الحميد شـعيب ، آليات 
و هو ما سنقصر عليه في هذا الفصل عبر تقسيمه لأربعة مباحث نتناول في كل مبحث وسيلة من تلكم الوسائل conseil d'Etat de france Questionnaire, pp. 5-8 . 


\section{الوسائل المستحدثة}

للفصل في الدعاوى الإدارية خلال مدة معقولة في النظام النقام النقام

القانوني الفرنسي خدال

\section{شعبان أحمد رمضنان}

\section{المبحث الأول}

الفصل في بعض الدعاوى الإدارية دون إعداد تقرير

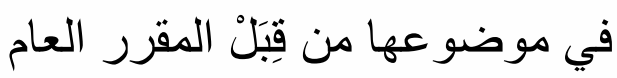

يلعب المقرر العام - و الذي كان يسمى مفوض الحكومة ـ سابقاً دور اً محورياً في تحقيق العدالة الإدارية عبر

إعداده لتقرير في موضوع الدعوى الإدارية يُحدد فيه أبعاد تلك الدعوى من الناحيتين الو اقعية والقانونية من خلال

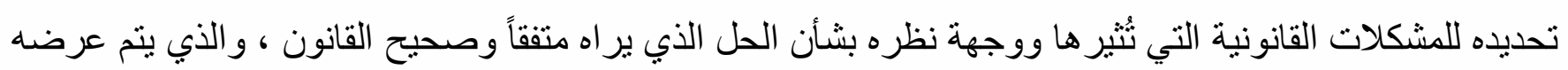
لاحقًا على هيئة الحكم المختصة بنظر ها (85).

وللمقرر في سبيل القيام بدوره اتخاذ عدة إجراءات قد تفضي لإطالة أمد الفصل في النزاع على النحو الذي يُعيق تحقيق العدالة الناجزة ـ الأمر الذي حدا بالمشرع الفرنسي بإدخال تعديل على تقنين العدالة الإدارية يتعلق بإعفاء المقرر العام من إعداد تقرير في موضوع الدعوى في بعض صور المنازعات الإدارية بحيث تفصل فيها المحكمة

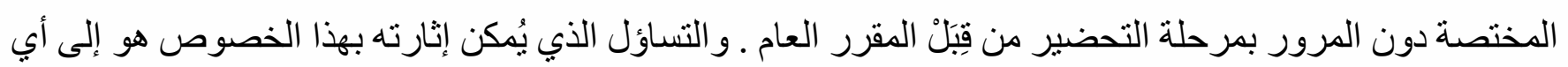
مدى أسهم هذا التعديل في تحقيق العدالة الناجزة ؟ وهل أثر سلباً على فكرة العدالة الجيدة ؟ وللإجابة على التساؤل المطروح بشقيه نُقسم هذا المبحث لمطلبين ، نخصص أولهما لتناول دور المقرر العام في الدعوى الإدارية ــ ونُعرض في الآخر للتعديل التشريعي بشأن إعفائه من إعداد تقرير في بعض الدعاوى و الفصل

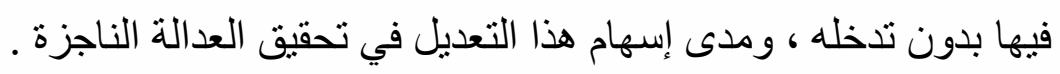

$$
\text { المطلب الأول }
$$

دور المقرر العام في الدعوى الإدارية

تمر الدعوى الإدارية بعدة مر احل لتحضير ها وتهيئتها تمهيداً للفصل في موضو عها على نحو يكفل در اسة كافة جو انبها الو اقعية و القانونية تحقيقاً للعدالة الجيدة ـ ويلعب المقرر العام " Le rqpporteur public " - مفوض الدولة سابقان(86)

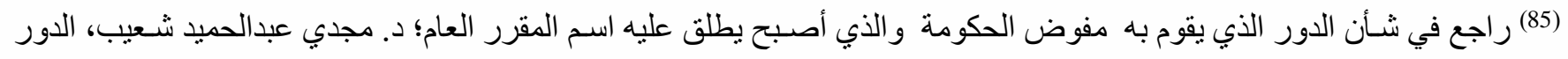

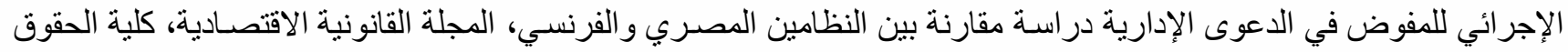

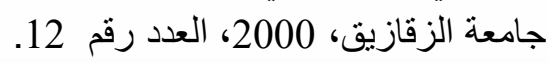
(86) Auby (J.-M.) et Drago (R.) ; Traité de Contentieaux administratif, T. 1, 2 ém. éd., L.G.D.J., 1975, no 180. Pp. 195-196; victore (H.)l le Commissaire du gouvernement et le resbect du contraditoire, Recueil Dalloz - 1999, 19 ém. Charonique, P. 204. 


\section{شعبان أحمد رمضان}

أ "le commissaire de gouvernment" - دوراً بالغ الأهمية في هذا الصدد على النحو الذي أضحى معه أحد دعامات القضاء الإداري الفرنسي نظر أل لما تتسم به تقارير المقررين في السعة والثمول ، و العمق في التحليل و التأصيل في در اسة ملف الدعوى وتحديد واقعاتها و المسائل القانونية التي تثير ها ، و اقتر اح الحل القانوني المناسب للفصل في

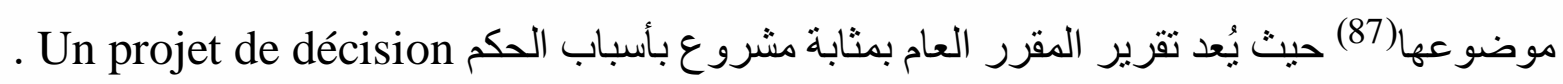
ولقد أسهمت تقارير مفوضي الدولة أمام محاكم جهة القضاء الإداري الفرنسي في إرساء عديد من نظريات و وبادئ القانون الإداري وتطوير قو اعده و أحكامه لكونهم يمتلون وجهة نظر القانون على النحو الذي يمكن معه تسميتهم

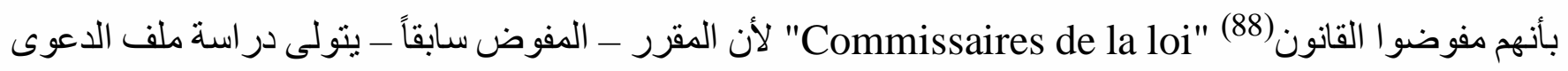
بشكلٍ وافٍ ، كما يتتبع الاتجاه القضائي للمحاكم الإدارية ومجلس الدولة ساعياً نحو تطويره ليقتر ح الحل القانوني واجب التطبيق على النزاع (89) و المفوض في سبيل قيامه بتلكم المهمة لا يقتصر على مصادر القانون المكتوبة فحسب ، و إنما يلجأ كذلك للمصادر غير المكتوبة ، وفتاوى وآراء مجلس الدولة ، وفقه القانون العام ، فضلاً عن القضاء الدستوري ، بل وقضاء محكمة النقض الفرنسية أحياناً عبر اقتراحه حلاً مشابهاً لما تسير عليه محكمة النقض(90) والتي نرتكز أحكامها على قو اعد القانون الخاص باعتبار تللك القو اعد تحوي مبادئ عامة تصلح للتطبيق على روابط القانون العام . و المفوض في قيامه بدر اسة ملف الدعوى لتحديد النصوص واجبة النطبيق على موضوع النزاع لا يقتصر

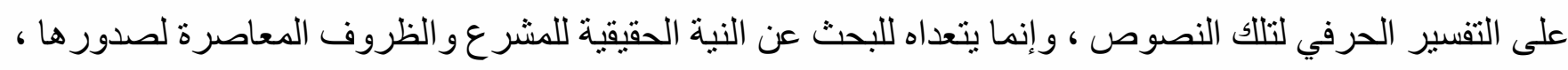
و هو المسلك الذي فعله مفوض الدولة David في قضية بلانكو الثهيرة(91) ـ كما أنه في استعانته بأحكام المحاكم

(87) Marcel (V.); Droit administratif, 9 ém. éd., 1966, p. 190 Chapus (R.); Droit du contentieaux administratif, 7 ém. éd., 1995 pp. 670 et suv.

= وراجع في الفقه العربي : د. مجدي عبدالحميد شعيب، الدور الإجرائي للمفوض في الدعوى الإدارية دراسـة مقارنة بين النظامين

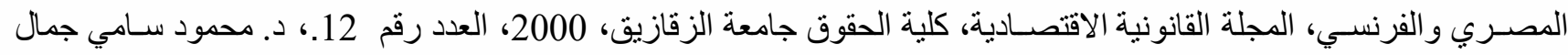

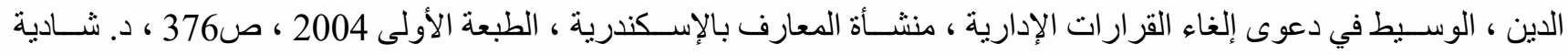

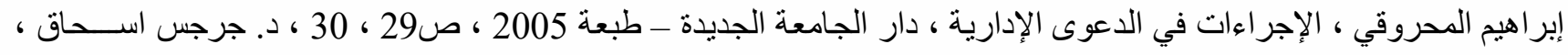

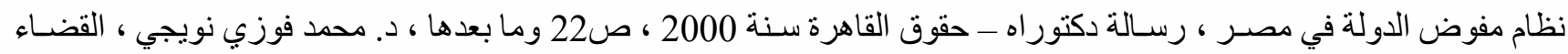

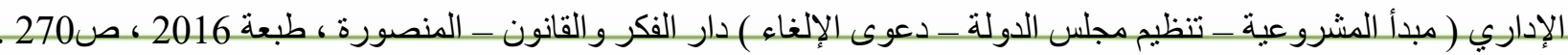

(88) Victor (H.); Le commissaire du gouvernement ... ,op.cit,. p. 204 ; marcel (V.); Droit administratif , op.cit., p. 191.

${ }^{(89)}$ Mari (C.); La commissaire des opèration de Baurle, 1991, p.13.

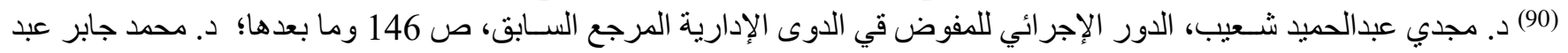

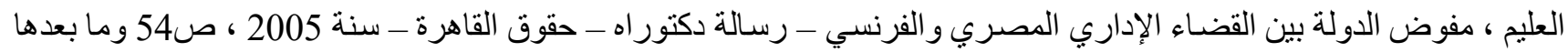

${ }^{\left({ }^{1}\right)}$ T.C., 8 fev. 1873, Rec., 1 er sup., 61, concl, David; D. 1873. 3.20; S. 1813.3.153 ; GAIA, 1996, P.1. 


\section{الوسائل المستحدثة}

للفصل في الدعاوى الإدارية خلال مدة معقولة في النظام القانوني الفرنسي

\section{شعبان أحمد رمضنان}

لتعضيد وجهة نظره لا يقتصر على الإشارة للحكم القضائي كسابقة قضائية فحسب(92) و إنما يتناول بالتحليل كافة ملابسات الحكم لتبيان العلاقة بينه وبين ما تثيره الدعوى موضوع التقرير من مشكلات قانونية على نحو لا يقتصر فيه المقرر على السو ابق المشابهة فحسب ، و إنما يتعداه لتلك التي تمكنه من القياس بمفهوم المخالفة(93). كما أنه في تبنيه للآراء الفقهية لأعلام القانون العام الفرنسي فإنه ييتدع ويؤسس وجهة نظره بشكل منطقي مثلما فعل المفوض في القضية Sufilia و الذي ضدنه آر اء كل من الفقيهين الكبيرين " اندريه دي لوبادير ، وجاسنون جيز " مؤكداً أن مبدأ استمر ارية المرفق العام لا يُعد الأساس الوحيد لمسلك القضاء فيما يتعلق بتطبيقه لنظرية الظروف الطارئة في مجال العقود الإدارية ، و إنما يتكامل جنباً إلى جنب مع فكرة العدالة الإدارية وما تقتضيه من ضرورة تحمل الإدارة لقدر من الخسارة التي لا تُعد مسئولة عنها لإعادة التوازن المالي للعقد الإداري (94).

و الأصل المسلم به طبقا للنظام القانوني الفرنسي هو التز ام المقرر العام ـ مفوض الدولة سابقا ـ بأعداد تقرير عن النزاع موضوع الدعوى واقتر اح الحل الذي ير اه ملائماً له بحيث لا بستطيع أن بتخذ موقفاً سلبياً ويترك الأمر لقناعة المحكمة ، و إلا كان الحكم الصادر في موضوع الدعوى مشوباً بالبطلان إعمالاً لنص المادة 67 من مرسوم 31 يوليه 1945 على نحو ما أثارت إليه أحكام مجلس الدولة الفرنسي ومنها حكمه الصادر بتاريخ 14 فبراير 1912 في قضية Ministre des travaux publics (95) وكذلك حكمه في قضية Adrasse عام 1955 و الذي خلص فيه إلى إلغاء الحكم المطعون فيه معتبراً أن مسلك المفوض الذي انطوى على ترك الأمر لعدالة المحكمة دون إبداء رأيه بُعد انتهاكاً لالتز امه بإعداد تقرير وتضمينه الحل القانوني الذي يقترحه(96) حيث يُسهم التزام المفوض بإعداد رأي مُسبب

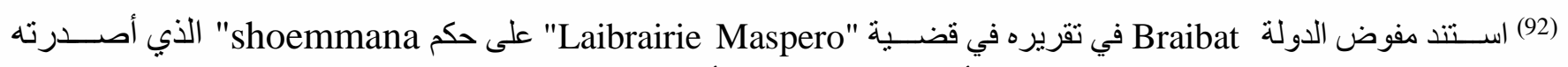

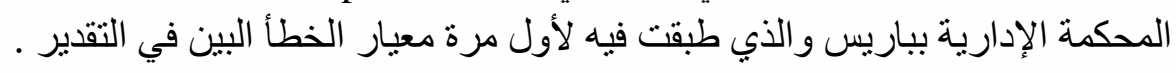

= Conclusiom Braibant sous, C.E., Ass novem. 1973.

و هو المسللك نفسه الذي تبناه المفوض Genvois في قضية Societé des Etablisemments cruse fils et frères والذي استند فيه على مسلك المجلس الدستوري فيما قرره من ضرورة احتر ام حقوق الدفاع باعتبار ها أحد المبادئ العامة للقانون . =C.E. scc, gamai 1980, socité des Etablisements cruse fils et frères , AJDA, 1980, P. 482 .

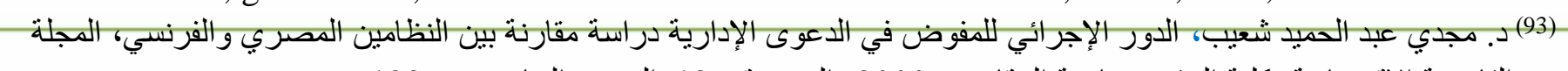

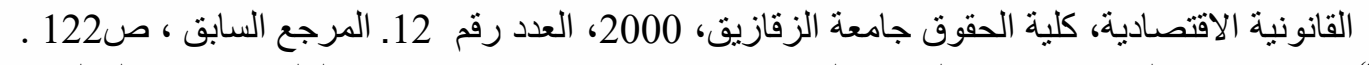

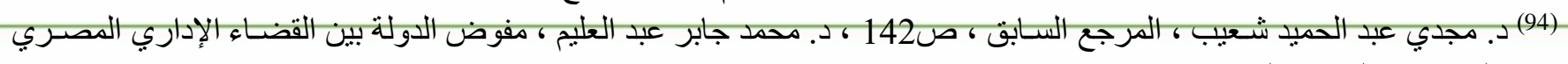

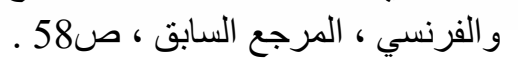
(95) C.E., 14 Fer. 1912. Ministre des traveaux publices, passard, Rec., P. 204

(96) C.E., M. Adresse, 18 Decemb. 1955, Rec., P.172. 


\section{الوسائل المستحدثة}

للفصل في الاعاوى الإدارية خلال مدة معقولة في النظام

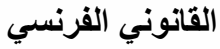

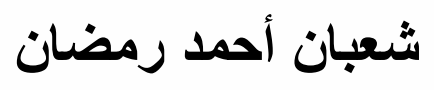

بشأن موضوع الدعوى في تحقيق حسن سير العدالة نظر آ لاستناده على اعتبار ات واقعية وقانونية تحمله على اقتر اح حل ملائُ يتفق ونظريات ومبادئ القانون العام ، و الرو ابط التي بحكمها ، دون تجاهل لأية معطيات أخرى(97).

وتجدر الإشارة أخير اً إلى أن دور المقرر العام يأتي - طبقاً للنظام الإجرائي المتبع أمام محاكم جهة القضاء الإداري الفرنسي - في مرحلة تالية لدور مقرر الدائرة المختصة أو القسم الفرعي المختص الذي يتسلم ملف الدعوى بعد تسجيلها بقلم الكتاب ويقوم بإعداد تقرير في موضو عها بتكليف من رئيس القسم المختص ، و الذي يُعد - أي هذا التقرير - حال المو اققة عليه بعد المداولة والتصويت من الدائرة المختصة في جلسة التحضير بمثابة مشروع الدائرة أو القسم الفرعي بشأن الحكم في موضوع الدعوى.

و عقب ذللك يتم تسليم ملف الدعوى للمقرر العام ليعاود در استها مجدداً و إعداد تقرير بشأنها يتم إيداعه وقيده بجدول أعمال جلسة هيئة الحكم Séance publique de jugement حيث يثر افع المقرر العام في نلكم الجلسة ويكون آخر المتحدثين ، وإن كان المشرع الفرنسي قد أجرى تعديلاً عام 2011 بالمرسوم رقم 1950 - 2011 " سمح بمقتضاه للخصو مبإبداء ملاحظاتهم بعد مُداخلة المقرر العام (98).

ويتوقف سير الدعوى الإدارية عقب ذلك على الرأي الذي ينتهي إليه المقرر العام والذي لا يخرج عن فرضين أحدهما أن يكون رأيه متفقا مع مشروع الحكم الذي انتهت إليه الدائرة المختصة ، ومن ثم فإنه يدعو ها لإصدار الحكم في الدعوى طبقا لهذا المشروع . و الآخر أن يكون رأيه متعارضاً مع مشروع الحكم الذي سبق وأن أقرته الدائرة المختصة على النحو الذي يدعوه لطلب انضمام دائرة أو أكثر إلى تللك الدائرة في محاولة منه لاقناع هيئة الحكم بالر أي الذي ير اه متفقاً وحكم القانون (99).

= د. مجدي عبد الحميد شعيب ، الدور الإجرائي للمفوض في الدعوى الإدارية،. المرجع السابق ، ص72 وما بعدها. (97) La Tournere ; Essai Sur les méthodes juridictionnelles au consiel d'etat , 1964, p. 239.

${ }^{(98)}$ Décret no 2011- 1950 du 23 décembre 2011 modifiant le code de justice administrative. L' article R. 732-1 du code de justice administrative, dans sa rédaction issue du décret du 23 décembre 2011 dispose désormais que les parties peuvent présenter leurs observation orales après que le rapporteur public s'est exprimé... voir, en ce qui concerne les observations orales devant les tribunaux administratifs et les cours administratives d'appel; art. R. 732-1 du code de justice administrative; en ce qui concerne les "brèves" observations orales, succédant aux première observations orales, devant le conseil d' Etat: art. R. 733-1 du code de justice administrative.

(99) د. مجدي عبد الحميد شـعيب ، آليات تمكين القضـاء الإداري من الفصـل في المنازعات في مدة معقولة ، المرجع السـابق ، ص37 ، 


\section{شعبان أحمد رمضنان}

وتُختتم المر احل السابقة بمُداخلة للمقرر العام أمام هيئة الحكم أياً كان العدد الذي تُشكل منه بحيث يتولى تفنيد الأسباب التي حملته على رفض مشروع الحكم ، مع تفصيله للحجج و الأسانيد التي شيد عليها رأيه ووجه اتفاقه مع حكم القانون(100). نظر آ لأن دور المقرر ينحصر على نحو ما أسلفنا في إعلاء حكم القانون بقطع النظر عن مدى اتفاقه أو اختلافه مع وجهة نظر الإدارة ، وهو ما حدا بالمشرع الفرنسي لتعديل تسميته من مفوض الحكومة للمقرر العام(101) لإز الة أي لبس يتعلق بالدور الذي يقوم به ، وتأكيداً لكونه يعمل لمصلحة القانون وحسن سير العدالة أمام محاكم جهة القضاء الإداري .

\section{المطلب الثاني}

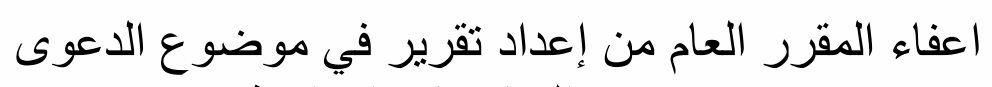
في بعض المناز عات الإدارية

يضطلع المقرر العام بدور بالغ الأهمية في إرساء حكم القانون ، و احتر ام المبادئ التي تُشيد عليها العدالة أمام القضاء الإداري عبر اسهامه في تمحيص المناز عة الإدارية وما تثيره من مشكلات متعددة تمحيصاً يُضيء ما أظلم من جو انبها ، ويوضح ما غمض من وقائعها برأي تتجسد فيه الحيدة لصالح الشرعية وحكم القانون تمهيداً للحكم في موضو عها على النحو الذي يكفل تحقيق العدالة الجيدة .

و إذا كان التز ام المقرر العام بإعداد تقرير في موضوع الدعوى الإدارية يُعد الأصل والقاعدة العامة طبقاً للنظام

الإجرائي المُتبع أمام القضاء الإداري الفرنسي باعتباره أحد المر احل الجوهرية اللازمة لتحضير الدعوى وتهيئتها للفصل في موضوعها ، و إلا كان الحكم الصادر فيها دون وجود هذا التقرير باطلاً ، وهو ما يُفضي من الناحية العملية لاستغر اق وقت طويل للفصل فيها بما يُعيق تحقيق العدالة الناجزة ، ويتناقض مع ما تقضي به الفقرة الأولى من المادة السادسة من الاتفاقية الأوربية لحقوق الإنسان من ضرورة الفصل في الدعوى في مدة معقولة ، فإن المشرع الفرنسي ـ خروجاً على ذالك الأصل وتلكم القاعدة ـ اتجه صوب إدخال بعض التعديلات على تقنين العدالة الإدارية من بينها إعفاء المقرر العام من إعداد هذا التقرير و الحكم في الدعوى دون تدخله في بعض صور المنازعات الإدارية اختصارًا للوقت ، وتحقيقاً لفكرة العدالة الناجزة .

(100) د. مجدي عبد الحميد شعيب ، الدور الاجر ائي للمفوض في الدعوى الإدارية، المرجع السابق ص 83-84. (101) Décret no 2009- 14 du 7 janvier 2009 relatif au rapporteur public des juridictions administratives et au déroulement de l'audience devant ces juridictions. 


\section{الوسائل المستحدثة}

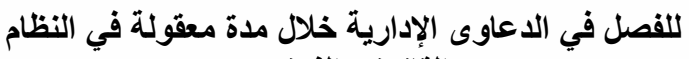

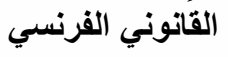

\section{شعبان أحمد رمضنان}

ويأتي في مقدمة تلك المناز عات ما ينظره القضاء المستعجل من ناحية ، وتلك التي لا ثُثير مشكلات حقيقية من ناحية أخرى ، وهو ما نوجزه في فرعين على النحو الآتي :

\section{الفرع الأول}

المناز عات التي ينظر ها القضاء المستعجل

ورد النص على هذا الاستثناء بالمادة " L 522-1 " من تقنين العدالة الإدارية المعلة بالمرسوم رقم " -2009 14 " بتاريخ 7 يناير 2009 والتي نصت على أن : "يفصل قاضي الأمور المستعجلة في النزاع وفقاً لإجر اءات حضورية مكتوبة أو شفهية . ويجب على القاضي منى طُلب منه اتخاذ الإجر اءات المنصوص عليها في المادتين " خ 521-1 " " 521-2 " لتعديلها أو إلغائهاو أن يُعلن الأطر اف على الفور بتاريخ وميعاد الجلسة مالم يتم إحالتها لهيئة ذات تتكيل متعدد ، تتعقد الجلسة دون تقرير المقرر العام ".

" Le juge des référés statue au terme d'une procédure contradictoire écrite ou orale. Lorsqu'il lui est demandé de prononcer les mesures visées aux articles L. 521-1 et L. 5212, de les modifier ou d'y mettre fin, il informe sans délai les parties de la date et de l'heure de l'audience publique. Sauf renvoi à une formation collégiale, l'audience se déroule sans conclusions du rapporteur public " (102).

وتجدر الإشارة إلى أن ما تضمنته المادة " L. 522-1 " يتعلق بإجر اءات الفصل في طلب وقف تنفيذ القرارات

الإدارية

" L. 521-1 " وكذا طلب الحماية المستعجلة للحريات الأساسية طبقًا لنص المادة "L. 521-2 " المستحدثة بالقانون رقم 597 - 2000 بتاريخ 30 يونيه 2000 و الذي يُعد أحد الإصلاحات الكبرى في تاريخ القضاء الإداري الفرنسي (103) لما خوله لقاضي الأمور المستعجلة الإداري من كفالة حماية فعالة وسريعة للحريات الأساسية بحيث يلتزم بإصدار أمر

${ }^{(102)}$ L' article " L. 522-1" du code de justice administrative, modifié par Décret no 2009 - 14 du 7 janvier 2009.

${ }^{(103)}$ Chapus (R.) ; Lecture du code de la justice administrative, R.F.D.Ad, 2000, P. 932; pacteau (B.); vue de l'intérieur : La loi du 30 juin 2000 : une réforme exemplaire. R.F.D. ad. 2000., P. 959 ; fouletier (M.); La loi 30 juin 2000, relative devant le juridictions administrative, R.F.D.Ad. 2000, p. 963. 


\section{الوسائل المستحدثة}

اللفصل في اللدعاوى الإدارية خلال مدة معقولة في النظام

$$
\text { القانوني الفرنسي }
$$

\section{شئبان أحمد رمضان}

الحماية في غضون ثمانية و أربعون ساعة من تقديم الطلب له حيث نصت تلك المادة على أنه " حال الاستعجال ـ وبناء على طلب ، يكون لقاضي الأمور المستعجلة الإدارية الأمر ، خلال ثمانية وأربعين ساعة ، باتخاذ جميع الإجر اءات اللازمة لحماية الحرية الأساسية من أي اعتداء جسيم بالغ عدم المشروعية يقع من أحد الأشخاص الاعتبارية العامة أو الخاصة المكلفة بإدارة مرفق عام على إثر ممارسته لأي من اختصاصاته "(104).

وتتجلى الحكمة من الفصل في المنازعات ذات الطبيعة المستعجلة ـ سواء كانت متعلقة بأحكام وقف تتفيذ

القر ار ات الإدارية ، أو طلب الحماية المستعجلة للحريات الأساسية ـ دون تقرير من المقرر العام في أن تلك المناز عات بطبيعتها تستوجب سر عة الفصل فيها للاعتبار ات التي قدر ها المشرع من ناحية ، و لأنها تُعد حماية ذات طبيعة وقتية من ناحية أخرى لا تُقيد محكمة الموضوع في الحالة الأولى ، أو تتغير بتغير الظروف في الحالة الثانية بحيث يغدو منطقياً الفصل فيها دون التوقف على كتابة تقرير في موضو عها من قِبَّْ المقرر العام .

\section{الفر ع الثاني}

المناز عات التي لا ثُثير مشكلات حقيقبة

حرصاً من المشرع الفرنسي على الحد من ظاهرة بطء إجراءات التقاضي على النحو الذي بضمن سرعة الفصل في الدعاوى الإدارية لكفالة تحقيق العدالة الناجزة أجازت المادة " R 732-1-1 " التي أضيفت لتقنين العدالة الإدارية في ديسمبر 2011 و المعدلة بالمرسوم رقم 730 - 2013 بتاريخ 13 أغسطس 2013 إعفاء المقرر العام من إعداد تقرير في المناز عات التي لا ثُثير مشكلات حقيقية (105).

وتجدر الإشارة إلى أن إعفاء المقرر العام من إعداد تقرير في تلكم المنازعات يتم بموجب قرار يصدره رئيس هيئة الحكم بناءً على اقتر اح المقرر العام ، كما أن نطاق هذا الإعفاء يقتصر على مناز عات محددة على سبيل الحصر أوردتها المادة الثالثة من المرسوم رقم " 730 - 2013 " المُعدلة للمادة " $732-1$ " " والتي نصت على أنه : " مع عدم الإخلال بتطبيق الأحكام الخاصة ببعض المناز عات التي تتعقد الجلسات في شأنها دون تقرير المقرر العام ، يجوز لرئيس المحكمة أو القاضي الفرد أن بُعفى المقرر العام ، بناءً على اقتر اح منه ، من تقديم تقريره في

${ }^{(104)}$ L abetaulle (D.) ; Le référé nouveau est arrivé. A.J. 2000, p. 211

${ }^{(105)}$ Article R132-1-1 " modifié par Décret no 2013 - 730 du 13 aout 2013 - art. 3 " 
2- رفض الاستعانة بالسلطة العامة لتنفيذ حكم قضائي .

4- دخول و إقامة الأجانب و إبعادهم ، باستثناء المطرودين .

5- ضريبة السكن ، و الضر ائب المفروضة على ملكية العقار ات السكنية و المخصصة للاستعمال المهني وفقاً

لحكم المادة (1496) من التقنين العام للضر ائب، وضر ائب المساهمة في البث السمعي و البصري العام .

6- المنافع أو الإعلانات أو المساعدات الاجتماعية ، أو المنازعات المتعلقة بالإيواء أو بالعاطلين عن العمل .

Sans préjudice de l'application des dispositions spécifiques à certains contentieux prévoyant que l'audience se déroule sans conclusions du rapporteur public, le président de la formation de jugement ou le magistrat statuant seul peut dispenser le rapporteur public, sur sa proposition, de prononcer des conclusions à l'audience sur tout litige relevant des contentieux suivants :

$1^{\circ}$ Permis de conduire;

$2^{\circ}$ Refus de concours de la force publique pour exécuter une décision de justice;

$3^{\circ}$ Naturalisation;

$4^{\circ}$ Entrée, séjour et éloignement des étrangers, à l'exception des expulsions;

$5^{\circ}$ Taxe d'habitation et taxe foncière sur les propriétés bâties afférentes aux locaux d'habitation et à usage professionnel au sens de l'article 1496 du code général des impôts ainsi que contribution à l'audiovisuel public;

$6^{\circ}$ Prestation, allocation ou droit attribués au titre de l'aide ou de l'action sociale, du logement ou en faveur des travailleurs privés d'emploi ${ }^{(106)}$.

(106) Article R732-1-1 " modifié par Décret no 2013-730 du 13 août 2013- art. 3 ". 
ولعل استقر اء الحالات التي أوردتها المادة سالفة الذكر يوضح بجلاء أنها دعاوى بسيطة لا يُثير الفصل فيها مشكلات قانونية حقيقية مما يستوجب تمكين القضاء من الفصل فيها خلال مدة معقولة دون إعداد تقرير في موضو عها من قِبِّْ المقرر العام تحقيقاً للعدالة الناجزة ، ودون إهدار في الوقت نفسه للعدالة الجيدة نظر اً لبساطتها ووضوح الحكم القانوني في موضو عها .

و التساؤل الذي يُمكن طرحه بصدد التعديل المتعلق بإعفاء المقرر العام من إعداد تقرير في بعض الدعاوى الإدارية و الفصل فيها مباشرة من قِبَّْ المحكمة المختصة هو هل يُعد هذا التعديل انتقاصًا للعدالة الجيدة ؟ أو بمعنى آخر هل يكون تحقيقه للعدالة الناجزة على حساب العدالة الجيدة ؟

نتفق في الإجابة على التساؤل المطروح مع ما قرره جانب فقهي (107). من أن التعديل الذي نحن بصدده لم يؤثر سلبا على جودة العدالة بل على العكس من ذللك. ذلك أن هذا التعديل بشقيه سو اء ما تعلق منه بالأعاوى المستعجلة التي تستوجب الفصل فيها على وجه السرعة نظر اً لطابعها الخاص ، فإن إعفاء المقرر العام من إعداد تقرير بشأنها ، فضلاً عن انعقاد جلسة الحكم دون الاستماع لوجهة نظره لهو أمرٌ بتفق وحال الاستعجال التي تفرض على القاضي الفصل في الدعوى في مدة محددة لا يمكن تجاوز ها ـ و الأمر نفسه ينطبق على الشق الآخر المتعلق بالمناز عات التي لا ثُثير مشكلات حقيقية ويمكن الفصل فيها دون إعداد تقرير في موضو عها لوضوح الحكم القانوني بشأنها حيث بمكن القول أن المسلك التشريعي بهذا الخصوص يُعد نوعاً من الموازنة المنطقية بين العدالة الناجزة وتلك الجيدة سعياً لتحقيقهما في آن و احد دون إهدار لإحداهما في سبيل تحقيق الأخرى لاسيما وأن تلك المناز عات تتسم بالبساطة و لا ثُثير مشكلات حقيقية ، مما بستوجب عدم إضاعة الوقت في إعداد تقرير بشأنها ، ومن ثم الفصل فيها في مدة معقولة خاصة و أن المشرع قصر ها على مناز عات محددة وجعل ذلك رهيناً باقتر اح من قِبَل المقرر العام ومو افقة رئيس هيئة الحكم ، وهي ضوابط في مجملها تُقيم التوازن المنشود بين تحقيق العدالة الناجزة والعدالة الجيدة في الوقت 


\title{
شعبان أحمد رمضنان
}

\author{
المبحث الثاني \\ الأخذ بنظام الدوائر الفردية
}

يُعد التشكيل الجماعي من السمات المُميزة للقضاء الإداري الفرنسي الذي ظل حتى وقت قريب لا يعرف نظام

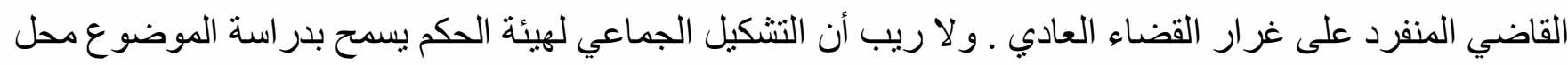
النزاع من كافة جو انبه، وتقليبه على وجو هه المختلفة عبر تمحيص المشكلات القانونية التي يُنثير ها ، وتداول الآراء بشأنها نوصلاً للحكم في موضو عه على النحو الذي يُشكل ضمانة كبرى لتحقيق العدالة الجيدة (108).

ونظر اً لأهية التشكيل الجماعي لهيئة الحكم أمام محاكم جهة القضاء الإداري الفرنسي فقد حرص واضعوا تقنين العدالة الإدارية على تسجيله كأحد المبادئ الجوهرية التي تحكم عمل القضاء الإداري(109).

ورغم أهمية مبدأ التثكيل الجماعي لهيئة الحكم فإن المشرع الفرنسي قد اتجه صوب اعتناق الأخذ بنظام القاضي المنفرد أو " الدوائر الفردية " في بعض المنازعات(110) للتغلب على مشكلة بطء إجراءات التقاضي(111) ولتمكين المحاكم من الفصل في النزاع بصورة سريعة(112) لمو اجهة تزايد عدد الدعاوى الذي أفضى لتأخر الفصل في المنازعات. و ولايُعد تبني نظام القاضي الفرد وفقا لما قرره المجلس الدستوري في غير مرة خروجا على الأحكام الدستورية وهو ما أعلنه بجلاء في الحكم الذي أصدره بتاريخ 22 أكتوبر 2009 فيما يخص المجال الجنائي أما فيما يتعلق بالمجال الإداري فلقد أعلن المجلس في الحكم الذي أصدره بتاريخ 22 أكتوبر عام 2010 أم القاضي اللجوء

${ }^{(108)}$ Foillard (ph.); Droit administratif, collection manuel , publication universtaires CPU, 8 ém.éd., pp. 294.

(109) د. مجدي عبد الحميد شعيب ، آليات تمكين القضاء الإداري من الفصل في المناز عات في مدة معقولة ، المرجع السابق ، ص 31 (2010. ${ }^{(110)}$ Rusen (E.); " Prévenir des Arriérés dans la justice administrative", colloque 7 juin 2010, Rapport du conseil d'Etat de France. Questionnaire, P. 8.

(111) Weber (A.); " Le juge administratif unique, nécessaire à l'efficacité de la justice ", RFAP, no 125. Janv. 2008, p. 180.

${ }^{(112)}$ En ce sens : «Une justice efficace est tout d'abord une justice rapide», Douchy-Oudot (M.), «Le souci d'efficacité de la justice, Propos introductifs », Gaz. Pa 1., n²28,2004, p. 188. V. également Prouvez (J.-B.), «Efficacité, rapidité : un nouveau discours de la méthode pour le juge administratif d'appel », Procédures, ${ }^{\circ}$ 6, 2003, pp. 3-5. 


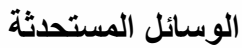

للفصل في الدعاوى الإدارية خلال مدة معقولة في النظام

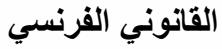

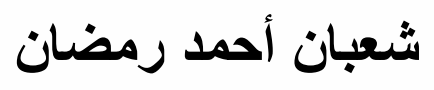

للقاضي الفرد لا بشكل خروجا على أي مبدأ دستوري ولا يشكل خروحا على مبدأ المشروعية أمام العدالة(113).

ولقد أخذ المشرع بنظام القاضي الفرد(114) بموجب القانون رقم 125-95 بتاريخ 8 فبر اير 1995(115) عبر

إضافة مادة جديدة لتقنين المحاكم الإدارية والمحاكم الإدارية الاستننافية برقم "1-4 " المُناظرة للمادة "R.222-13" من تقنين العدالة الإدارية و التي نصت على أنه " لرئيس المحكمة الإدارية أو من يفوضه من قضاتها ممن شغلو ادرجة مستشار من الفئة الأولى الفصل في جلسة علنية ، وبعد سماع مفوض الدولة ، في الدعاوى الآتية " : (116).

(113) «Le Conseil constitutionnel s'est prononcé à plusieurs reprises sur cette question, notamment le 22 octobre 2009 sur la matière pénale et le 14 octobre 2010 sur la matière administrative : il a estimé que le recours au juge unique, qui n'est contraire à aucun principe constitutionnel de collégialité des juridictions, ne porte pas atteinte au principe de l'égalité devant la justice ».

(114) V. Pacteau Pacteau (B. ), Contentieux administratif, 7e édition refondue, Paris, P.U.F., 2005, p. 74. ; (B. ), « Le juge unique dans les juridictions administratives », Gaz. Pa 1., 1998, D., pp. 177-182. ; Chevallier-Govers (C.), «Le président du tribunal administratif au secours de la célérité de la justice administrative », Gaz. Pa 1., 2000, D, pp. 1030-1047. V. également Boiteau (C.), « Le juge unique en droit administratif », RFDA, 1996, pp. 10-30.; Marion (A. ), « Du mauvais fonctionnement de la juridiction administrative et de quelques moyens d'y remédier », P ouvoirs, $n^{\circ}$ 46,1988, pp. 21-34. Paillet (M. ), « Le juge administratif, juge unique », in Les juges uniques, Dispersion ou réorganisation du contentieux ?, (Contributions coordonnées par Bolze (C. ) et Pédrot (P. )), Paris, Dalloz, 1996, pp. 93-111.

(115) Loi no 95-125 du 8 février 1995 relative à l'organisation des juridictions et à la procédure civile. Pénale et administrative.

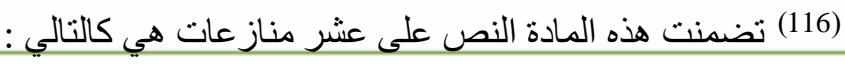

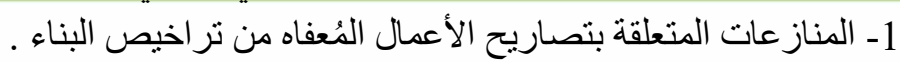

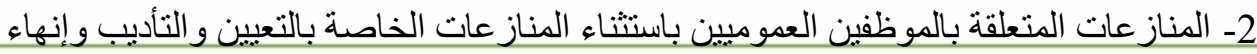

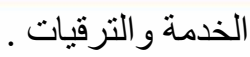

3- المناز عات المتعلقة بالنفقات و إعانات السكن ، و المنازعات الخاصة بالمستندات الإدارية

و الخدمة الوطنية.

4- المنازعات المتعلقة بالاجرة المستحقة عن خدمات الإذاعة و التلإفزيون.

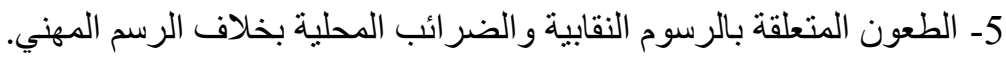

6- المنازعات المتعلقة بمسئولية الدولة عن رفض الاستجابة لطلب الاستعانة بالقوة الجبرية لتنفيذ

حكم قضائي.

7ـ الدعاوى ضد مسؤولية الوحدات العامة حينما يكون مبلغ التعويض المطلوب أقل من المبلغ

المحدد بمرسوم مجلس الدولة (و وقد حدد المرسوم رقم 831 بتاريخ 3 يونيه 1995 هذا الحدا

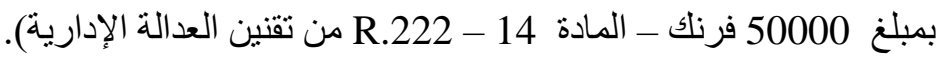

8- الطعون ضد القرارات الصادرة في المسائل الضريبية على الأخص فيما يتعلق بطلب الإعفاء الإداء

من الضر ائب.

9- المناز عات المتعلقة بالمنشآت الآيلة للسقوط. 


\section{الوسائل المستحدثة}

للفصل في الاعاوى الإدارية خلال مدة معقولة في النظام

القانوني الفرنسي

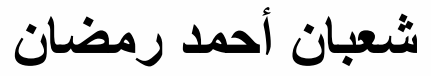

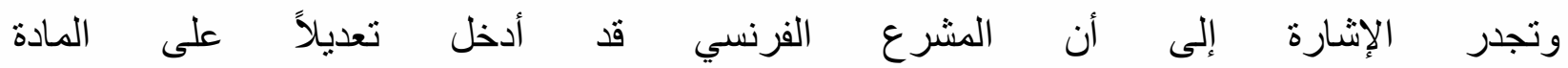
"R.222-13" بالمرسوم رقم "730 - 2013 " بتاريخ 13 من أغسطس 2013 (117) والمتعلقة بالمنازعات التي يتم الفصل فيها بمعرفة القاضي المنفرد أو عن طريق الدو ائر الفردية ، والتي تم تعديلها مؤخر اً بالمرسوم رقم -2019 " "82 بناريخ 7 فبر اير 2019 مادة /10 و التي جرى نصها على النحو الآتي :

" مع مر اعاة أحكام المادة " R. 732-1-1 " ، وبعد الاستماع إلى المقرر العام ، يتولى رئيس المحكمة الإدارية أو القاضي الذي يُعين لهذا الغرض من قضاتها ممن شغلو ا درجة مستشار أول أو لديه أقدمية لمدة عامين على الأقل الفصل في الخصومات الآتية:

1- الدعاوى الخاصة بالمنافع أو الإعانات أو المساعدات الاجتماعية ، أو المتعلقة بالإيواء أو العاطلين عن العمل ، و المشار إلبها في المادة "R. 772-5" .

2- الدعاوى المتعلقة بالتقييم المهني للموظفين العدومبين ، و الجز اءات التأديبية الصادرة في شأنهم من غير طريق المجلس التأديبي . 3- الدعاوى الخاصة بالمعاثات التقاعدية للموظفين العموميين . 4- الدعاوى المتعلقة بالإطلاع أو تبليخ الوثائق الإدارية ، أو بالمحفوظات العامة . 5- دعاوى الضر ائب المحلية ، وضريبة المساهمة في البث السمعي و البصري العام ، ويُستثنى من ذللك الدعاوى الخاصة بالمساهمات الاقتصادية الإقليمية. . 6- الدعاوى الخاصة برفض الاستعانة بالسلطة العامة لتنفيذ حكم قضائي . 7- الدعاوى المقدمة للطعن في القرار ات الصادرة في المسائل الضريبية. . 8- الدعاوى الخاصة بالمباني الآيلة للسقوط أو التي لا تتوفر فيها الاشتر اطات الصحية . 9- دعاوى رخص السياقة.

10- لبات التعويض المتعلقة بالعقود - فيما عداد عقود المشتريات العامة ـ التي لا تتجاوز النصاب المحدد

10- المناز عات المتعلقة بالمخالفات الو اقعة على طرق المو اصلات الكبرى. = Pacteau (B.) ; Le juge unique dans les juridictions a administratives , Gaz. Pal, 30 janr 1998, no 30, pp. 7 et suv. ; Corouge (E.); Le juge unique " Le contradictoire et les moyens relèves d'office " Gaz. Pal,8 nov. 1997, no 311, pp. 1464- 1466 ; Pouvoirs, n 46,1988, pp. 21-34. Paillet (M. ), « Le juge administratif, juge unique », in Les juges uniques, Dispersion ou réorganisation du contentieux ?, (Contributions coordonnées par Bolze (C. ) et Pédrot (P. )), Paris, Dalloz, 1996, pp. 93-111. ; Boiteau (C.), « Le juge unique en droit administratif », RFDA, 1996, pp. 10-30

(117) Article " R. 222-13" Modifie par Décret no 2013 -730 du 13 aout 2013 - art. 2. 


$$
\text { في المادتين (R.222-14) (R.222-15) وقد جاء نص تللك المادة بالفرنسية كالآتي : }
$$

\section{Article R222-13 Modifié par Décret n²019-82 du 7 février 2019 - art. 10 dispose que :}

Le président du tribunal administratif ou le magistrat qu'il désigne à cette fin et ayant atteint au moins le grade de premier conseiller ou ayant une ancienneté minimale de deux ans statue en audience publique et après audition du rapporteur public, sous réserve de l'application de l'article R. 732-1-1

$1^{\circ}$ Sur les litiges relatifs aux prestations, allocations ou droits attribués au titre de l'aide ou de l'action sociale, du logement ou en faveur des travailleurs privés d'emploi, mentionnés à l'article R. 772-5 ;

$2^{\circ}$ Sur les litiges relatifs à la notation ou à l'évaluation professionnelle des fonctionnaires ou agents publics ainsi qu'aux sanctions disciplinaires prononcées à leur encontre qui ne requièrent pas l'intervention d'un organe disciplinaire collégial ;

$3^{\circ}$ Sur les litiges en matière de pensions de retraite des agents public ;

$4^{\circ}$ Sur les litiges en matière de consultation et de communication de documents administratifs ou d'archives publiques ;

$5^{\circ}$ Sur les litiges relatifs aux impôts locaux et à la contribution à l'audiovisuel public, à l'exception des litiges relatifs à la contribution économique territoriale ;

$6^{\circ}$ Sur les litiges relatifs aux refus de concours de la force publique pour exécuter une décision de justice ;

$7^{\circ}$ Sur les requêtes contestant les décisions prises en matière fiscale sur des demandes de remise gracieuse ;

$8^{\circ}$ Sur les litiges relatifs aux bâtiments menaçant ruine ou aux immeubles insalubres ;

(118) Article "R. 222-13" Modifié par Décrit no 2019-82 du 7 février 2019 - art. 10. 


\section{الوسائل المستحدثة}

للفصل في الدعاوى الإدارية خلال مدة معقولة في النظام

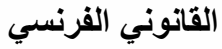

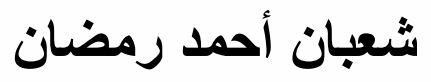

$9^{\circ}$ Sur les litiges relatifs au permis de conduire ;

$10^{\circ}$ Sauf en matière de contrat de la commande publique sur toute action indemnitaire ne relevant pas des dispositions précédentes, lorsque le montant des indemnités demandées n'excède pas le montant déterminé par les articles R. 222-14 et R. 222-15. Article "R. 222-13" Modifié par Décrit no 2019-82 du 7 février 2019 - art. 10.

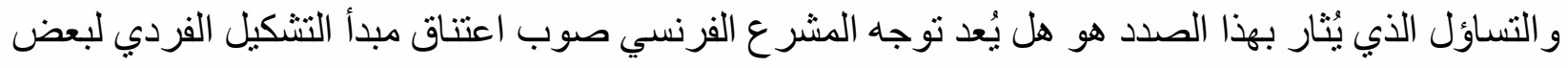

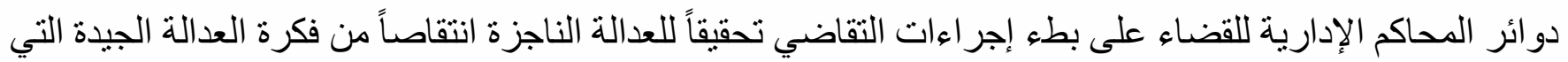
يكفلها التشكيل الجماعي لهيئة الحكم

نتفق في الاجابة على التساؤل المُثنار مع ما ير اه نظر فقهي (119) من أن تأمل النصوص التشريعية المتعلقة

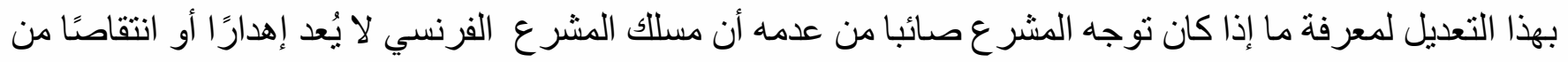
تحقيق العدالة الجيدة ، و إنما يصبُ في خانة تحقيق العدالة الناجزة دون إهدار العدالة الجيدة باعتبار أن كليهما مطلوب للحصول على الترضية القضائية كهدف نهائي للحق في التقاضي ـ وسندنا في ذلك ثلاث حجج أولها أن المشرع قصر " R. 222-13 " مجال اختصاص الدو ائر الفردية على عدد محدود من النازعات الإدارية ورد النص عليها في المادة من تقنين العدالة الإدارية والتي وردت على سبيل الحصر على النحو الذي لا يجوز التوسع فيه أو القياس عليه .

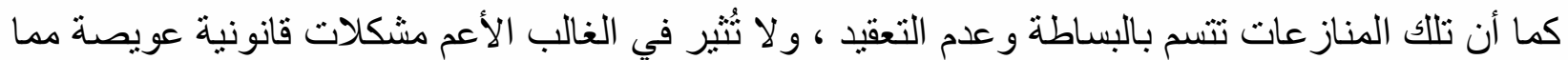
يسهل الحكم في موضوعها بالثكل الذي يجعل الفصل فيها عن طريق قاضٍ فرد " دائرة فردية " أولى من عرضها على هيئة جماعية تحقيقاً للعدالة الناجزة ، ودون إهدار للعدالة الجيدة لسهولة ووضوح الحكم في موضوعها(120).

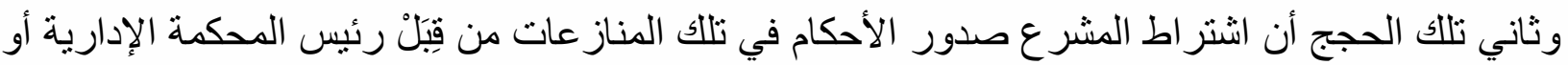
من يُكلف بذلك من قضاتها شريطة أن يكون شاغلاً لدرجة مستشار أول على الأقل ، أو لا تقل مدة أقدميته عن عامين " .... au moins le grade de premier conseiller au ayant une antiémeute minimale de deux ans ...."

$$
\text { يعكس حرص المشرع الفرنسي على ضمانة تحقيق العدالة الجيدة و الناجزة في آن واحد . }
$$

(119) د. مجدي عبد الحميد شـعيب ، آليات تمكين القضـاء الإداري من الفصل في المنازعات في مدة معقولة ، المرجع السـابق ، ص 31-

(120) Laureote (X.); " Le procès équitable devant le juge administratif français " http: Lexpublicaoverblog.com/2014/011 le - proc\% c3\% A85-\%C3\% A9 équitable - devant - le - juge - administratif fran- \% C3\% A 7 ais - Xavier - laureate, html.consulté le 26 novembre 2019. P.8. 


\section{الوسائل المستحدثة}

للفصل في الدعاوى الإدارية خلال مدة معقولة في النظام

القانوني الفرنسي خداري

\section{شعبان أحمد رمضان}

و آخر تللك الحجج يتجلى فيما أتاحه المشرع للقاضي المنفرد المختص بنظر المناز عة من إمكانية عرض النزاع للفصل فيه بمعرفة نشكيل جماعي "هيئة حكم جماعية" متى قدَّر أن النزاع يُثير من المشكلات ما يستوجب الفصل فيه بمعرفة قضاة متعددين على النحو الذي يضمن تحقيق العدالة الجيدة .

و الحقيقة أن هذا المسلك من قِبَّْ المشرع الفرنسي يتسم بالمرونة من ناحية ، ومر اعاته للو اقع العملي من ناحية أخرى بحيث أنه لا يضع قاعدة جامدة تحول دون الوصول للهدف المُبتغي ، و إنما راعى تحقيق العدالة الناجزة في الحالات التي يُقِّر القاضي المنفرد بشأنها إمكانية فصله فيها دون عرضها على هيئة جماعية ، و اقتراح عرض الأمر على تلكم الهيئة كلما كان النز اع يستوجب ذلك تحقيقاً للعدالة الجيدة ، وهو بلا شك مسلك متوازن يتسم بحسن السياسة التشريعية.

و إذا بدا على هذا النحو أن تبني المشرع الفرنسي لنظام القاضي الفرد "الدوائر الفردية" لا يعني تغليبه لاعتبار ات العدالة الناجزة على العدالة الجيدة فإن ثمة تساؤل آخر يتبادر إلى الذهن وهو هل حقق هذا التعديل الهدف المُبتغى منه و المتمنّل في تحقيق العدالة الناجزة ؟

يمكن الإجابة على هذا التساؤل من خلال استقر اء التقارير السنوية لمجلس الدولة الفرنسي في الأعو ام الماضية و التي تؤكد نجاح نظام القاضي المنفرد في الحد من ظاهرة بطء إجر اءات التقاضي بشكل كبير حيث ثُبرز تلكم التقارير المُتعاقبة مساهمة هذا النظام في الفصل في عدد كبير من القضايا خلال وقت قصير مقارنة بما يتم الفصل فيه من جانب الدو ائر الجماعية. فعلى سبيل المثنال بالنسبة لتقرير مجلس الدولة لعام 2013 يتضح طبقاً للإحصاءات أن نسبة الفصل في المنازعات المنظورة أمام الدوائر الفردية قد بلغت 30\% (121). وأن تللك النسبة قد ازدادت بتقرير المجلس عام 2015 لتصل إلى 31.3\% وهو ما يقرب من 60 ألف قضية من إجمالي 188783 قضية. كما يتضح من مر اجعة التقرير الذي أصدره المجلس عن الأنشطة التي قام بها خلال عام، 2018 وعام 2019(122) أن هذه النسبة لم تتر اجع. ويرجع ذللك إلى الزيادة النسبية لعدد القضايا المسجلة أمام محاكم جهة القضاء الإداري. إذ بلغ عدد القضايا المسجلة أمام المحاكم الإدارية خلال عام 2019231280 قضية مقارنة بنلك المسجلة عام 2018 حيث سجلت خلالها 213029 قضية. و هو عدد أكبر قليا من تلك المسجلة عام 2017.

(121) Conseil d'Etat; Rapport public 2013; Activité juridictionnelle des juridictions administratives en 2012, Rapport adopté par l'assemblée générale du conseil d' Etat en 2013, p. 85.

(1) Conseil d'Etat ; Rapport public 2019; Activité juridictionnelle des juridictions administratives en 2019, Rapport adopté par l'assemblée générale du conseil d'Etat en 26 mars 2020, la documentation Française, p. 14. 


\section{الوسائل المستحدثة}

للفصل في الدعاوى الإدارية خلال مدة معقولة في النظام

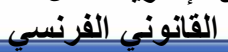

\section{شعبان أحمد رمضنان}

بينما بلغ عدد القضايا المسجلة المسجلة أمام محاكم الاستئناف الإدارية خلال عام 201935684 قضية مقارنة بتلك المسجلة عام 2018 حيث سجلت خلالها 33773 قضية. وهو بدوره يزيد قليا عن تلك المسجلة عام

وبلغ عدد القضايا المسجلة أمام مجلس الدولة خلال عام 10216 قضية مقارنة بتلك المسجلة عام 2018 حيث سجلت خلالها 9563 قضية.

وجملة القول أن اعتناق المشرع الفرنسي لنظام الدوائر الفردية بالدحاكم الإدارية كإحدى وسائل تحقيق العدالة الناجزة قد أسهم إلى حد كبير في تمكين المحاكم الإدارية من الفصل في المنازعات المعروضة عليها خلال مدة زمنية معقو لة على النحو الذي يعالج بصورة عملية مشكلة بُطء إجر اءات التقاضي ، و الحصول على الترضية القضائية لر افع الدعوى خلال مدة معقولة . 


\section{شعبان أحمد رمضنان}

\section{المبحث الثالث}

\section{حظر الطعن بالاستئناف على بعض أحكام المحاكم الإدارية}

يُعد مبدأ التقاضي على درجتين أحد المبادئ الأساسية التي يقوم عليها أبي نظام قضائي لكونه يُتيح للخصم الذي ألي أني

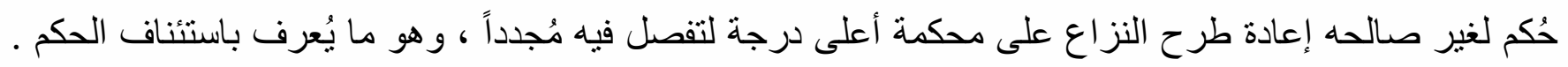

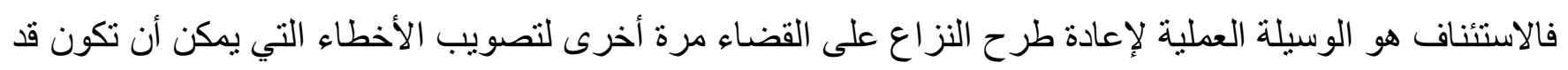
اعترت حكم الدرجة الأولى(123) حيث يُشكل الاستئناف في مجال المنازعات الإدارية ضمانة كبرى لحقوق المتقاضين(124) وأحد معايير حسن سير العدالة الإدارية كمايرى العلامة رينيه شابي R.Chapus (125). وقد أثثر التساؤل حول القيمة القانونية لمبدأ التقاضي على درجنين وهل يُعد مبداً قانونياً ؟ أم مبداً ذو قيمة دستورية ؟ لاسيما وأن تحديد تلك الطبيعة ينعكس على مدى جواز الخروج على هذا المبدأ من قِبَّْ المشرع بحيث يستطيع ذلك حال كونه محض مبدأ قانوني ، بينما يعد مسلكه مشوباً بعدم الدستورية حال اعتباره أحد المبادئ الدستورية

ودون الدخول في جدل فقهي بهذا الصدد فقد استقر قضاء مجلس الدولة الفرنسي بعد إنشاء المحاكم الإدارية الابتدائية عام 1953 على اعتباره - أي مبدأ التقاضي على درجتين - أحد المبادئ القانونية العامة ذات الطابع الإجر ائي(126) و أنه يتعلق بالنظام العام بحيث لا يجوز الخروج عليه إلا بنص تثريعي بمعنى أنه لا يجوز لمرسوم أن يسلب حق الاستئناف نظر اً لأن التقاضي على درجتين يُعد أحد المبادئ العامة في الإجراءات القضائية ، وأن التشريع وحده يملك المساس بهذا الحق (127). كذلك استقر المجلس الدستوري الفرنسي على أن مبدأ التقاضي على درجنين لا

(123) " Les juges sont faillibles, et compte tenu de la gravité des décisions qui peuvent être prononcées, il est ben qu'un second juge, d'un rang plus élevé , puisse éventuellement rectifier les erreurs du premier ".

$=$ PERROT (R.) ; institutions judiciaires, 12 ém. éd., Montchrestien. 2006, p. 77.

(124) Marc (G.); Le contrôle du juge d'appel en contentieux administratif, éd. 2014, p. 233.

(125) CHAPUS (R.); Droit du contentieux administratif, Montchrestien, 11 ém. éd., 2004, p. 1085.

(126) C.E.,ASS. 4 janv. 1957:" La règle du double degré de juridiction est une principe général de procédure " ayant donc valeur législative. constituent, une garantie essentielle aux intérêts des plaideurs et à l'intérêt supérieur de la justice ".

(127) DE GUERGUE (M.); " Le double degré de juridiction " ; A.J.D.A., 2006, citant à l'appui, l'avis du conseil d'Etat du 4 avril 2005, société cabinet JPR ingénierie. 
يُعد ذو قيمة دستورية بحيث يجوز للمشرع الخروج عليه(128) بموجب سلطته التقديرية في تنظيم درجات التقاضي . وللإلمام بالاستثناء المتعلق بحظر الطعن بالاستنئاف على بعض أحكام المحاكم الإدارية فإننا سنقسم هذا المبحث لمطلبين نخصص الأول للأحكام الجائز استئنافها ونكرس الآخر للأحكام غير الجائز استئنافها ومدى إسهام ذلك في تحقيق العدالة الناجزة .

(128) C.C., décision du 12 fev. 2004, loi complétant le statut d'autonomie de la Polynésie francaise , J.o. du 2 mars 2004, p. 4227. 


\title{
الوسائل المستحدثة
}

للفصل في الدعاوى الإدارية خلال مدة معقولة في النظام النقام النقام

القانوني الفرنسي

\section{شعبان أحمد رمضنان}

\author{
المطلب الأول \\ الأحكام الجائز استئنافها
}

تُعد المحاكم الإدارية منذ إنشائها بموجب قانون الإصلاح القضائي الأول رقم 934 - 1953 خلفاً لمجالس

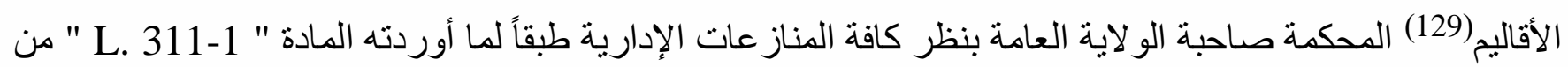

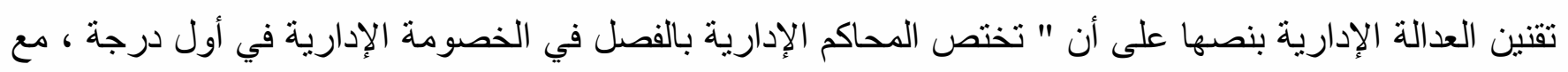
الأخذ في الاعتبار اختصاص مجلس الدولة بنظر النزاع بحكم موضوعه ، أو نو افر شرط مصلحة حسن سير القضاء

فالمحاكم الإدارية طبقاً للنظام الفرنسي تُعد قاضي أول درجة بحيث يؤول إليها الاختصاص بنظر جميع المناز عات الإدارية التي تقع في نطاق اختصاصها المكاني فيما عدا بعض الاستثناءات التي نص القانون على اختصاص لهاص هيئة قضائية أخرى بنظر ها ، أو تلك التي يختص بنظر ها القسم القضائي بمجلس الدولة كقاضي أول و آخر درجة (130). و الأصل و القاعدة أن كافة الأحكام الصادرة عن المحاكم الإدارية في حدود اختصاصها القضائي تخضع للطعن عليها بالاستئناف طبقاً لنص المادة "R. 811-1" من تقنين العدالة الإدارية التي تنص على أنه " يجوز لكل خصم مُتل

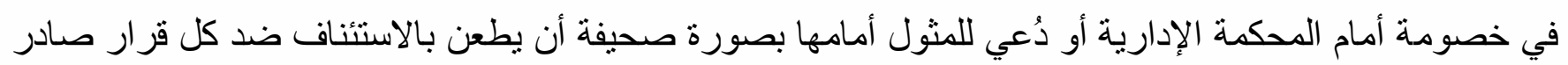

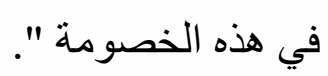

وقد كان الطعن بالاستئناف بادئ الأمر على أحكام المحاكم الإدارية طبقا لمرسوم الإصلاح القضائي الأول في

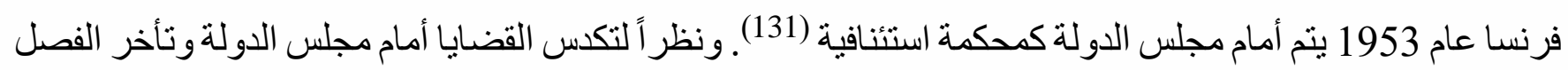
فيها لاختصاصه بنظر بعض المناز عات الإدارية ـ الهامة أو بحسب طبيعتها ـ كمكمة أول وآخر درجة ، فضلاً عن كونه قاضي استئناف لأحكام المحاكم الإدارية فقد تدخل المشرع بموجب قانون الإصلاح الإداري الثاني بتاريخ 31

(129) De L'aubadere (A.); Venezia (CL.) ; Gaudement (Y.); Droit administratif. 17ém. éd., 2002, p.39.

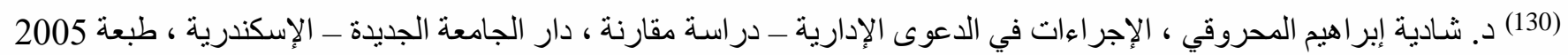

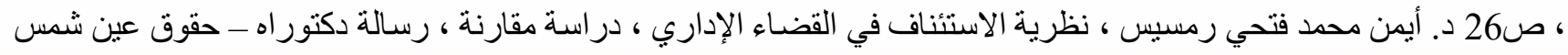

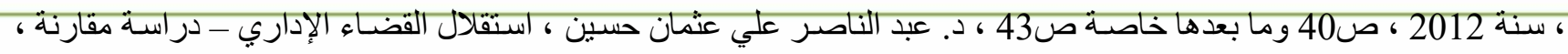

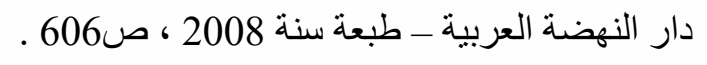

${ }^{(131)}$ Debbach (ch.); Contentious administrative, Dalloze- paris, 1975, pp. $232-234$. 


\section{الوسائل المستحدثة}

للفصل في الاعاوى الإدارية خلال مدة معقولة في النظام

القانوني الفرنسي

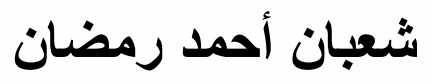

ديسمبر عام 1987 بإنشاء محاكم الاستئناف الإدارية(132) - Les cours administratives d'appel و التي أضحت بمثابة محكمة ثاني درجة بالنسبة لأحكام المحاكم الإدارية حيث بتم الطعن بالاستئناف أمامها في أحكام تلكم المحاكم ـ باستثناء ما يختص به مجلس الدولة بهذا الصدد كالطعون على الأحكام الصادرة في دعاوى إلغاء القرار ات اللائحية ، و الطعون على الأحكام الصادرة في الدعاوى المتعلقة بالانتخابات المحلية و البلدية (133)، ودعاوى تقدير المشروعية ـ و إن كان هذا القانون قد قصر الطعن بالاستئناف أمامها في أحكام المحاكم الإدارية على بعض الدعاوى كتلك المتعلقة بالقضاء الكامل كدعاوى المسؤولية والعقود الإدارية(134) ، و الدعاوى المتعلقة بثر اخيص البناء ، ونزع الملكية للمنفعة العامة، وكذا في المسائل الضريبية (135).

وفي عام 1994 سن المشرع الفرنسي قانوناً يقضي بتوسيع اختصاص محاكم الاستئناف الإدارية بحيث يستغرق نظر الطعون الاستئنافية على أحكام المحاكم الإدارية الصادرة في الدعاوى المتعلقة بالوظيفة العامة ، ثم نظر الطعون الاستئنافية على الأحكام الصادرة من المحاكم الإدارية في كافة دعاوى الإلغاء (136).

\section{المطلب الثاني}

الأحكام غير الجائز الطعن عليها بالاستنئاف

يرى نظر من فقه القانون العام الفرنسي أن المحاكم الإدارية منذ إنشأها المشرع الفرنسي -وررغم كونهاصاحبة الو لاية العامة بنظر المنازعات الإدارية كقاضي أول درجة إلا ما استثنى بنص خاص - فإن معدل فصلها في القضايا التي تنظر ها يتم على نحو سريع حيث بلغ معدل مدد الفصل في تلك الدعاوى ما بين سنة أثهر إلى سنة ، و أنها تُصدر سنويا حو الي 166000 حكم (137). ونظر اً لما تقوم به المحاكم الإدارية من دور بالغ الأهمية في تحقيق العدالة الناجزة فقد بادر المشرع الفرنسي

(132) Drago (R.); Les cours administratives d'Apple, R.F.D.A., no.. 2, 1988, pp. 196 et suv.

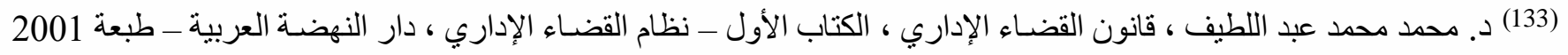

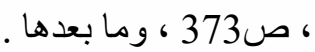

(134) Pinault (M.); perspectives ou vertes par la loi de 1987, E.D.C.E., 1988, no 40.

${ }^{(135)}$ Gerbay (P.); Les effets d'Apple en voie d'annulation, D. 1993, chr.p. 143 .

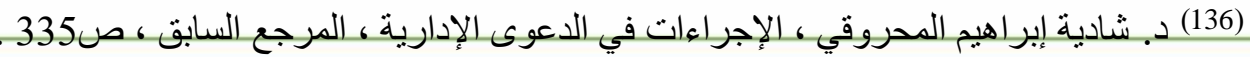

(137) Peiser (B.); Contentieux administrative, 12 ém. éd., Dalloz. 2000, P.24. 


\section{الوسائل المستحدثة}

للفصل في الاعاوى الإدارية خلال مدة معقولة في النظام

القانوني الفرنسي

\section{شُعبان أحمد رمضان}

بإدخال تعديل على تقنين العدالة الإدارية عام 2003 مفاده حظر الطعن بالاستئناف على بعض أحكام المحاكم الإدارية بمعنى أن تحكم في بعض المناز عات التي تختص بنظر ها كمحكمة أول و آخر درجة وذلك للحد من سيل الطعون أمام محاكم الاستنئاف الإدارية على النحو الذي يجعل تللك الأخيرة - محاكم الاستئناف الإدارية ـ متفرغة للفصل في المناز عات الاستئنافية التي ثُثير مشاكل قانونية أكثر تعقيدًا من تلك التي يُحظر الطعن فيها أمامها ، وذللك في مدة معقولة بما يتفق ونص الفقرة الأولى من المادة السادسة من الاتفاقية الأوربية لحقوق الإنسان (138).

ونظر اً للنجاح الذي حققه تعديل عام 2003 فقد اتجه المشرع الفرنسي صوب توسيع مجال اختصاص المحاكم الإدارية كمحاكم أول و آخر درجة بحيث يستغرق مناز عات جديدة لم تكن تلتزم بنظر ها بتلك الصفة من ذي قبل وذللك في أغسطس عام 2013 بموجب المادة "1-811 " من كود العدالة الإدارية و المعدلة بالمرسوم رقم 233 - 215 في 27 فبر اير 2015(139) و التي تم تعديلها مؤخر اً بالمرسوم رقم "82-2019" في 7 فبر اير 2019 و التي نصت على أنه :

" يجوز للخصم أن يطعن بالاستئناف في الأحكام الصادرة عن المحكمة الإدارية ، و إن لم يقدم مذكرة بدفاعه

أمام المحكمة.

ومع ذلك ، تكون أحكام المحاكم الإدارية نهائية متى كانت صسادرة في الخصومات الآتية : 1- الدعاوى الخاصة بالمنافع أو الإعانات أو المساعدات الاجتماعية ، أو المتعلقة بالإيواء أو بالعاطلين عن العمل ، و المُشار إليها في المادة (R-772-5) ، بما في ذللك كل ما يتعلق بالحق في الإيو اء أو السكن المنصوص عليها

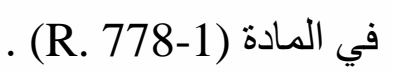

2- الدعاوى المتعلقة بالإطلاع أو تبليغ الوثائق الإدارية ، أو بالمحفوظات العامة . 3- الدعاوى الخاصة برفض الاستعانة بالسلطة العامة لتنفيذ حكم قضائي. 4- دعاوى الضر ائب المحلية ، وضريبة المساهمة في البث السمعي والبصري العام ، ويستنى من ذلك الدعاوى الخاصة بالمساهمات الاقتصادية الإقليمية. 5- الدعاوى المتعلقة للطعن في القرارات الصادرة في المسائل الضريبية والتي يطلب فيها التجاوز (تأجيل) عن دين الضريبة . 6- - دعاوى رخص السياقة.

(138) د. مجدي عبد الحمبد شعيب ، آليات تمكين القضاء الإداري من الفصل في المنازعات في مدة معقولة ، المرجع السابق ، ص41 ـ . . . . . . (139) Article "R. 811-1" Modifier par Décret no 2015-233 du 27 Fev. 2015. 


\section{الوسائل المستحدثة}

للفصل في الاعاوى الإدارية خلال مدة معقولة في النظام

القانوني الفرنسي

\section{شُبان أحمد رمضنان}

7- الدعاوي الخاصة بالمعاشات التقاعدية للموظفين العمومبين .

8- طلبات التعويض المتعلقة بالعقود - فيما عدا عقود المشتريات العامة ـ التي لا تتجاوز النصاب المحدد في المادتين

(R.222-15), (R.222-14)

9- الدعاوى المتعلقة بالتصرفات المشار إليها في البند (5) من المادة (R.311.2) ، وذللك متى كان الحكم فيها قد

$$
\text { صدر قبل الأول من يناير } 2019 .
$$

كما تكون أحكام المحاكم الإدارية انتهائية متى كانت صادرة في خصومة متعلقة بالاعاوى المُشنار إليها في الفقرة السابقة ، و الصادرة بموجب مر اسيم تطبيقاً لأحكام البابين الر ابع و الخامس .

كما أن الأحكام الصادرة طبقاً لحكم البند (6) من المادة (1-222) تكون غير قابلة للطعن عليها مهما كانت طبيعة النزاع . - مبع.

و استثناءً مما تقدم ، في حالة ارتباط النزاع بآخر مما يجوز الطعن عليه بالاستنئاف، فإن القرارات المتعلقة

بالإجر اعات المنصوص عليها في البند (8) تكون قابلة للاستئناف ، وكذلك القرار ات الصادرة في الطعون الضريبية على العقار ات عندما تفصل كذلك في المطالبات المتعلقة بالمستحقات العقارية للثركات بناء على طلب من الممول وذللك عندما تستند الضريبتين أو جزء منها على قيمة العقار ات الخاضعة للضريبة و المقدرة في العام نفسه.

وتُصدر المحكمة الإدارية أحكامها باعتبار ها محكمة أول وآخر درجة في الطعون المحالة إلبها من سلطة

قضائية أو من جهات ذات اختصاص قضائي (.....) بالتطبيق لنص المادة 49 من قانون الإجر اءات المدنية (140).

(140) "Toute partie présente dans une instance devant le tribunal administratif ou qui y a été régulièrement appelée, alors même qu'elle n'aurait produit aucune défense, peut interjeter appel contre toute décision juridictionnelle rendue dans cette instance.

Toutefois, le tribunal administratif statue en premier et dernier ressort :

$1^{\circ}$ Sur les litiges relatifs aux prestations, allocations ou droits attribués au titre de l'aide ou de l'action sociale, du logement ou en faveur des travailleurs privés d'emploi, mentionnés à l'article R. 772-5, y compris le contentieux du droit au logement défini à l'article R. 778-1 ;

$2^{\circ}$ Sur les litiges en matière de consultation et de communication de documents administratifs ou d'archives publiques ;

$3^{\circ}$ Sur les litiges relatifs aux refus de coneours de la foree publique pour exéeuter une déeision de justice ;

$4^{\circ}$ Sur les litiges relatifs aux impôts locaux et à la contribution à l'audiovisuel public, à l'exception des litiges relatifs à la contribution économique territoriale ;

$5^{\circ}$ Sur les requêtes contestant les décisions prises en matière fiscale sur des demandes de remise gracieuse 


\section{الوسائل المستحدثة}

للفصل في الدعاوى الإدارية خلال مدة معقولة في النظام

القانوني الفرنسي

\section{شعبان أحمد رمضنان}

وقد أفضى هذا التعديل إلى تقليص المدة الزمنية اللازمة للفصل في الطعون الاستئنافية أمام محاكم الاستئناف

الإدارية ـ ولعل الإحصائيات المتعلقة بسرعة الفصل في تللك الطعون أمام محاكم الاستئناف الإدارية كنتيجة لحظر الطعن على بعض أحكام المحاكم الإدارية والتي تتظر ها كمكمة أول وآخر درجة على إثر التعديل سالف الذكر يوضح بجلاء جدوى هذا التعديل حيث أضحت محاكم الاستئناف الإدارية تفصل في المنازعات الأخرى الجائز استئنافها أمامها في وقت أقصر مما كانت عليه من ذي قبل بحيث انخفضت مدة الفصل في الطعن بنسبة 25\% بعد عام 2015 عما كانت عليه في الفترة ما بين عامي 2000 إلى 2015 على النحو الذي أسهم في القضاء على بطء إجراءات التقاضي أمام تللك المحاكم بما يصب في اتجاه تحقيق العدالة الناجزة ...." الإحصاءات الجديدة ..... ". . وهو الأمر الذي يتضح بجلاء من خلال مطالعة تقارير مجلس الدولة عن عام 2019 و عام 2018. فيما يخص مدة الفصل في النزاع أمام المحاكم الإدارية في عام 2019 تسعة أشهر و عشرة أيام وهي تقل تسبيا مقارنة بعام 2018 حيث كانت تسعة أشهر وخمسة عشر يوما(141). وكانت هذه المدة أمام محاكم الاستنناف الإدارية في عام 2019 عشرة أشهر وخمسة و عشرون يوما بينما كانت في عام 2018 عشرة أشهر وثناثة و عشرون يوما(142). وفيما يخص مدة الفصل في الدعاوى أمام

$6^{\circ}$ Sur les litiges relatifs au permis de conduire ;

$7^{\circ}$ Sur les litiges en matière de pensions de retraite des agents publics ;

$8^{\circ}$ Sauf en matière de contrat de la commande publique sur toute action indemnitaire ne relevant pas des dispositions précédentes, lorsque le montant des indemnités demandées n'excède pas le montant déterminé par les articles R. 222-14 et R. 222-15 ;

$9^{\circ}$ Lorsque la juridiction en a été saisie avant le 1er janvier 2019, les litiges afférents aux actes énumérés par le $5^{\circ}$ de l'article R. 311-2.

Les ordonnances prises sur le fondement du titre IV du livre V sont également rendues en premier et dernier ressort lorsque l'obligation dont se prévaut le requérant pour obtenir le bénéfice d'une provision porte sur un litige énuméré aux alinéas précédents. Les ordonnances prises sur le fondement du $6^{\circ}$ de l'article R. 222-1 sont rendues en premier et dernier ressort quel que soit l'objet du litige. Par dérogation aux dispositions qui précèdent, en cas de connexité avec un litige susceptible d'appel, les décisions portant sur les actions mentionnées au $8^{\circ}$ peuvent elles-mêmes $=$ =faire l'objet d'un appel. Il en va de même pour les décisions statuant sur les recours en matière de taxe foncière lorsqu'elles statuent également sur des conclusions relatives à cotisation foncière des entreprises, à la demande du même contribuable, et que les deux impositions reposent, en tout ou partie, sur la valeur des mêmes biens appréciée la même année. Le tribunal administratif statue également en premier et dernier ressort sur les recours sur renvoi de l'autorité judiciaire et sur les saisines de l'autorité judiciaire en application de l'article 49 du code de procédure civile". Article " R. 811-1" Modifie par Décret no 2019-82 du 7 févier 2019-art. 47.

(1) -Conseil d'Etat ; Rapport public 2019; Activité juridictionnelle des juridictions administratives en 2019, Rapport adopté par l'assemblée générale du conseil d'Etat en 26 mars 2020, la documentation Française, p. 41.

( ${ }^{1}$ 'Conseil d'Etat ; Rapport public 2019 ; Activité juridictionnelle des juridictions administratives en 


\section{الوسائل المستحدثة}

للفصل في الاعاوى الإدارية خلال مدة معقولة في النظام

القانوني الفرنسي

\section{شُبان أحمد رمضنان}

مجلس الدولة فإن هذه المدة لم تتجاوز في عام 2019 ستة أشهر وخمسة أيام، وهي تقل نوعا ما عن المدة التي كانت تستغرقها الدعوى عام 2018 حيث كانت ستة أشهر وسبع عشرة يوما(143).

و إذا بدأ على هذا النحو تحقيق هذا التعديل لفكرة العدالة الناجزة ، فإن تساؤلاً ذو شقين بمكن إثارته وهو هل أثر هذا التعديل سلباً على تحقيق العدالة الجيدة ؟ وهل يتعارض مع مبدأ التقاضي على درجتين كأحد مفردات الحق في التقاضي؟

وفي معرض الإجابة على التساؤل المُثار يرى نظر فقهي جدير بالتأييد أن التوسع في حالات حظر الطعن بالاستنناف على بعض أحكام المحاكم الإدارية على النحو الذي يجعلها تفصل في تللك المنازعات كمحمة أول و آخر درجة لا يتعارض وتحقيق العدالة الجيدة ، كما لا يؤثر سلباً على تحقيقها ـ ذلك أن تلكم المنازعات تتسم في مجملها بالبساطة وعدم الأهمية لكونها لا ثُثير مشكلات قانونية صعبة ، فضلاً عن أنها منازعات محددة على سبيل الحصر " R. 811-1 هذا من ناحية ، ومن ناحية أخرى فإن حظر الطعن بالاستئناف على الأحكام التي تضمنتها المادة " من تقنين الإجراءات الإدارية الفرنسي و المعدلة بالمرسوم رقم " 82 - 2019 " بتاريخ 7 فبراير 2019 لا يُعد خروجاً على مبدأ التقاضي على درجتين - كأحد أهم مبادئ تحقيق العدالة الإدارية - بشكل مطلق ـ وآية ذلك أن الطعن بالاستئناف على الأحكام الصـادرة من المحاكم الإدارية بصدد تلك المنازعات يظل جائزاً عندما تكون مرتبطة بمناز عة أخرى مما يجوز الطعن على الحكم الصادر فيها بحيث يمكن الطعن عليها بالاستنناف بمناسبة الطعن تلكم الأخيرة المرتبطة بها .

و أخير اً فإن الأحكام التي تُصدر ها المحاكم الإدارية كمكمة أول وآخر درجة يمكن الطعن عليها بالنقض أمام مجلس الدولة على النحو الذي يشي بعدم خروج التعديل المانل على مبدأ التقاضي على درجنين كأحد أهم المبادئ التي تُشيد عليها العدالة الإدارية أمام القضاء الإداري الفرنسي لاسيما وأن قضاء المجلس الدستوري الفرنسي قد استقر على أن هذا المبدأ - التقاضي على درجتين - لا بُعد ذو قيمة دستورية بحيث يستطيع المشرع العادي الخروج عليه للاعتبار ات التي يُقدر ها بما يملكه من سلطة تقديرية بهذا الصدد (145).

2019, Rapport adopté par l'assemblée générale du conseil d'Etat en 26 mars 2020, la documentation Française, p. 46.

(2) -Conseil d'Etat ; Rapport public 2019 ; Activité juridictionnelle des juridictions administratives en 2019, Rapport adopté par l'assemblée générale du conseil d'Etat en 26 mars 2020, la documentation Française, p. 50.

(144) د. مجدي عبد الحميد شعيب ، آليات تمكين القضاء الإداري من الفصل في المنازعات في مدة معقولة ، المرجع السابق ، ص43

(145) Conseil constitutionnel, Décision du 12 février 2004, loi complétant le statut d'autonomie de la 


\section{شبعبان أحمد رمضان}

$$
\begin{aligned}
& \text { المبحث الرابع } \\
& \text { الأخذ ببعض مظاهر التقاضي الإلكتروني }
\end{aligned}
$$

يُعد من أبرز منجزات عصرنا الر اهن ما يُعرف بثورة المعلومات وتكنولوجيا الاتصالات التي ألقت بظلالها

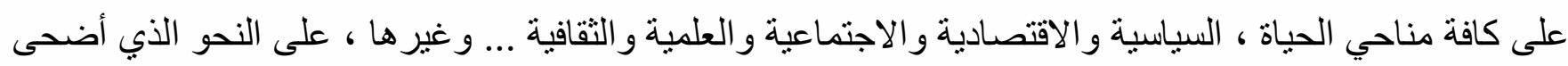
معه العالم بمثابة قرية صغيرة عبر تبادل المعلومات من خلال شبكة المعلومات الدولية المعروفة بالإنترنت internet

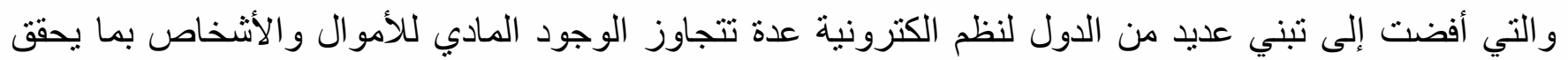
معاملات أيسر وأسر ع عبر تطبيقات عدة مثل الحكومة الإلكترونية Electronique gouvernement ، و التجارة الإلكترونية Electronique commerce ، والتعليم الإلكتروني Electronique enseignement .... و غبرها

و التساؤل الذي يطرح نفسه بهذا الصدد هو هل يُمكن لمرفق العدالة تبني نظام التقاضي الإلكتروني لمعالجة مشكلة بطء إجر اءات التقاضي بما يحقق فكرة العدالة الناجزة ؟ وهي يؤثر التقاضي الالكتروني نسبياً على فكرة العدالة

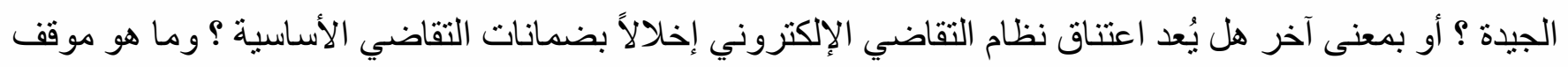
المشر ع الفرنسي من تبني نظام التقاضي الإكتروني أمام جهة القضاء الإداري كأحد وسائل تحقيق العدالة الناجزة ؟ وللإجابة على التساؤلات المطروحة سنقسم هذا المبحث إلى مطلبين نتناول في أولهما مفهوم التقاضي الإلكتروني ووسائله ـ ونتصدى في الآخر لتبيان موقف المشر ع الفرنسي من تبني نظام التقاضي الإلكتروني أمام جهة القضاء الإداري كأحد وسائل تحقيق العدالة الناجزة ومدى تأثيره على تحقيق العدالة الجيدة .

\section{المطلب الأول}

مدلول التقاضي الإلكتروني ووسائله

يُعد مصطلح التقاضي الإكتروني أحد المصطلحات المستحدثة على صعيد الدراسات القانونية بالنظر لحداثة

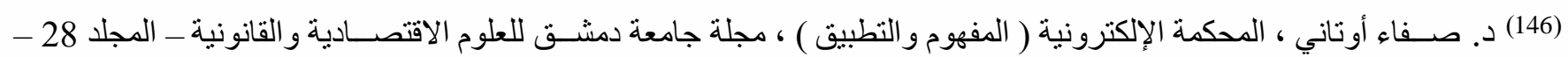

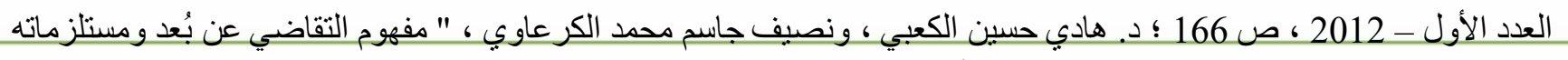

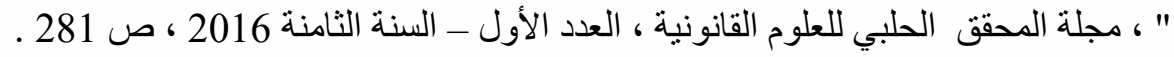




\section{الوسائل المستحدثة}

للفصل في الدعاوى الإدارية خلال مدة معقولة في النظام القانوني القرنسي خدارل

\section{شعبان أحمد رمضنان}

تبني بعض النظم القانونية لتلكم الفكرة . كما يُعد أحد إبداعات الفكر القانوني في مجال تطبيق تقنية المعلومات في مجال التقاضي عبر تيسير إجراءات التقاضي باتباع إجر اءات سريعة ومتطورة منذ بدء رفع الدعوى حتى صدور حكم في موضو عها بُخية تحقيق عدالة ناجزة جيدة توفير اً للوقت و الجهد و النفقات.

و نظر اً لعدم تعرض المشرع ، في بعض النظم القانونية التي تبنت بعضاً من جوانب التقاضي الإلكتروني ، لوضع تعريف للتقاضي الإلكتروني تاركاً تلك المههة للفقه والقضاء فقد تصدى بعضاً من الفقهاء لوضع تعريف لهذا المصطلح ، فضلاً عن تبيان أهم وسائله . وهو ما نوجزه في فرعين على النحو الآتي : 


\section{الوسائل المستحدثة}

للفصل في الدعاوى الإدارية خلال مدة معقولة في النظام

القانوني الفرنسي خداري

\section{شعبان أحمد رمضنان}

الفرع الأول

مفهوم التقاضي الإلكتروني وخصائصه

أولاً - تعريف التقاضي الإلكتروني :

ولى نظر فقهي وجهه صوب تعريف التقاضي الإلكتروني بأنه " الحصول على صور الحماية القضائية عبر استخدام الوسائل الإكترونية المساعدة للعنصر البشري، من خلال إجراءات تقنية تضمن تحقيق مبادئ وضمانات التقاضي في ظل حماية تشريعية لتلك الإجراءات تتفق مع القو اعد و المبادئ العامة في قانون المر افعات مع مر اعاة الطبيعة الخاصة للوسائل الإلكترونية " (147). في حين اتجه نظر آخر شطر القول بأن التقاضي الإلكتروني هو عبارة عن " سلطة لمجموعة متخصصة من القضاة النظاميين بنظر الدعوى ومباشرة الإجر اءات القضائية برسائل الكترونية مستحدثة ، ضمن نظام أو أنظمة قضائية معلو ماتية متكاملة الأطر اف و الوسائل ، تعتمد منهج تقنية شبكة الربط الدولية الدئل

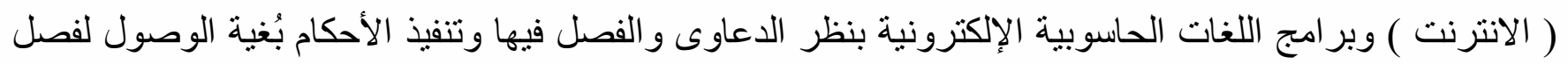
سريع في الدعاوى و التسهيل على المتقاضين " (148). و اتجه نظر ثالث إلى تعريف التقاضي الإلكتروني بأنه " سلطة المحكمة المختصة للفصل الكترونياً في النزاع المعروض أمامها من خلال شبكة الربط الدولية (الانترنت) وبالاعتماد على أنظمة الكترونية و آليات تقنية فائقة الحداثة بهدف سرعة الفصل في الخصومات و التسهيل على المتخاصمين " (149).

و أخير اً يرى نظر فقهي رابع أن التقاضي الإلكتروني لا يعدو كونه " نظام قضائي معلوماتي جديد يتم بموجبه تطبيق كافة إجراءات التقاضي عن طريق المحكمة الإلكترونية بواسطة أجهزة الحاسوب المرتبطة بشبكة الانترنت و عبر البريد الإلكتروني ، لغرض سر عة الفصل في الدعاوى وتسهيل إجر اءاتها على المتقاضين وتنفيذ الأحكام الكترونياً

و الحقيقة أن التعاريف السابقة على اختلاف ألفاظها وتعابير ها تتمحور حول معني و احد يتمثل في استخدام تقنية

(147) د. يوسف سيد سيد عو اض ، خصوصية القضاء عبر الوسائل الإلكترونية ، رسالة دكتوراة - كلية الحقوق - جامعة عين شمس ،

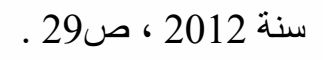

(148) القاضي / محمد عصـام الترسـاوي ، تداول الدعوى القضـائية أمام المحاكم الإلكترونية ، دار النهضـة العربية ـ طبعة سنة 2013 ، .66 ص (149) د. أسـعد فاضـل منديل ، التقاضــي عن بُعد ، مجلة الكوفة للعلوم القانونية والسـياسـية ، المجلد الأول ـ العدد 21 ، ســنة 2014 ،

(150) د. هادي حسين الكعبي ، ونصيف جاسم محمد الكرعاوي ، مفهوم التقاضي عن بُعد ومستلزماته ، المرجع السابق ، ص283 . 
للفصل في الدعاوى الإدارية خلال مدة معقولة في النظام

القانوني الفرنسي

\section{شعبان أحمد رمضنان}

المعلومات ووسائلها الحديثة في إيداع صحف الدعاوى و الطعون وممارسة كافة إجر اءات التقاضي من قِبِّلْ الخصوم

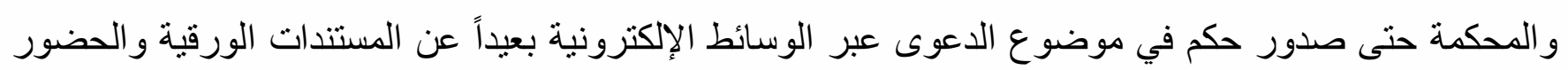

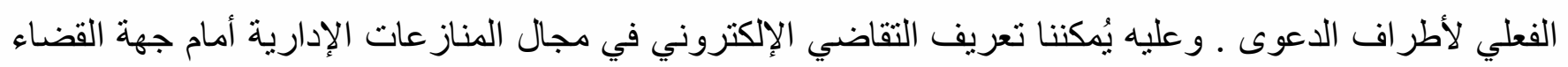

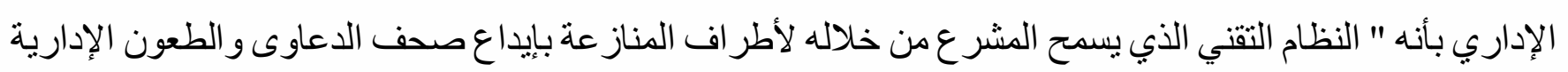

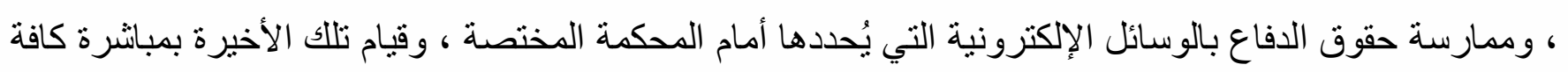
إجر اءات التقاضي وتحقيق الدعوى و الفصل فيها بالوسائل نفسها بُغية تيسير إجر اءات التقاضي تحقيقا للعدالة الناجزة

\section{ثانياً - خصائص التقاضي الإلكتروني :}

يتسم التقاضي الإلكتروني بجملة خصائص يُمكن بلورة أهمها في النقاط الآتية:

\section{التحول من النظام الورقي إلى النظام الالكتروني :}

يُعد من أهم سمات التقاضي الإلكتروني الاستغناء عن المستندات و الوثائق الورقية في كافة مر احل الدعاوي

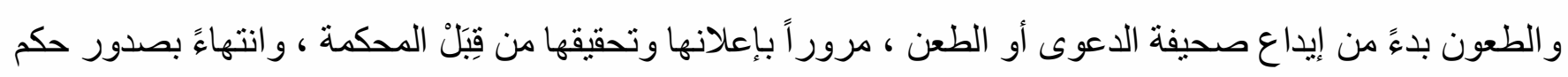

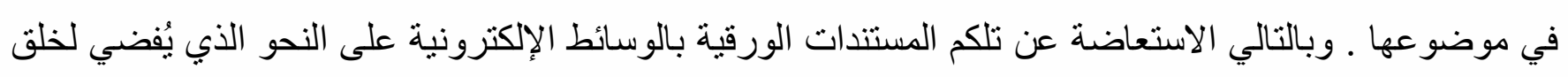
مجتمع المعاملات اللاورقية(151) في مجال التقاضي وتحويل كافة مستندات الدعاوى و الطعون لمستندات الكترونية يسهل حفظها وتخزينها و الاطلاع عليها بيسر وسهولة من جانب المتقاضين ، و المحكمة ، وكذا الباحثين و المشتغلين بالحقل القانوني.

\section{استخدام الوسائط الالكترونية في مباشرة إجراءات التقاضي:}

يرتكز التقاضي الإلكتروني على استخدام الوسائط الإلكترونية في مباثرة إجر اءات التقاضي من خلال جهاز

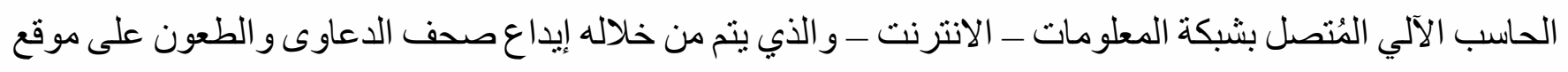

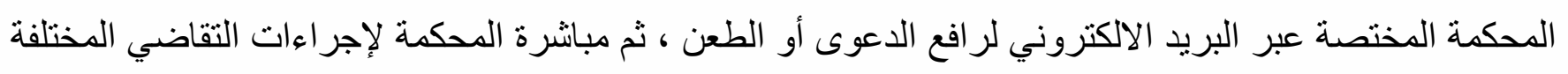

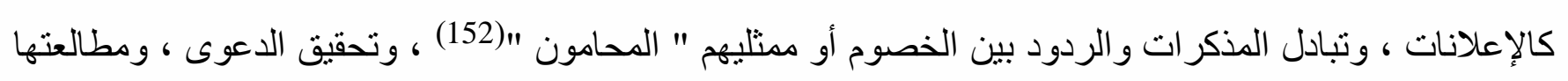

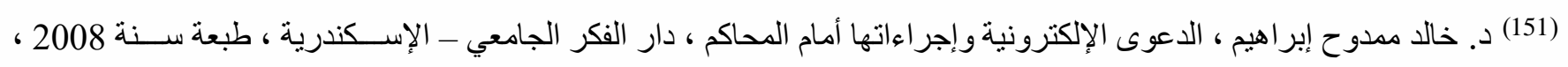

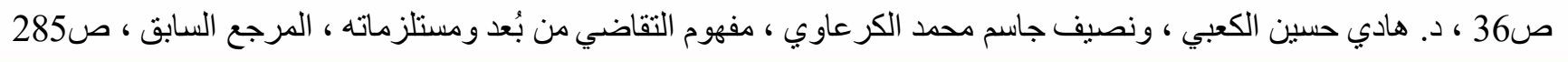

(152) د. سيد أحمد محمود ، دور الحاسب الإلكتروني أمام القضاء ، دار النهضة العربية ، طبعة سنة 2008 ، ص30 . 


\section{الوسائل المستحدثة}

للفصل في الدعاوى الإدارية خلال مدة معقولة في النظام القانوني الفرنسي ملادة مداري

\section{شعبان أحمد رمضنان}

لتقارير الخبر اء وكافة مستندات الدعوى أو الطعن بشكل الكتروني حتى تتمكن من الفصل في موضوعها على نحو

سريع .

\section{سرعة البت " الفصل " في الدعوى:}

يفترف التقاضي الإلكتروني عن نظيره التقليدي ـ الورقي ـ فيما يُتيحه من سر عة في مباشرة إجر اءات التقاضي

، و اختصار الوقت والجهد و النفقات على النحو الذي يُفضي لسرعة الفصل في الدعوى حيث تتم عملية قيد الدعوى ، و إعلانها للخصوم ، و إرسال و استلام كافة مستنداتها وردود الخصوم عليها من خلال موقع المحكمة المختصة بنظر ها و ما يوفره من وسائل الكترونية تُتيح للخصوم ومحامو هم الدخول عليها من بريدهم الالكتروني ، وكذللك هيئة المحكمة و الإدار ات المعاونة لها ، دون أن يتطلب ذلك حضور الخصوم لمقر المحكمة بأنفسهم لجلسات عديدة كما يحدث في التقاضي التقليدي ، وهو ما يوفر وقت وجه المحكمة والخصوم على سواء مما يُتيح للمحكمة سرعة الفصل في الدعاوى(153) و الطعون ، فضلاً عن تحسين مستوى أداء مرفق العدالة ورفع جودة الخدمة المقدمة للمتقاضين تحقيقاً لفكرة العدالة الناجزة الجيدة، علاوة على ربط معلومات الدعاوى بين المحاكم المختلفة(154) على النحو الذي يُيسر الإطلاع عليها سو اء في مرحلة الطعن على الأحكام ، أو كسابقة قضائية بالنسبة للمحاكم الدُناظرة لتلك التي فصلت في

$$
\begin{aligned}
& \text { الفر ع الثاني } \\
& \text { وسائل التقاضي الإلكتروني }
\end{aligned}
$$

يتوقف نجاح التقاضي الإلكتروني على وسيلتين رئيسيتين تُعدان بمثنابة لُحمة هذا النظام وسُداه هما الوسيلة القانونية المتمثلة في أساسه التشريعي ، و الوسيلة التقنية المتمثلة في المحكمة الإلكترونية ـ وهو ما نوجزه في نقطتين .

$$
\text { أولاً - الأساس القانوني للتقاضي الإلكتروني: }
$$

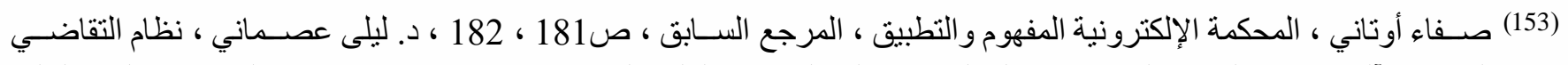

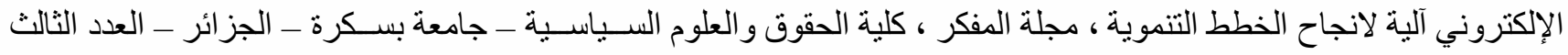

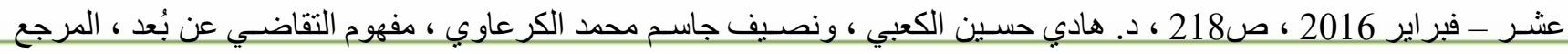

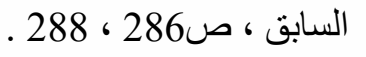
(154) د. خالد ممدوح إبر اهبيم ، الدعوى الإلكترونبة وإجراءواتها ، المرجع السابق ، ص40 


\section{الوسائل المستحدثة}

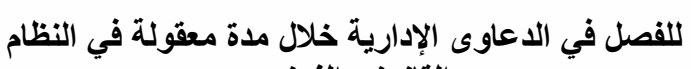

القانوني الفرنسي

\section{شعبان أحمد رمضان}

يتطلب التقاضي الإلكتروني بنية تشريعية تُلائم طبيعته ، تختلف عن التشريعات المنظمة لمرفق القضاء التقليدي ، على النحو الذي يخوّل القضاة المختصون بالعمل في المحاكم الإلكترونية سلطة الفصل في الدعاوى عبر استخدام وسائل التقنية الحديثة في مباشرة إجر اءات التقاضي المختلفة بدءً بإيداع صحف الدعاوى و الطعون على الموقع إع الإلكتروني للمحكمة المختصة عن طريق البريد الإلكتروني - وكذا إعلانها للخصوم - مروراً بتحقيقها وتبادل الردود على مستنداتها ، و انتهاءً بالفصل في موضوعها ـ الأمر الذي يقتضي سن المشرع لقو اعد قانونية تواكب التطور التكنولوجي في مجال الاتصالات لتطويعها في مجال التقاضي الإلكتروني (155) نظر اً لاحتياج هذا الأخير لبنية تشريعية يستمد منها القضاة المختصون سلطتهم في نظر الدعاوى الكترونياً بحيث تُمثل السند القانوني للفصل في الدعاوى باستخدام وسائل التقنية الحديثة تيسير آ لإجر اءات التقاضي ، ووصو لاً للحصول على ترضية قضائية ناجزة وجيدة لر افع الدعوى أو الطعن .

\section{ثانياً - الوسيلة التقتية (المحكمة الإلكثرونية) :}

تُعد المحكمة الإلكترونية إحدى دعامتي التقاضي الإلكتروني. ويُعرفها نظر فقهي بأنها حيذ تقني معلوماتي ثنائي الوجود بسمح ببرمجة الدعوى الكترونياً ، ويتألف من شبكة الربط الدولية internet ومبنى المحكمة على النحو الذي يُتيح الظهور المكاني الإلكتروني لوحدات قضائية وإدارية ، ويباشر من خلاله مجموعة من القضاة مهمة النظر في الدعاوى و الفصل فيها بموجب تثريعات تخو لهم مباثرة الإجر اءات القضائية ، مع اعتماد آلية تقنية فائقة الحداثة لتدوين الإجر اءات القضائية وحفظ وتداول ملفات الدعوى (156).

كما عرفها نظر آخر بأنها المحكمة التي تقوم بجميع الأعمال الموكلة إلبها قانوناً باستخدام الحاسب الإلكتروني الذي يحتوي على البر امج الخاصة بتطبيق إجراءات التقاضي و الموصولة بشبكة الاتصالات الدولية ( الانترنت ) ،

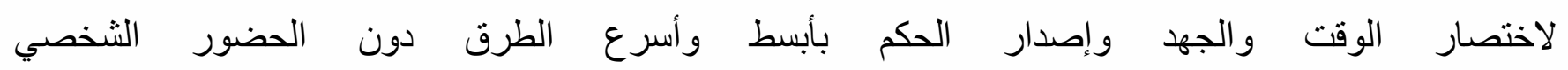
للمحكمة (157).

و الحقيقة أن ما يعنينا في هذا المقام ليس وضع تعريف محدد لمصطلح المحكمة الإلكترونية بقدر ضبط آلية

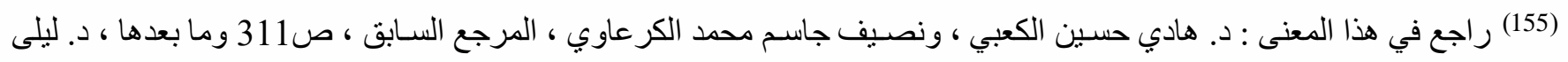

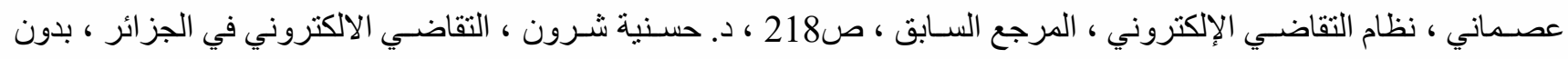

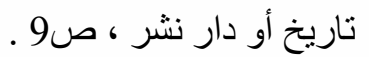

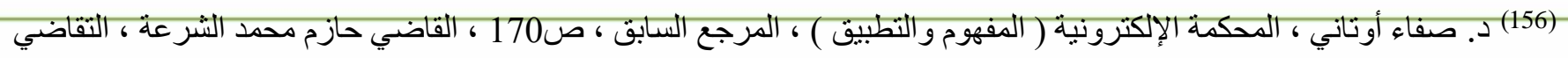

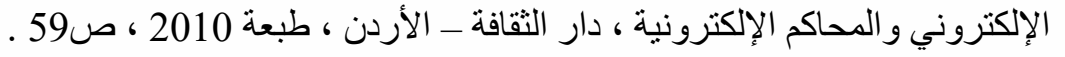

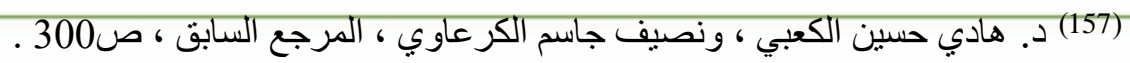




\section{الوسائل المستحدثة}

للفصل في الدعاوى الإدارية خلال مدة معقولة في النظام القانوني الفرنسي خدارة مداني

\section{شعبان أحمد رمضنان}

العمل عن طريق ذاك النوع من المحاكم والذي يرتكز ابتداءً على وجود تشريع يخوّل مجمو عة من القضاة الاختصاص بالنظر في الدعاوى و الطعون و الفصل فيها بطريقة الكترونية من خلال تحديد موقع الكتروني للائرة المختصة بنظر الدعوى عبر ربطها بشبكة المعلومات الدولية ـ الانترنت - على النحو الذي يسمح لتلك الدائرة ومثيلاتها - وكذا الجهاز الإداري الالكتروني المعاون لها - بتسجيل صحف الدعاوى و الطعون المختصة بنظر ها ، و إعلانها ، وتبادل الردود

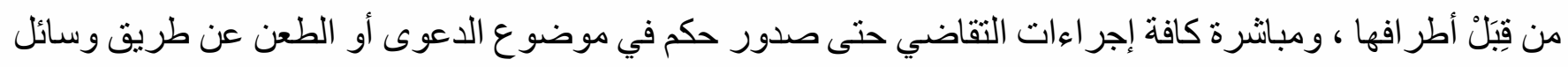

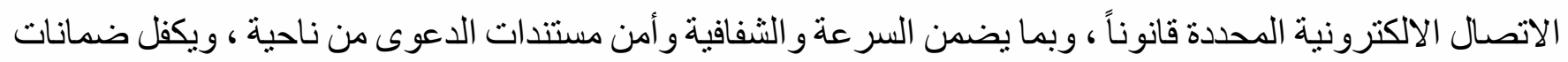
التقاضي من ناحية أخرى، دون تطلب الحضور الفعلي لجلسات المحاكمة في مجال الدعاوى و الطعون الإدارية . 


\section{الوسائل المستحدثة}

للفصل في الاعاوى الإدارية خلال مدة معقولة في النظام

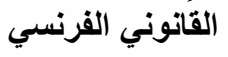

\section{شعبان أحمد رمضنان}

المطلب الثاني

اعتناق النظام القانوني الفرنسي لبعض وسائل التقاضي

الإلكتروني أمام جهة القضاء الإداري

حرص المشرع الفرنسي على تدعيم جهة القضاء الإداري ببنية معلوماتية ووسائل تقنية متطورة تمكنه من

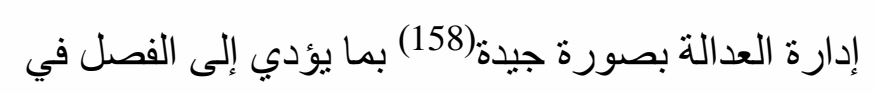

الدعاوى الإدارية خلال مدة معقولة عبر عدة تطبيقات الكترونية تتعلق بايداع صحف الدعاوى والطعون ، وحفظ وترتيب ملفاتها والمعلومات المتعلقة بها ، وتيسير الإطلاع عليها على النحو الذي يُمكن القضاة وقلم الكتاب من القيام

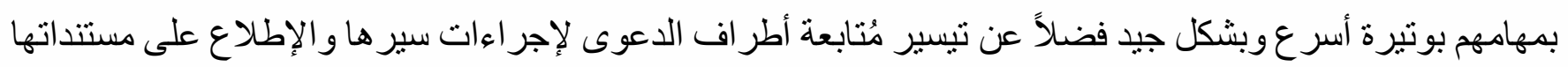
وتبادل الردود عليها (159).

ويُعد من أهم تلك التطبيقات التقنية التي يتمكن من خلالها أطر اف الدعاوى و الطعون ، وقلم الكتاب ، و القضاة

من ممارسة إجر اءات التقاضي على نحو أسر عو أفضل تطبيق Skipper ، وتطبيق Tele-Recours وتطبيق -Poste (160) Arian Rapporteur

وطبقاً لتطبيق Skipper يستطيع قلم كتاب المحكمة المختصة تسجيل كافة بيانات الدعوى أو الطعن الكترونياً سو اء تلك المتعلقة بأطر اف الدعوى أو الطعن ، وطبيعتها ، ومحامي الخصم ، و المستندات و المذكرات التي يتم إيداعها

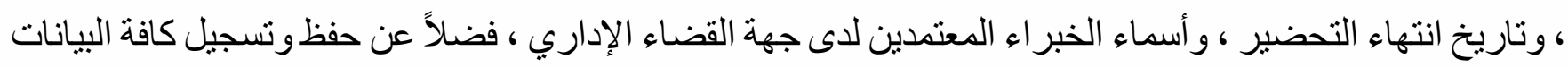
المتعلقة بالحكم بعد صدوره .

و لا ريب أن هذا التطبيق يُيسر على نحو سريع وجيد عمل مساعدي العدالة ويُمكنهم من إنجاز أعمال متعددة في وقت وجيز بما يؤدي إلى تبسيط إجر اءات التقاضي تحقيقاً للعدالة الناجزة المجيدة.

(158) Caroline Boyer-Capelle, Gestion des dossiers et qualité de la justice, La Revue française d'administration publique ${ }^{\circ} 159,2016$, pages 727 à 738 .

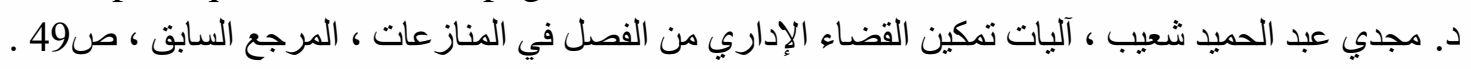

(160) Forey, Elsa, «La dématérialisation de la justice et l'accès au juge », p. 456 in Donier Virginie, Lapérou-Scheneider Béatrice, L'accès au juge, Recherche sur l'effectivité d'un droit, Bruylant, 2013 ; Janin, Marc, "La visioconférence à l'épreuve du procès équitable », in «La visioconférence dans le prétoire », Les cahiers de la justice, $\mathrm{n}^{\circ} 2,2011$. 


\section{الوسائل المستحدثة}

للفصل في الاعاوى الإدارية خلال مدة معقولة في النظام

القانوني الفرنسي خلارل مداري

\section{شُبان أحمد رمضنان}

وبالنسبة لتطبيق Tele-Recours فقد تم تعميم العمل به أمام القضاء الإداري الفرنسي ابتداءً من عام 2013 ـ وهو تطبيق يسمح بوضع صور الكترونية لوثائق الدعوى ومستتداتها على الموقع الإلكتروني للمحكمة المختصة بنظر ها على النحو الذي يُمكِن أطر افها من تبادلها والإطلاع عليها ، وكذا تبادل الردود بشأنها بسهولة ويُسر (161). ويتعين لاستفادة أطر اف الدعوى من هذا التطبيق تو افر شرطين أحدهما وجود محامي للخصم يتولى مهمة إرسال و استقبال وثائق الدعوى عبر هذا التطبيق للتأكد من تطابق الصورة الالكترونية للمستند أو الوثيقة مع الأصل . و الآخر يتعلق بمو افقة جهة الإدارة - الطرف الآخر في الدعوى الإدارية - حيث يجب موافقتها بدور ها على استخدام هذا التطبيق كوسيلة للاتصال مع المحكمة المختصة . كما يُتيح هذا التطبيق لقلم كتاب المحكمة المختصة سرعة إرسال مذكر ات الدعوى ومستتداتها للخصوم ، وكذلك ردودهم عليها على النحو الذي يُسهم بفاعلية في التغلب على بطء إجر اءات التقاضي .

وطبقاً لبعض التقارير والإحصاءات بشأن تطبيق Tele-Recours فقد بلغت نسبة استعماله حتى أغسطس 2014 (43.5\%) أمام محكمة الاستئناف الإدارية ، 48.3\% أمام المحاكم الإدارية ، في حين بلغت نسبته أمام المحكمة الإدارية لمدينة فرساي $34.3 \%$ ، 42.5\% أمام محكمة الاستنئنف الإداري لمدينة Versailles

و فيما يتعلق بتطبيق Poste-Rapporteur فيُعد أحد التطبيقات التي تحوي عدداً من أنماط الأحكام الإدارية بحيث يستطيع القاضي من خلال اختيار النمط الذي يُريده - وكتابة رقم الدعوى المنظورة أمامه و المُسجلة سلفاً على تطبيق Skipper - إعداد مشروع الحكم أو الحكم النهائي في وقت قصبر ـ ذلك أن استخدام القاضي لهذا التطبيق بعد كتابة رقم الدعوى يظهر لله الكترونياً كافة البيانات والمستندات المتعلقة بتلكم الدعوى ، وما قُدّم فيها من مذكر ات ، وما تم بشأنها أثناء مرحلة التحضير (163).

و أخيراً يوجد تطبيق آخر يستطيع القضاة من خلاله الدخول على البوابة القانونية لفرنسا وهو تطبيق Arian

(161) Pastor, Jean-Marc; Poupeau, Diane, « Télérecours, l'application qui bouscule les habitudes », AJDA, p. 1612J 2015. ; Jouanneau, François, «Télérecours, quel bilan deux ans après sa généralisation ?», Veille juridique, Alain Bensoussan Avocats, 28 octobre 2015 (http://www.alainbensoussan.com/telerecours-bilan/2015/10/28.

(162) Voir L' intervention de jean - Marc Sauvél (avec la collaboration de) M. Stéphane Eustache. Audience solennelle de rentrée de la cour administrative d' appel et du tribunal administratif de Versailles, 6 octobre 2014, p.6.

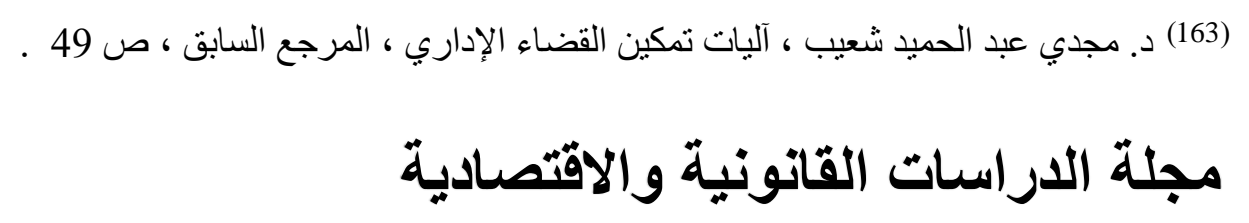




\section{الوسائل المستحدثة}

للفصل في الدعاوى الإدارية خلال مدة معقولة في النظام

القانوني الفرنسي

\section{شعبان أحمد رمضان}

الذي يرتبط بالبو ابة الالكترونية Legifrance و هو عبارة عن وسيلة بحث تقنية فائقة السرعة و الفاعلية للوصول إلى الأحكام القضائية الصادرة عن القضاء الإداري وما تحويه من مبادئ تصلح للتطبيق على موضوع الدعوى أو الطعن المطروح أمام المحكمة المختصة على النحو الذي يُمكنها من الفصل فيها في غضون مدة معقولة استهداءٌ بتلك الأحكام.

ولعل تفحص تقارير مجلس الدولة بشأن الأنشطة التي تطلع بها محاكم جهة القضاء الإداري وبصفة خاصة

تللك التي تنتعلق بالوظيفة القضائية تظهر بما لا بدع مجالا للثك النجاح الذي حقفته الوسائل آنفة الذكر في جعل القضاء الإداري يجمع بين مفهوم العدالة الجيدة دون الإخلال بقدر المستطاع بالالتز ام الوارد النص عليه في المادة السادسة من الاتفاقية الأوربية لحقوق الإنسان(164).

ففيما يخص متوسط مدة التقاضي أمام محاكم جهة القضاء الإداري يظهر أحدث تقرير أصدره المجلس بشأن الأنشطة التي اضطلعت بها محاكم جهة القضاء الإداري عن العام المنصرم أن متوسط المدة أمام المحاكم الإدارية كانت تسعة أشهر و عشرة أيام و هي تقل خمسة أيام مقارنة بعام 2018 حيث كانت تسعة أشهر وخمسة عشر يوما(165). وفي السياق ذاته حدث تطور بصدد مدة الفصل في النزاع أمام محاكم الاستئناف الإدارية ؛ إذ يتضح من التقرير أن هذه المدة في عام 2019 عشرة أشهر وخمسة وعشرون يوما(166). وهي تزيد يومان عن المدة التي سجلت في عام 2018، بيد أن ذلك لا يمنع من القول بأن ذلك يعد تطورا جيدا إذا ما قورن بزيادة عدد الدعاوى التي سجلت أمام هذه المحاكم بالمقارنة بتلك التي سجلت عام 2018.

ولم يختلف الوضع فيما هو عليه الوضع بالنسبة لمدة الفصل في الدعاوى أمام مجلس الدولة؛ إذ لم تتجاوز في عام 2019 ستة أثهر وخمسة أيام، وهي تقل نوعا ما عن المدة التي كانت تستغرقها الدعوى عام 2018 حيث كانت ستة أشهر وسبع عشرة يوما(167)

(1) Conseil d'Etat ; Rapport public 2019 ; Activité juridictionnelle des juridictions administratives en 2019, Rapport adopté par l'assemblée générale du conseil d'Etat en 26 mars 2020, la documentation Française, p. 15 et $\mathrm{s}$.

(2) Conseil d'Etat ; Rapport public 2019 ; Activité juridictionnelle des juridictions administratives en 2019, Rapport adopté par l'assemblée générale du conseil d'Etat en 26 mars 2020, la documentation Française, p. 41.

(3) Conseil d'Etat ; Rapport public 2019 ; Activité juridictionnelle des juridictions administratives en 2019, Rapport adopté par l'assemblée générale du conseil d'Etat en 26 mars 2020, la documentation Française, p. 46.

(4) Conseil d'Etat ; Rapport public 2019 ; Activité juridictionnelle des juridictions administratives en 2019, Rapport adopté par l'assemblée générale du conseil d'Etat en 26 mars 2020, la documentation Française, p. 50. 


\section{الوسائل المستحدثة}

للفصل في الدعاوى الإدارية خلال مدة معقولة في النظام القانوني الفرنسي مداني

\section{شعبان أحمد رمضنان}

وصفوة القول أن تقارير المجلس تُفصح بجلاء عن مدى إسهام الوسائل التي عرضنا لها في معالجة كثير من البطء الذي يعتري إجر اءات التقاضي أمام جهة القضاء الإداري في فرنسا ، وتسريع الفصل في الدعاوى و الطعون

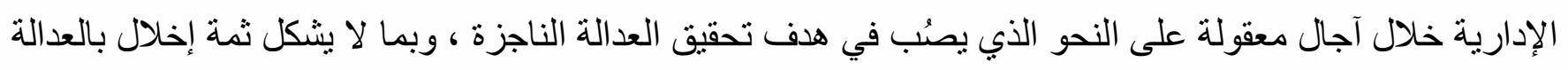

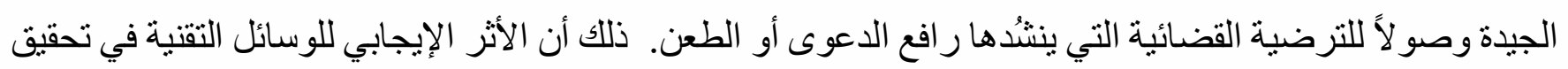

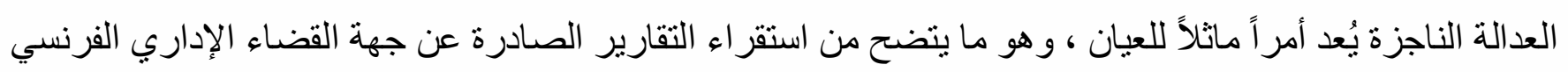

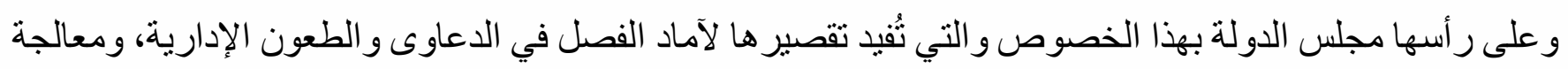
مشكلة بُطء إجر اءات التقاضي بما يحقق العدالة الناجزة ـ هذا من ناحية ، ومن ناحية أخرى فإن استعمال تلكم الوسائل

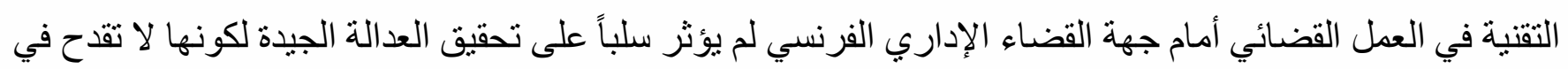

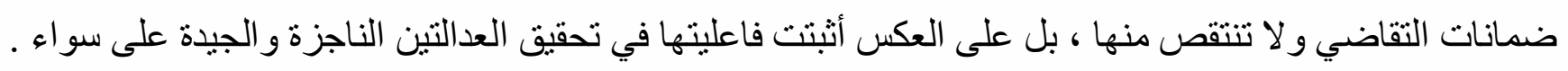
و ونظر اً لما حققته الوسائل المستحدثة في النظام القانوني الفرنسي للفصل في الدعاوى والطعون الإدارية خلال

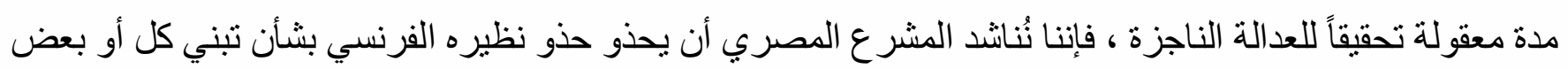

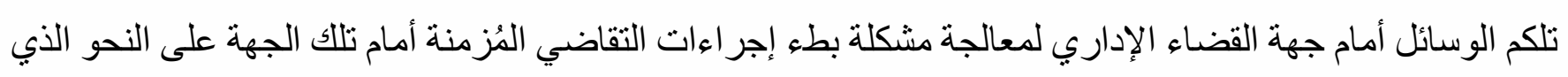

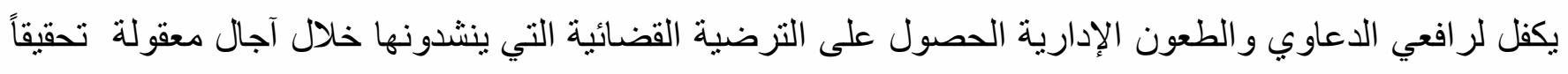

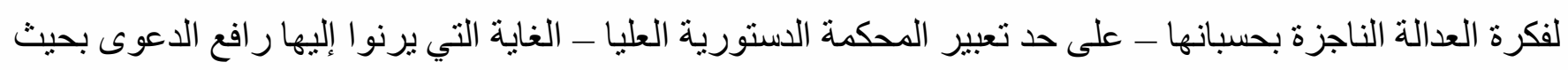

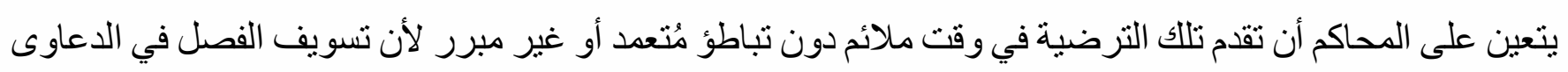

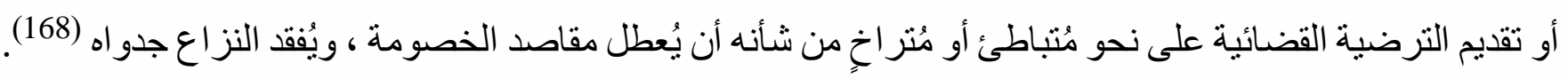

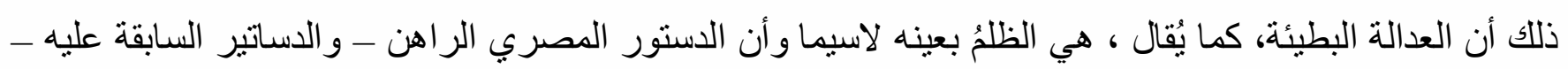
تضمن النص في المادة 97 على سرعة الفصل في القضايا (169) باعتباره ، فيما نرى ، مبدأ ذو قيمة دستورية يتعين على المحاكم الالتز ام به و إعمال حكمه و إلا لما ارتفع به المشرع الدستوري إلى مصاف النصوص الدستورية .

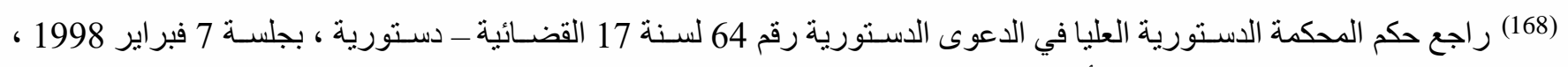

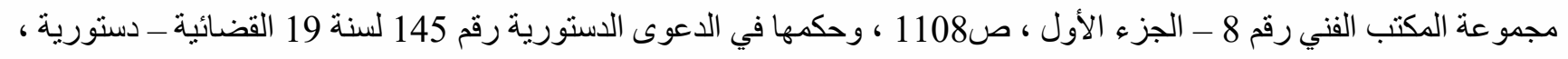

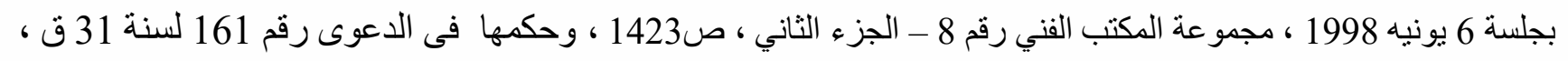

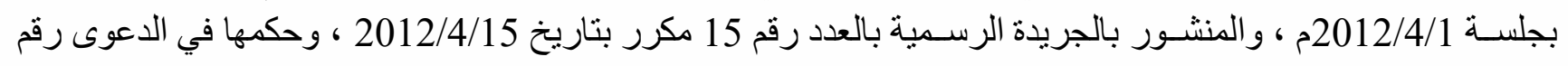

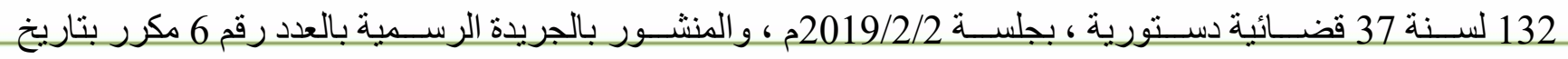
2019/2/11

(169) تتص المادة 97 من الدستور المصـري لعام 2014 على أن " التقاضـي حق مصسون ومكفول للكافة ، وتلتزم الدولة بتقريب جهات

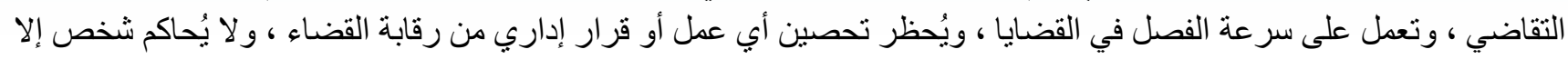

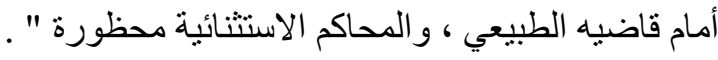


للفصل في الاعاوى الإدارية خلال مدة معقولة في النظام

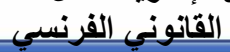

\section{شعبان أحمد رمضنان}

كما يتعين على المشرع العادي سرعة تعديل قانون مجلس الدولة ، أو سن قانون جديد ينظم إجر اءات التقاضي

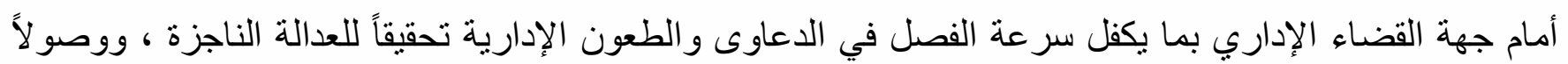

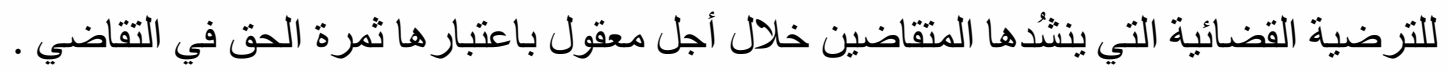


للفصل في الدعاوى الإدارية خلال مدة معقولة في النظام

$$
\text { شعبان أحمد رمضان }
$$




\section{شعبان أحمد رمضنان}

\section{الفصل الثالث}

$$
\text { مدى اعتناق القضاء الإداري المصري للفصل في الدعاوى الإدارية خلال مدة معقولة }
$$


للفصل في الدعاوى الإدارية خلال مدة معقولة في النظام

$$
\text { شعبان أحمد رمضان }
$$




\section{الوسائل المستحدثة}

للفصل في الدعاوى الإدارية خلال مدة معقولة في النظام القانوني الفرنسي ملارك

\section{شعبان أحمد رمضنان}

\section{الفصل الثالث}

مدى اعتناق القضاء الإداري المصري للفصل في الدعاوى الإدارية خلال مدة معقولة

تتاولنا في الفصل الثاني من الدراسة الماثلة بعضًا من الوسائل التي استحدثها المشرع الفرنسي بتقنين العدالة الإدارية للفصـل في الدعاوى الإدارية خلال مدة معقولة على النحو الذي يضــمن تحقيق العدالة الناجزة ، دون إخلال بالعدالة الجيدة .

والتساؤل الذي يُمكن إثارته بهذا الصدد هو إلى أي مدى يمكن للمشرع المصري محاكاة نظيره الفرنسي بهذا الخصوص ؟ لاسيما وأن النظام الدستوري المصري - عبر الدساتير المصرية المتعاقبة - تضمن النص صراحة على إلى سـرعة الفصـل في القضـايا ، فضــلا عن تحديده آجالاً محدة للفصـل في بعض المنازعات الإدارية ـ كما أن قانون مجلس الدولة المصري رقم 47 لسنـة 1972 ، وتعديلاته ، قد تضمن بدوره عدة نصوص تتعلق بسرعة الفصل في بعض المنازعات ، وأخرى تتصـل بمعالجة بطء بعض إجراءات التقاضـي ـ الأمر الذي يمكن معه القول بأن النظام القانوني المصري يُقر مبدأ العدالة الناجزة كأحد مرتكزات الحق في التقاضي وثمراته في آن واحد. فإلى أي مدى التزام القضاء الإداري المصري بمبدأ الفصل في الدعاوي الإدارية خلال مدة معقولة ؟

وللإجابة على التساؤلين المطروحين نقسم هذا الفصل لمبحثين نُعرض في أولهما للأسـاس الدستوري والقانوني للفصل في الدعاوى الإدارية خلال مدة معقولة في النظام القانوني المصري ـ ونتناول في الآخر بعض تطبيقات القضاء الإداري المصري للفصل في بعض المنازعات الإدارية خلال مدة معقولة ، وذلك على النحو الآتي :

$$
\text { المبحث الأول مدأه }
$$

الأساس الدستوري و القانوني للفصل في الدعاوى

الإدارية خلال مدة معقولة في النظام القانوني المصري

تحرص النظم الدسـتورية على اختلاف مشـاربها على النص على الحقوق والحريات التي يتمتع بها الأفراد . كما تحرص على كفالة وسائل الحماية الموضوعية والإجرائية لها على النحو الذي يمكن الجميع من ممارستها والزود

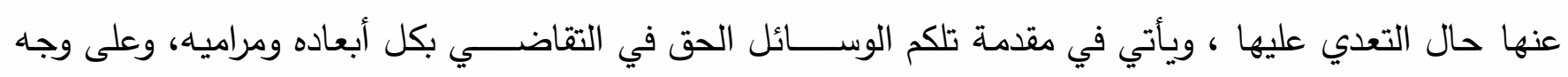
الخصـوص الحصــول على الترضـية القضــائية لرافع الدعوى خلال أجل معقول تحقيقا للعدالة الناجزة ـ كما تحرص القوانين والتشريعات المنظمة لجهات التقاضي والإجراءات المتبعة أمامها على كفالة الحق نفسه إنفاذًا لأحكام الدستور 
للفصل في الدعاوى الإدارية خلال مدة معقولة في النظام القانوني الفرنسي خداري مداني

\section{شعبان أحمد رمضنان}

، وردًا للحقوق إلى أصحابها .

وللحديث عن الأساسين الدستوري والقانوني للفصل في الدعاوى الإدارية خلال مدة معقولة نقسم هذا المبحث لمطلبين نتصــى في الأول لبيان الأسـاس الدستوري ، ونعرض في الآخر للأسـاس القانوني على أن يقتصـر الأمر على نصوص قانون مجلس الدولة وبعضًا من نصوص القوانين المتعلقة ببعض الدعاوى الإدارية . 


\section{الوسائل المستحدثة}

للفصل في الدعاوى الإدارية خلال مدة معقولة في النظام

القانوني الفرنسي

\section{شعبان أحمد رمضنان}

المطلب الأول

الأساس الدستوري للفصل في الدعاوى الإدارية

خلال مدة معقولة في النظام القانوني المصري

تبنت الدســـاتير المصــرية المتعاقبة بدء بدســـور عام 1971(170) ، مرورًا بالإعلان الدســـتوري عام

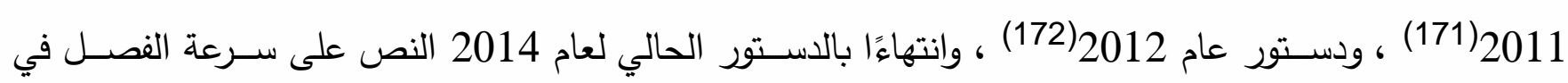
القضـايا حيث نصــت المادة 97 منه على أن "التقاضـي حق مصــون ومكفول للكافة ـ وتلتزم الدولة بتقريب جهات التقاضي، وتعمل على سرعة الفصل في القضايا .... " (173).

والحقيقة أن تبنى الدسـاتير المصـرية المتعاقبة لهذا التوجه بشـأن سـرعة الفصـل في القضـايا يثـي بالأهمية البالغة لهذا الأمر بحسبانه الثمرة المرجوة لرافع الدعوى للحصـول على الترضـية القضـائية خلال وقت معقول تحقيقًا للعدالة الناجزة كأحد مرتكزات الحق في التقاضي.

والتشــاؤل الذي يُثار بهذا الصــد هو هل يُعد الفصـل في الدعاوى خلال مدة معقولة - سـرعة الفصـل في

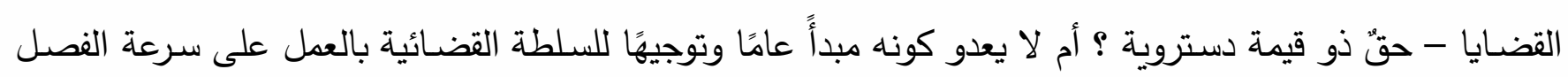

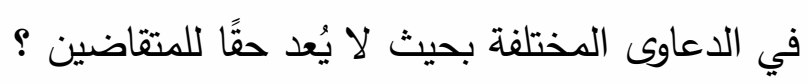
ولإجابة على التسـاؤل المُثنار نُعرض لوجهتي النظر الفقهية والقضـائية - تحديداً القضـاء الدسـوري - بهذا الخصوص في فرعين متتاليتين نتبعهما بوجهة نظر الباحث . الفرع الأول - رأي الفقه : اتجه نظرٌ من فقه القانون الجنائي في معرض تفسـيره لنص المادة 68 من دســتور عام 1971 - المقابلة لنص المادة 97 من الدسـتور الراهن لعام 2014 - صــوب القول بأن هذا النص الدسـتوري لا يتضــمن حقاً محدداً

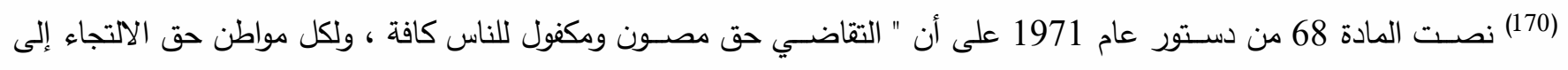
قاضيه الطبيعي ، وتكفل الدولة تقريب جهات القضاء من المتقاضين وسرعة الفصل في القضايا .... " .

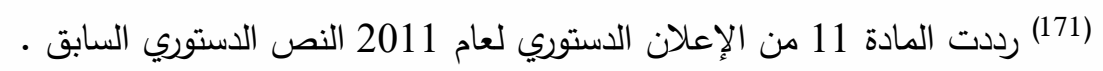

(172) نصــ المادة 75 من الدستور المصـري لعام 2012 على أن " التقاضـي حق مصـون ومكفول للناس كافة ــوتلتزم الدولة بتقريب جهات القضاء وسرعة الفصل في القضايا ... "

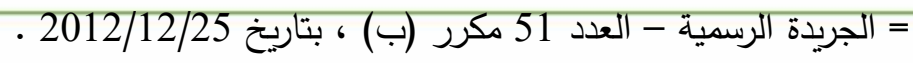

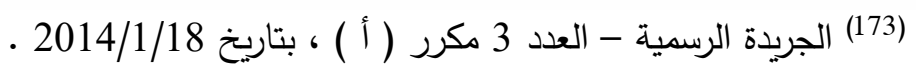




\section{الوسائل المستحدثة}

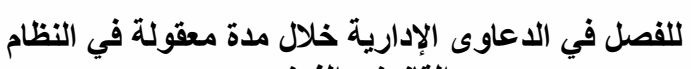

القانوني الفرنسي

\section{شُبان أحمد رمضنان}

للمتقاضين إزاء الدولة بأن يُفصل في قضـاياهم على وجه السرعة ، وإنما محض مبدأ عام وتوجيه للحث على سرعة الفصـل في القضـايا دون أن يُرتب أثراً على اسـتطالة أمد الفصـل في الدعوى(174) فضـلاً عن كونه لا يقتصـر على يلى نوعية بعينها من القضــايا ، وإنما يسـتغرق الإجراءات القضــائية أياً كان موضــوعها جنائية كانت أم مدنية ، وسـواء أكانت تجارية أم إدارية أو غيرها (175).

ويُدِّمِ جانب من أنصـار هذا الاتجاه وجهة نظرهم بالقول بأن القضــاء المصـري بشـقيه العادي والإداري ، مستقر على التفرقة في مجال المواعيد التي تتضمنها النصوص القانونية المنظمة لإجراءات التقاضي بين نوعين منها هما المواعيد الحتمية والتنظيمية ، وأن الأولى دون الثانية هي التي يترتب البطلنن على مخالفتها حتى وإن تم الإجراء صحيحاً طالما جاوزها ، بينما المواعيد التنظيمية لا تعدو كونها من قبيل حث المشرع للمحاكم على سرعة الفصل في القضــــايا على النحو الذي لا يرقى لإقرار حق للمتقاضـــين حال مخالفتها ســــواء ببطلان الإجراء أو المطالبـة بالتعويض(176).

وخلافًا للنظر السـابق ، يرى نظر آخر جدير بالتأييد أن نص المادة 97 من الدستور الراهن - وما يقابله من نصسوص دسـتورية في الدسـاتير السـابقة عليه - يقطع بكونه يقرر حقاً للمتقاضـين إزاء الدولة بالفصـل في قضـاياهم على وجه السرعة ، أي خلال مدة معقولة دون تراخٍ ، وأنه ليس مجرد توجيه للمحاكم ، وإنما التزام عليها بالفصل في القضـايا على وجه السـرعة لأن القول بغير ذلك يتعارض مع فلسـفة النص عليه في الدسـتور ، كما يناقض الطبيعة الآمرة للنصوص الدستورية وإخلالا بمبدأ سمو الدستور (177) على نحو ما استقر عليه القضاء الدستوري المصري في أحكامه المتواترة.

ثانيًا : موقف القضاء الدستوري المصري :

(174) د. غنام محمد غنام ، حق المتهم في محاكمة سـريعة في القانون الأمريكي ، مجلة الحقوق - جامعة الكويت - القسم الأول ، عام .878 1992

(175) د. أحمد فتحي سرور ، الحماية الدستورية للحقوق والحريات ، المرجع السابق ، ص757 ، 757 وما بعدها ، د. شريف سيد كامل ، الحق ،

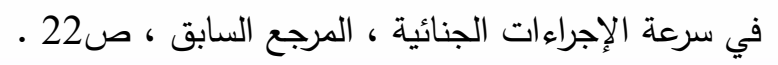

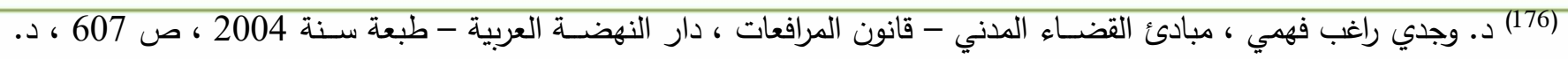

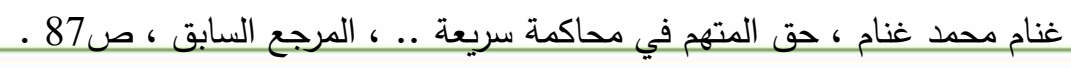

(177) د. عبد الحفيظ الثيمي ، الحماية الدستورية للحقوق والحريات الأساسية - دراسة مقارنة ، دار النهضة العربية ، طبعة سنة 2001 ، 2013 ، ص73 ، د. إسلام إبراهيم شيحا ، الحق في محاكمة خلال مدة معقولة ... ، المرجع السابق ، ص15 ، ص23 ، د 
استقر قضـاء المحكمة الدستورية العليا على تأكيد الطبيعة الدستورية للحق في محاكمة سريعة تحقيقًا للعدالة الناجزة المنصــفة ، وأن الحصــول على الترضــية القضــائية يُعد الغاية النهائية للحق في التقاضــي حماية للحقوق والحريات التي يتضــنها الدسـتور ومن أحكامها بهذا الخصــوص حكمها في الدعوى الدسـتورية رقم 81 لسـنة 19 القضـائية بجلسـة 6 فبراير 1999 (178). وحكمها في الدعوى الدستورية رقم 68 لسـنة 40 القضـائية بجلسـة 4 مايو 2019 الذي جاء بأحد أسبابه " ..... وحيث إن الدستور قد كفل لكل مواطن - بنص مادته السابعة والتسعين - حق الالتجاء إلى قاضيه الطبيعي ، مخولاً إياه بذلك أن يسعى بدعواه إلى قاض يكون بالنظر إلى طبيعتها ، وعلى مختلف العناصــر التي لابســتها ، مهيئًاً دون غيره بالفصـل فيها ، كذلك فإن لحق التقاضــي غاية نهائية يتوخاها ، تمثلها الترضية القضائية التي يُناضل المتقاضون من أجل الحصول عليها ، لجبر الأضرار التي أصابتهم من جراء العدوان على الحقوق التي يطلبونها ، فإذا أرهقها المشــرع بقيود تعسـر الحصــــل عليها أو تحول دونها ، كان ذلك إخلالاً بالحماية التي كفلها الدستور لهذا الحق، وإنكارًا لحقائق العدل في جوهر ملامحها"(179). وقد أكدت المحكمة الدسـترية قضـائها السـابق بحكم آخر هو حكمها في الدعوى الدسـتورية رقم 132 لسـنة 37 القضـائية بجلسـة 2 فبراير 2019 والذي جاء بأحد أسـبابه " .... وحيث إنه إذا كان ذلك ، وكان الالتزام الملقى على عاتق الدولة، وفقًا لنص المادة 97 دن الدستور ، يقتضيها تمكين كل متقاض من النفاذ إلى القضاء نفاذًا ميسرًا ، لا تثقله أعباء مـاليـة ، ولا تحول دونـه عوائق إجرائية بـا يعنيـه من حق كل فرد في أن يتوفر لله حقا متكاملاً ، ومتكافيًا مع غيره في محاكمة منصفة وعلنية ، تقوم عليها محكمة مستقلة ومحايدة ، ينشئها القانون ، تتولى الفصل خلال مدة معقولة - في حقوقه والتزاماته المدنية ، أو في التهمة الجنائية الموجهة إليه ، ويتمكن في كنفها من عرض دعواه ، وتحقيق دفاعه ، ومواجهة أدلة خصـــومهه ، ردًا وتعقيبًا ، في إطار الفرص المتكافأة ... ، إذا كان ما تقدم وكان حق التقاضـي لا تكتمل مقوماته أو يبلغ غايته ، ما لم توفر الدولة للخصـومة في نهاية مطافها حلاً منصـفاً ، يمثل التشـويـة التي يعمد من يطلبها إلى الحصــول عليها ، بوصـفها الترضـية القضــائية التي يسـعى إليها لمواجهة الإخلال بالحقوق التي يدعيها ... فإن هذه الترضـية ... تتدمج في الحق في التقاضـي باعتبارها الحلقة الأخيرة فيه ،

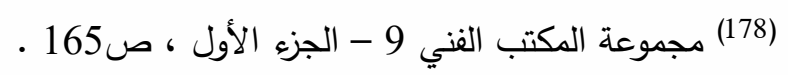

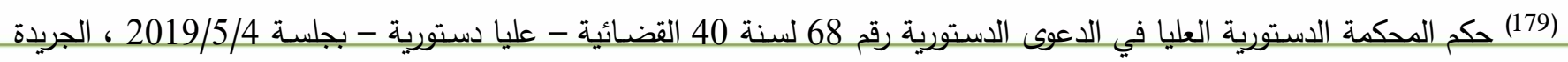
الرسمية - العدد رقم 19 مكرر بتاريخ 2019/5/12 . 
الوسائل المستحدثة

للفصل في الدعاوى الإدارية خلال مدة معقولة في النظام

القانوني الفرنسي

\section{شعبان أحمد رمضنان}

$$
\text { ولارتباطها بالغاية النهائية المقصودة منه برابطة وثقى ... " (180). }
$$

وتجدر الإثـارة إلى أن المحكمة الدستورية العليا وإن كان قضـاؤها قد تواتر على ضـمان الحق في المحاكمة السـريعة تحقيقاً للعدالة الناجزة المنصـفة في المجال الجنائي لتعلقه بالحرية الثـخصـية والحق في الحياة ، إلا أنها قد أظلت بتلكم الضـــمانة المحاكمات الأخرى من غير المجال الجنائي ، ومن أحكامها في المجال الجنائي حكمها في الدعوى الدسـتورية رقم 64 لســنة 17 القضــائية بجلسـة 7 فبراير 1998 والذي جاء بعض أسـبابه " أن الحق في محاكمة منصفة يتضـمن بين ما يشتمل عليه الحق في محاكمة لا يكتنفها بطء ملحوظ باعتباره من الحقوق الجوهرية التي لا يجوز أن يكون الاتهام معها متراخياً دون مســـوغ معلقًا أمداً طويلاً بما يثير قلق المتهم ، ويعوق بالضــرورة مباشـــرته للحقوق والحريات التي كفلها الدســـتر ، وعلى الأخص ما يتعلق منها بحريـة التعبير وحق الاجتماع ، والإســهام في مظاهر الحياة العامة ... كذلك فإن محاكمته بطريقة متأنية تمتد إجراءاتها زمناً طويلاً ، يعرقل خطأه ، ويقترن بمخاطر تتهدد بها فرص الاتصـال بشـهوده ، ويُرجح معها كذلك احتمال اختفائهم ، ووهن معلوماتهم في شـأن الجريمة حتى مع وجودهم ... " (181).

وقد أكدت المحكمة الدسـوريـة اتجاهها السـابق بحكم آخر هو حكمها في الدعوى الدسـتورية رقم 202 لسـنة 32 القضـائية بجلسـة 3 فبراير 2018 والذي جاء بأحد أسبابه فيما نحق بصدده " .... أن المحاكمة المنصفة تعتبر أكثر لزوماً في الدعوى الجنائية ، وذلك أياً كانت طبيعة الجريمة ، وبغض النظر عن درجة خطورتها، وعلى ذلك فإن إدانة المتهم بالجريمة ، إنما تعرضـــه لأخطر القيود على حريته الثــصــية، وأكثرها تهديداً لحقه في الحياة ، وهي مخاطر لا سبيل إلى توقيها ، إلا في ضوء ضمانات فعلية توازن بين حق الفرد في الحرية من ناحية ، وحق الجماعة في الدفاع عن مصــالحها الأســاسـية من ناحية أخرى ، ويتحقق ذلك كلما كان الاتهام الجنائي، معرفاً بالتهمة مبيناً طبيعتها ، مفصـلاً أدلتها ، وكافة العناصـر المرتبطة بها ، .... وبمراعاة أن يكون الفصـل في هذا الاتهام عن طريق محكمة مستقلة محايدة ، ينشئها القانون ، وأن تجري المحاكمة علانية ، وخلال مدة معقولة ... " (182).

(180) حكم المحكمة الدستورية العليا في الدعوى الدستورية رقم 132 لسنة 37 القضائية - عليا دستورية - بجلسة 2019/2/2 ، الجرية ، الجريدة

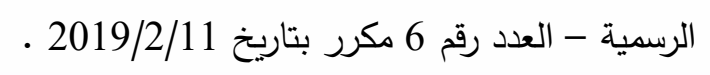

(181) حكم المحكمة الدستورية العليا في الدعوى الدستورية رقم 64 لسنة 17 القضائية ، بجلسة

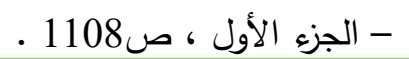

(182) حكم المحكمة الدستورية العليا في الدعوى الدستورية رقم 202 لسنة 32 القضائية - عليا دستورية - بجلسة 2018/2/3 ، الجريدة 


\section{الوسائل المستحدثة}

للفصل في الدعاوى الإدارية خلال مدة معقولة في النظام

القانوني الفرنسي

\section{شُبان أحمد رمضنان}

وفي غير المجال الجنائي أكدت المحكمة الدســتورية العليا أن الحق في محاكمة ســـريعة ومنصـــفة يمتـ ليستغرق المحاكمات الأخرى ، ومن ذلك حكمها في الدعوى الدستوريـة رقم 145 لسنة 19 القضـائية بجلسـة 6 يونيه 1998 (183)، وحكمها في الدعوى الدسـتورية رقم 161 لسـنة 31 القضـائية ، بجلسـة 1 من إبريل 2012 ، والذي جاء بأحد أسبابه " ..... أن ضمان سرعة الفصل في القضايا ، غايتها أن يتم الفصل في الخصومة القضائية - بعد عرضــها على قضــاتها - خلال فترة زمنية ، لا تجاوز باسـتطالتها كل حد معقول ، ولا يكون قصـرها متناهياً ... "

وكذلك حكمها في الدعوى الدسـتورية رقم 132 لسـنة 37 القضـائية ، بجلسـة 2 فبراير 2019 الذي أكدت مجدداً من خلاله أن " .....الالتزام الملقى على عاتق الدولة، وفقًا لنص المادة 97 من الدستور ، يقتيها تمكين كل متقاضٍ من النفاذ إلى القضـاء نفاذاً ميسـراً ... تقوم عليه محكمة مسـتقلة ومحايدة يُنشـئها القانون ، تتولى الفصـل خلال مدة معقولة - في حقوقه والتزاماته المدنية ، أو في التهمة الجنائية الموجهة إليه .... " (185).

وجملة القول أن قضــاء الدسـتورية العليا قد اسـتقر على ضـرورة الفصـل في الدعاوى المختلفة - الجنائية ، والمدنية ، والإداريـة ... وغيرها ، خلال مدة معقولة بحســب ظروف الدعوى وملابســــاتها ، تحقيقًا للعدالة الناجزة المنصفة وصولًا للترضية القضائية التي يبتغيها رافع الدعوى باعتبارها الثمرة النهائية للحق في التقاضي ، وأن تأخير الفصـل في القضـايا ، دون مبرر ، يُعد انتهاكًا للحماية التي كفلها الدسـتور والقانون للحقوق والحريات ، كما يُعد من ناحية أخرى انكارًا للعدالة . رأي الباحث: : نرى عن وجهة نظرنا أن ما تضــنته المادة 97 من الدسـتور الراهن لعام 2014 - وما يُقابلها من الدسـاتير السابقة عليه - بشأن سرعة الفصل في القضايا يُعد التزامًا على عاتق المحاكم بالفصل فيما يُعرض عليها من دعاوى

$$
\text { الرسمية - العدد رقم } 45 \text { مكرر ، بتاريخ 2018/11/13 . }
$$

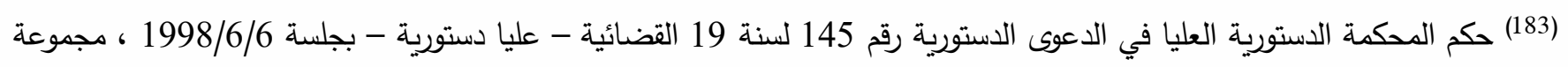

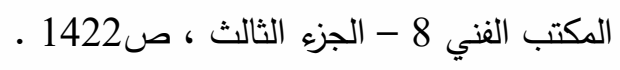

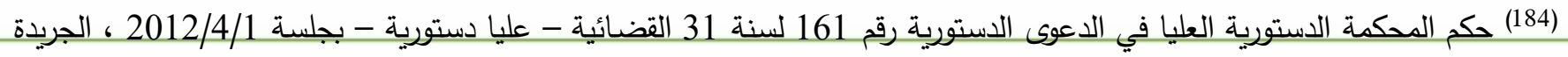

$$
\text { الرسمية - العدد } 15 \text { مكرر ، بتاريخ 2012/4/15 . }
$$

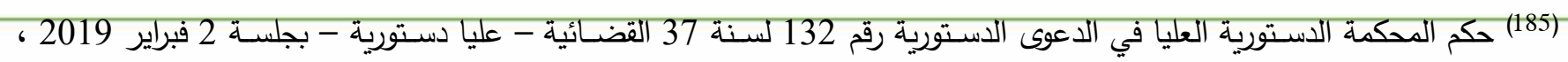
الجريدة الرسمية - العدد رقم 6 مكرر ، بتاريخ 2019/2/11 . 


\section{الوسائل المستحدثة}

للفصل في الدعاوى الإدارية خلال مدة معقولة في النظام

القانوني الفرنسي

\section{شُبان أحمد رمضنان}

ومنازعات ، أيًا كانت طبيعتها جنائية أو مدنية أو إدارية ، على نحو سربع خلال مدة معقولة طبقًأ لظروف كل دعوى ومالابسـاتها ، وبمراعاة ضـمانات التقاضـي الأسـاسـية لاسـيما كفالة حقوق الدفاع ، وأنه ليس محض توجيه للمحاكم وحث لها على سـرعة الفصــ في القضــايا كما يرى نظر فقهي لأن التسـليم بذلك النظر يُفرغ النص الاســتوري من مضــمونه ويُحيله لمضض لغو وعبث يتعين تتزيه المشــرع الدسـتوري عن التردي فيه ـ. هذا من ناحية ، ومن ناحية أخرى فإن مُجاراة هذا النظر يتناقض مع ما هو مُسـلم به من طبيعة آمرة للنصوص الدستورية ، وإخلالاً بمبدأ سموها بحسبانها تتبوأ مقام الصدارة على قمة البناء القانوني داخل الدولة على نحو يجعلها مُلزمة للمشرع والقاضي على سواء

\section{المطلب الثناني}

الأساس القانوني للفصل في الدعاوى الإدارية خلال مدة معقولة

تبنى المشـرع المصـري في عديد من التشـريعات في مجال القانون العام عقب صـدور الدسـتور الحالي لعام

2014 النص على سرعة الفصل في بعض الدعاوى الإدارية تحقيقًا للعدالة الناجزة إعمالاً لنص المادتين 97 ، 210 من هذا الدسـتور (186). ومن أهم تلكم التشـريعات قانون الهيئة الوطنية للانتخابات رقم 198 لســنة 2017 (187). وقانون مباشـرة الحقوق السـياسـية رقم 45 لسـنة 2014 (188). وقانون مجلس النواب رقم 46 لسـنة 2014 (189). وقانون تتظيم ممارسة العمل الأهلي رقم 49 لسنة 2019 (190).

ويُعد هذا الاتجاه التشـريعي من جانب المشـرع المصـري تتويجاً لمسـكه ببعض نصـوص قانون مجلس الدولة رقم 47 لسنة 1972 وتعديلاته المختلفة بشأن سـرعة وتبسيط الإجراءات أمام محاكم جهة القضـاء الإداري ، وسـرعة الفصل في بعض الدعاوى تحقيقًا للعدالة الناجزة ، وهو ما نوجزه في نقطتين •

(186) نصـت الفقرة الأخيرة من المادة 210 من الدسـتور الراهن لعام 2014 على أنه : " ..... وتختص المحكمة الإدارية العليا بالفصـل في الطعون على قرارات الهيئة المتعلقة بالاستفتاءات والانتخابات الرئاسية والنيابية ونتائجها ، ويكون الطعن على انتخابات المحليات أمام محكمة القضـاء الإداري ، ويحدد القانون مواعيد الطعن على هذه القرارات على أن يتم الفصل فيله بحكم نهائي خلال عشـرة أيام

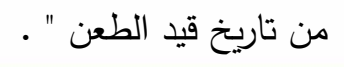

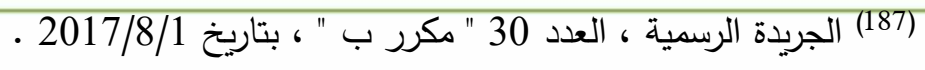

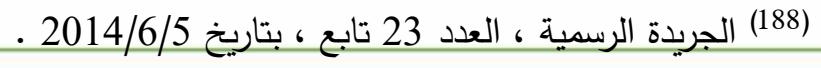

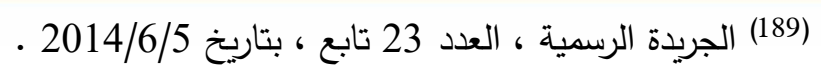

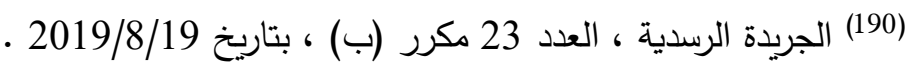




\section{الوسائل المستحدثة}

للفصل في الدعاوى الإدارية خلال مدة معقولة في النظام

القانوني الفرنسي

\section{شعبان أحمد رمضنان}

أو لاً : مبدأ العدالة الناجزة في قانون مجلس الدولة :

حرص المشـرع المصــري في قانون مجلس الدولة على تحقيق مبدأ العدالة الناجزة في غير موضـع ، سـواء

على صـعيد تبسـيط الإجراءات أمام المحاكم الإدارية ومحاكم القضـاء الإداري طبقاً لنص المادتين 26 : 30 (191).

أو على صـــيد المحاكمات التأديبية لتعلقها باســتقرار الأوضــاع الوظيفية للموظف المحال للمحاكمة ، فضــلاً عن انتمائها لثـريعة العقاب مما يسـتوجب سـرعة الفصـل فيها لما يترتب عليها من آثار خطيرة بالنسـبة للموظف العام ،

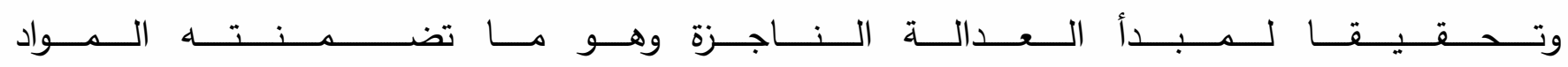
(34 ، 35) من هذا القانون حيث أوجب المشرع على المحكمة - طبقاً لنص المادة 34 نظر الدعوى في جلسة تُعقد خلال خمســة عشـر يومًا من تاريخ إيداع أوراقها قلم كتاب المحكمة (192). كما تضــنت المادة 35 النص على أن تفصـل المحكمة في القضـايا التي تُحال إليها على وجه السـرعة ، مع حظر تأجيل نظر الدعوى أكثر من مرة للسـبب نفسـه على ألا تتجاوز فترة التأجيل اسبوعين ، وأن تصدر المحكمة حكمها في مدة لا تجاوز شهرين من تاريخ إحالة الدعوى إليها.

وعلى صـعيد آخر فقد انتهج المشـرع المصـري في قانون مجلس الدولة الحالي فلسـفة مفادها اسـتثناء بعض الدعاوى الإداريـة دن إعداد تقرير بشـأنها بمعرفة هيئة مفوضــي الدولة تحقيقاً لمبدأ العدالة الناجزة ، ومراعاة للطبيعة الخاصـة لتلكم الدعاوى ، مثل دعوى تهيئة الدليل بحكم كونها تتغيا إثبات الحالة على النحو الذي لا يستوجب إحالتها لهيئة المفوضـين ، والإشكالات في تنفيذ الأحكام الإدارية ، فضـلاً عن الدعاوى التأديبية والطعون الانتخابية حيث لم يجعل المشرع لهيئة مفوضـي الدولة ثـة دور أمام القضـاء التأديبي وكذلك الطعون الانتخابية ، تطبيقًا لمبدأ الاقتصـاد في الخصومة على النحو الذي يكفل سرعة الفصل في تلكم النوعية من الدعاوى . ثانياً : مبدأ العدالة الناجزة في القوانين المنظمة للانتخابات والعمل الأهلي :

(191) تتص المادة 26 من قانون مجلس الدولة على أنه : " على الجهة الإدارية المختصسة أن تودع قلم كتاب المحكمة خلال ثلاثين يومًا

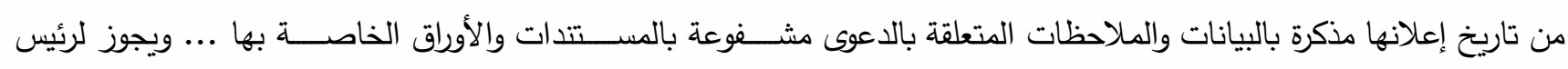

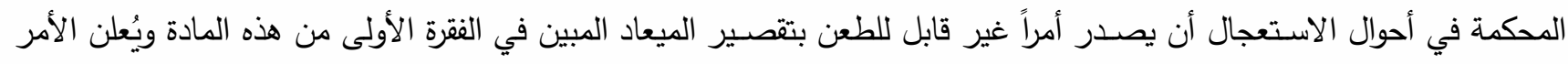
إلى ذوي الثأن خلال أربع وعشرين ساعة من تاريخ صدوره وذلك بطريق البريد ويسري الميعاد المقصر من تاريخ الإعلان .... " .

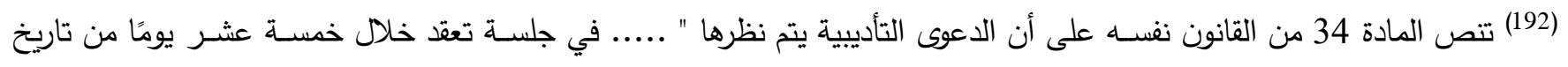
إيداع أوراقها قلم كتاب المحكمة ، ويتولى رئيس المحكمة تحديدها خلال الميعاد المذكور على أن يقوم قلم كتاب المحكمة بإعلان ذوي الشأن بقرار الإحالة وتاريخ الجلسة خلال أسبوع من تاريخ إيداع الأوراق ...." . . 


\section{الوسائل المستحدثة}

\section{القانوني الفرنسي}

\section{نें}

أسلفنا القول في مستهل هذا المطلب أن المشرع المصري قد انتهج سياسـة الاقتصاد في الخصومة في بعض الدعاوى الإداريـة مراعاة لطبيعتها الخاصــــة من ناحية، وتحقيقاً لمبدأ العدالة الناجزة من ناحية أخرى إعمالاً لنص المادتين 97 ، 210 من الدستور الراهن لعام 2014 ، ويأتي في مقدمة تلك التشـريعات القوانين المنظمة للانتخابات الرئاسـية والبرلمانية والمحلية ، وكذا قانون تتظيم ممارسـة العمل الأهلي حيث تضـــت تلكم التثـريعات نصـوصًا صريحة بشأن سرعة الفصل في الطعون الانتخابية خلال آجال محددة ، فضـلاً عن استثنائها من العرض على هيئة المفوضين ، وهو ما تضمنه كذلك قانون تظظيم ممارسة العمل الأهلي رقم 149 لسنة 2019. ونكتفي في هذا المقام بإيراد بعض النصوص التي وردت بتلك التشريعات بشأن سرعة الفصل في القضايا .

\section{( أ ) قانون مباشرة الحقوق السياسية رقم 45 لسنة 2014 (193):}

تضـــن قانون مباشـرة الحقوق السـياسـية عدة نصــوص تتعلق بسـرعة الفصـل في الطعون التي يرفعها المترشحون لعضوية مجلس النواب ضد قرارات لجان القيد وهما المادتان 21 ، 22 ـ والأمر نفسـه بشـأن الفصل في طلب رئيس الهيئة الوطنية للانتخابات من قِبَّ المحكمة الإدارية العليا بشـأن شطب اسـ المترشـح المخالف للضـوابط المتعلقة بالدعاية الانتخابية طبقاً لنص المادة 52 من هذا القانون حيث ألزمت تلك النصوص محكمة القضاء الإداري ، والمحكمة الإدارية العليا بالفصـل في تلك الطعون والطلبات على وجه السـرعة ، ودون العرض على هيئة مفوضـي الدولة.

وبهذا الخصــوص تتص المادة 21 من هذا القانون على أنه " لكل من رُفض طلبه أو تقرر حذف اســمه ، الطعن بغير رسوم في قرار اللجنة المشار إليها في المادة السـابقة أمام محكمة القضـاء الإداري المختصـة ، وعلى قلم كتاب هذه المحكمة قيد تلك الطلبات .. وإخطار مقدم الطلب ورئيس لجنة القيد ... وذوي الثـــأن بكتاب مســــل مصحوب بعلم الوصول بتاريخ الجلسة المحددة لنظر الطعن ، على أن يتم الإخطار قبل ذلك بخمسـة أيام على الأقل

كما نصـــ المادة 22 من القانون نفسـهـ على أن " تفصـل محكمة القضــاء الإداري في الطعون على وجه السـرعة .... " . كذلك نصــ المادة 52 - بعد تعديلها عام 2017 - على أنه " إذا ثبت للهيئة الوطنية أن مترشـاً 


\section{الوسائل المستحدثة}

للفصل في الدعاوى الإدارية خلال مدة معقولة في النظام

القانوني الفرنسي

\section{شعبان أحمد رمضنان}

قد ارتكب مخالفة للضـوابط الواردة في الدسـتور أو القانون أو قرارات الهيئة الوطنية بثـأن الدعاية الانتخابية ، فعلى رئيس الهيئة التقدم بطلب إلى المحكمة الإدارية العليا لشطب اسم هذا المترشح من القائمة النهائية للترشح في الدائرة ، ويُخطر قلم كتاب المحكمة المترشح أو وكيله لاى الهيئة الوطنية بالطلب ، وذلك خلال أربع وعشرين ساعة من تاريخ إيداع الطلب ... وللمترشـح أن يطلع على الطلب ومرفقاته ويودع ما يثــاء من مذكرات دفاع ومسـتندات وذلك خلال

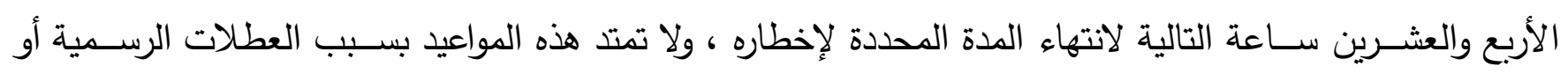
المسـافة ، ومع مراعاة كفالة حق الدفاع ، للمحكمة أن تفصل في الطلب على وجه السـرعة ، ولهها أن تفصل فيه دون سماع مرافعة أو العرض على هيئة مفوضي الدولة .... " . . (ب) قانون مجلس النواب رقم 46 لسنة 2014 (194):

تضـــن قانون مجلس النواب الحالي بدوره نصَّــا يتعلق بـــرعة الفصــل في قرارات لجنة قيد المترشـــين لانتخابات المجلس وهو نص المادة 17 التي نصت على أن "يكون الطعن على القرار الصادر من اللجنة المنصوص عليها بالمادة (15) من هذا القانون أمام محكمة القضاء الإداري خلال ثلاثة أيام تبدأ من تاريخ عرض القوائم وأسماء المترشـــين ، وعلى المحكمة أن تفصـل في الطعن خلال خمســـة أيام على الأكثر ، ولا يجوز وقف تتفيذ الحكم الصادر من محكمة القضاء الإداري ، ولو تم الاستشكال في تنفيذه أمام أية جهة ، إلا إذا قررت دائرة فحص الطعون بالمكمة الإدارية العليا وقف التنفيذ عند الطعن على الحكم " (195). ( ج ) قانون الهيئة الوطنية للانتخابات رقم 198 لسنة 2017 (196) :

اعتنق المشرع المصري بقانون الهيئة الوطنية للانتخابات مبدأ العدالة الناجزة عبر إلزامه لمحاكم جهة القضاء الإداري بالفصــل في الطعون على قرارات الهيئة على نحو ســريع طبقا لصــريح نص المادتين 12 ، 13 من هذا القانون حيث نصـت المادة 12 على أن " لكل ذي شـأن الطعن على قرارات الهيئة ، خلال ثمانية وأربعين سـاعة من

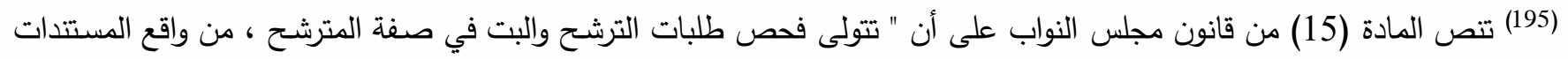

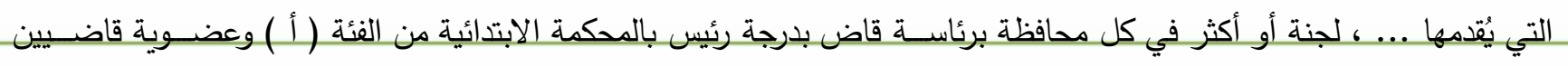
بالمحاكم الابتدائية ... ".

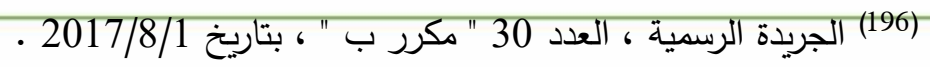




\section{الوسائل المستحدثة}

للفصل في الدعاوى الإدارية خلال مدة معقولة في النظام

القانوني الفرنسي

\section{شُبان أحمد رمضنان}

تاريخ إعلانها ، وتختص المحكمة الإداريـة العليا بالفصــلـ في الطعون على قرارات الهيئة المتعلقة بالاســـتفتاءات والانتخابات الرئاسـية والنيابة ونتائجها ، وتختص محكمة القضــاء الإداري بالفصـل في الطعون على قرارات الهيئة المتعلقة بالانتخابات المحلية ونتائجها ، وتُقدم الطعون إلى المحكمة وفقًا للإجراءات المنصـــوص عليها في قانون

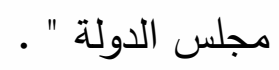

وتتص المادة 93 من القانون ذاته على أن " تفصــل المحكمة في الطعون على قرارات الهيئة بحكم نهائي ،

غير قابل للطعن فيه ، خلال عشرة أيام من تاريخ قيد الطعن ، دون العرض على هيئة مفوضي الدولة . ( د ) قانون تتظيم ممارسة العمل الأهلي رقم 149 لسة 1919 :

جريًا من المشرع المصري على سنته بشأن إعمال مبدأ الاقتصـاد في الخصومة وسرعة الفصل في الدعاوى الإدارية المتعلقة بطلبات عزل مجلس إدارة الجمعيات الأهلية ، وبحل تلك الجمعيات فقد تضـمن قانون تتظيم ممارسـة العمل الأهلي رقم 149 لســنة 2019 النص في المادة 49 منه على أنه " اســثناءً من قانون مجلس الدولة رقم 47 لسـنة 1972 تفصل المحكمة المختصـة في الدعاوى المقامة في الأحوال المنصـص عليها في المادتين ( 47 ، 48 ) من هذا القانون ، على وجه السرعة دون العرض على هيئة مفوضي الدولة ، وللوزير المختص بقرار يصدر منه إيقاف النشـاط المخالف مؤقتًا وتشـكيل لجنة من الجهة الإدارية أو من غيرها لإدارة نشـاط معين لحين صـدور حكم المحكمة .... " " (198).

والناظر المتأمل لنصـوص التشـريعات السـابقة يجد أن المشـرع المصـري قد حرص على تبني مبدأ الاقتصـاد في الخصومة وسرعة الفصل في بعض الدعاوى والطعون الإدارية تحقيقاً لمبدأ العدالة الناجزة على النحو الذي يُشكل أساسًا قانونيًا للفصل في بعض المنازعات الإدارية خلال مدة معقولة .

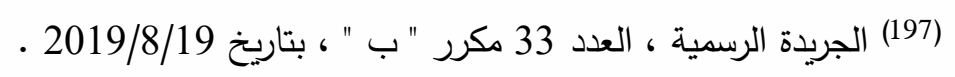

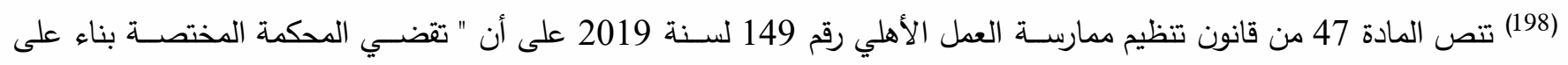
طلب الجهة الإدارية أو كل ذي صـفة ، بعزل مجلس إدارة الجمعية ، وتعيين مجلس مؤقت ، لاتخاذ إجراءات الدعوة لجمعية عمومية

$$
\text { لانتخاب مجلس إدارة جديد ، وذلك إذا توافرت أي من الحالات الآتية : ...... " }
$$

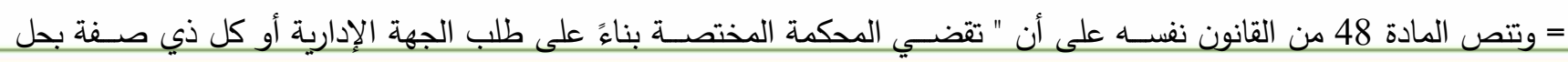

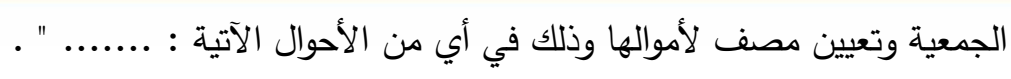


للفصل في الدعاوى الإدارية خلال مدة معقولة في النظام

$$
\text { شعبان أحمد رمضان }
$$




\section{الوسائل المستحدثة}

للفصل في الدعاوى الإدارية خلال مدة معقولة في النظام القانوني الفرنسي خداري

\section{شعبان أحمد رمضنان}

\section{المبحث الثاني}

بعض تطبيقات الفصل في الدعوى خلال مدة معقولة

في بعض صور المناز عات الإدارية

إذا كان المشرع الفرنسي قد أدخل تعديلات على قانون الإجراءات الإدارية عبر استحداثه لبعض الوسائل التي

أمكن من خلالها معالجة بطء إجراءات التقاضي وتمكين محاكم جهة القضاء الإداري من الفصل في الدعاوى الإدارية خلال مدة معقولة على نحو ما تتاولته الدراسـة الماثلة في فصـلها الثاني ، فإن المشـرع المصــري وإن لم ينص على إنى مثل تلكم الوسائل بشكل صريح في قانون مجلس الدولة الحالي رقم 47 لسنة 1972 ، إلا أن هذا القانون قد تضمن بعض النصوص التي تكرس فكرة العدالة الناجزة ومُعالجة بطء إجراءات التقاضي لاسيما في مجال الدعاوى التأديبية ـ كذلك تضمنت بعض التشريعات ذات الصلة بالطعون الانتخابية نصوصاً صريحة تتعلق بسرعة الفصل في بعض إله

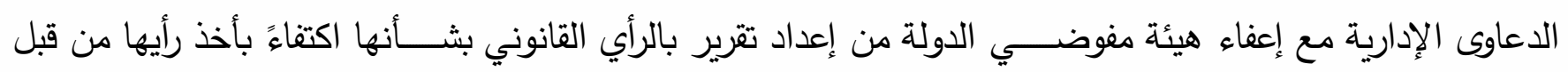
المحكمة المختصــة شـفاهة بالجلســة ، وهو ما التزم به القضــاء الإداري المصــري سـواء من جانب محاكم القضــاء

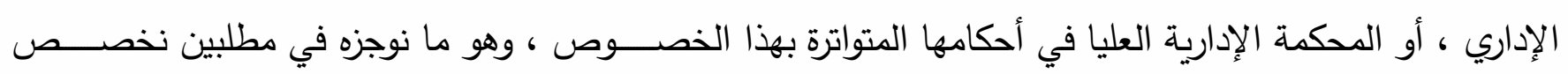
أحدهما لتناول الفصل في الدعاوى التأديبية خلال مدة معقولة ، ونكرس الآخر لإعفاء هيئة مفوضي الدولة من إعداد تقرير في الدعاوى والطعون الانتخابية وذلك على النحو الآتي : 


\section{الوسائل المستحدثة}

للفصل في الاعاوى الإدارية خلال مدة معقولة في النظام القانوني الفرنسي ملارل

\section{شعبان أحمد رمضنان}

\section{المطلب الأول}

الفصل في الدعاوى التأديبية خلال مدة معقولة

ينتمي قضاء التأديب لشرعة العقاب ، شأنه في ذلك شأن القضاء الجنائي ، فما الجزاء التأديبي سوى ضرب من ضــروب العقوبة في مجال الوظيفة العامة. الأمر الذي يتعين معه خضــوع المحاكمات التأديبية لما تخضــع له

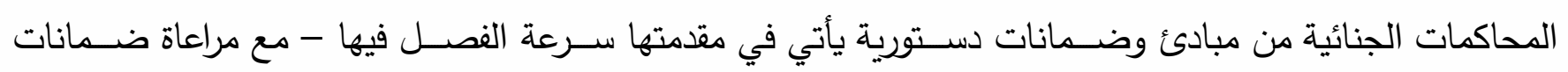
التقاضي الأساسية لاسيما كفالة حقوق الدفاع - حتى لا يظل الاتهام التأديبي سيفًا مسلطًا على الموظف العام لفترة

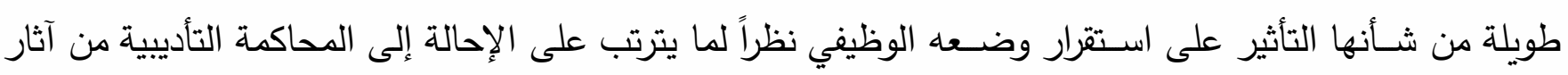
خطيرة بهذا الصــدد ، وكذلك اسـتقرار الأوضــاع الإدارية للمرفق الذي يعمل به على النحو الذي يكفل الموازنة بين مصلحة الموظف والمرفق العام على سواء .

وانطلاقًا من ذلك حرض المشـرع المصــري في قانون مجلس الدولة على كفالة سـرعة الفصــل في الدعاوى التأديبية تحقيقًا لفكرة العدالة الناجزة سواء على صعيد استثناء الدعاوى التأديبية من خضوعها للتحضير من قِتِلْ هيئة مفوضـــي الدولة ، أو على صـــيد الإجراءات المتبعة أمام المحاكم التأديبية والتي تحكمها فلســفة الاقتصـــاد في الإجراءات التي تتضـح من نصـوص المواد 34 ، 35 ، 43 من قانون مجلس الدولة حيث أوجبت الفقرة الأخيرة من

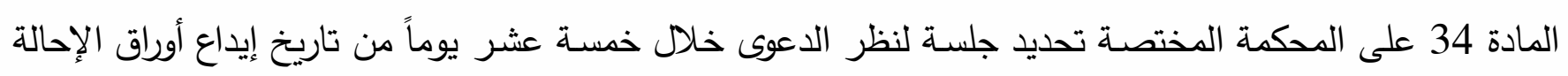

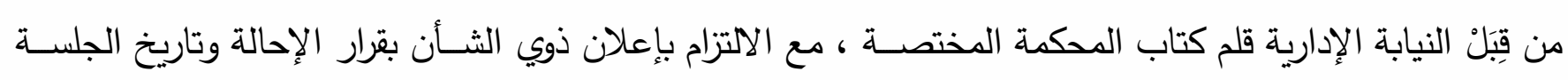
خلال أسبوع من تاريخ إيداع الأوراق المذكورة .

وفي السـياق نفسـهـ جاء نص المادة 35 بضــرورة أن تفصـل المحكمة التأديبية في الدعاوى التي تُحال إليها على وجه السـرعة ، فضــاً عن حظر تأجيل نظر الدعوى أكثر من مرة للسـبب نفسـهـ على ألا تجاوز فترة التأجيل

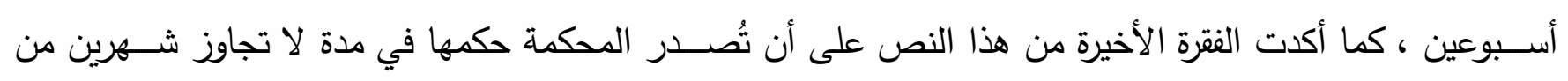
تاريخ إحالة الدعوى إليها ـ كذلك أوردت المادة 43 النص على عدم جواز تأجيل النطق بالحكم أكثر من مرة . موقف المحكمة الإدارية العليا من فكرة العدالة الناجزة في المجال التأديبي : انتهجت المحكمة الإدارية العليا في مجال رقابتها على أحكام المحاكم التأديبية سياسـة قضائية مفادها تكريس تحقيق العدالة الناجزة في مجال الدعاوى التأديبية من خلال تفسـيرها للنصــوص القانونية المتعلقة بالمدد التي يتعين إقامة الدعوى التأديبية خلالها سواء بطلب من رئيس الجهاز المركزي للمحاسبات بصدد المخالفات المالية مُكيفة إياها 


\section{الوسائل المستحدثة}

للفصل في الاعاوى الإدارية خلال مدة معقولة في النظام

القانوني الفرنسي

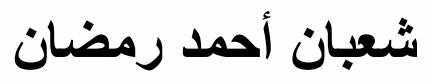

منذ بواكير عهدها(199) كمدة ســـقوط ، وكذلك المدة المحددة للنيابة الإدارية لإقامة تلك الدعوى بطلب من رئيس الجهاز المركزي للمحاسـبات حيث اعتبرتها بدورها ، طبقا لاتجاهاتها الحديثة ، مدة سـقوط باعتبارها ضــمانة مقررة للموظف المحال للمحاكمة التأديبية حتى لا يظل الاتهام التأديبي سيفًا مسلطًا عليه فترة طويلة من الزمن ، فضلاً عن دواعي استقرار وضعه الوظيفي ، وهو ما يصب في اتجاه تحقيق العدالة الناجزة في المجال التأديبي ، يستوي في ذلك أحكامها التي انتهت فيها إلى رفض الطعون المقامة من النيابة الإدارية بإلغاء أحكام المحاكم التأديبية الصــادرة بعدم قبول الدعوى التأديبية لرفعها من قِبَلْ النيابة الإدارية بعد المواعيد المحددة لرفعها بحسـبانها مواعيد سـقوط ، وتأييدها لهذا الاتجاه القضائي من جانب المحاكم التأديبية .

ومن أحكام الإدارية العليا بهذا الخصوص حكمها في الطعن رقم 221 لسنة 60 قضائية(200) عليا بجلسة 3 سـبتمبر 2016 الذي شـيدته النيابة الإدارية على فسـاد حكم المحكمة التأديبية القاضـي بعدم قبول الدعوى لرفعها بعد الميعاد المحدد للنيابة الإدارية - في الاســـدلال والخطأ في تطبيق القانون على ســند من القول بوجوب التفرقة بين الميعاد المحدد لاعتراض رئيس الجهاز المركزي للمحاسبات على قرار الجزاء التأديبي كميعاد سقوط ، والميعاد المحدد للنيابة الإدارية لإقامة الدعوى التأديبية باعتباره ميعادًا تنظيميًا .

وفي معرض رد المحكمة الإدارية العليا على هذا الدفع جاء بأحد أســـباب حكمها " ..... وحيث إن الحكمة التي تغياها المشـرع من جعل الميعاد المقرر لرئيس الجهاز المركزي للمحاسـات هو ميعاد سـوط يُسـط حق الجهاز المركزي للمحاســبات في الاعتراض على قرار الجزاء بفواته ، يرجع إلى أن هذا الميعاد مقرر لمصـــلحة الموظف ، وبالتالي فالجهاز إما أن يُعلن موافقته على قرار الجزاء أو يعترض عليه أو يقعد عن الإفصـــاح عن موقفه منه ، فإذا تُرك الأمر كذلك دون وضـــع حد أقصــى للميعاد ظل موقف الموظف معلقًا تحت ســطوة الاعتراض إلى أجل غير مســى ، وهي ذات الحكمة التي أوجب بسببها المشـرع على النيابة الإدارية إقامة الدعوى التأديبية على العامل خلال الثلاثين يومًا التالية ، وهو ميعاد مقرر أيضًا لــا لمصـلحة الموظف ، حتى لا يظل سـيف الاتهام مسـلطًا على متهم الأصـل فيه البراءة ، وحتى لا يجمد وضــعه الوظيفي فلا تُقبل اسـتقالته ويُحرم من ترقياته ، وهو ميعاد مقرر أيضًا

(199) راجع في ذلك أحكام المحكمة الإدارية العليا في الطعون أرقام 672 لسنة 6ق ، بجلسة 1962/1/12 ، 1435 لسنة 34ق ، بجلسة

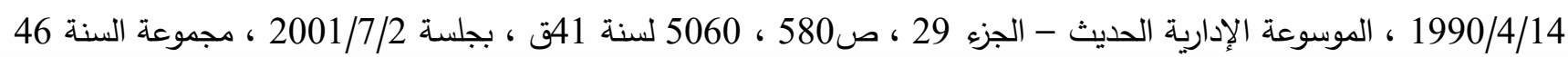




\section{الوسائل المستحدثة}

للفصل في الدعاوى الإدارية خلال مدة معقولة في النظام

القانوني الفرنسي خداري

\section{شعبان أحمد رمضان}

لمصـلحة النيابة الإدارية فإذا تجاوزت هذه المدة فقد يترتب على هذا التجاوز ضـياع معالم المخالفة واختفاء أدلتها ، ومن ثم فان اعتبار هذا الميعاد ميعاد سقوط يؤدي بطبيعة الحال إلى استقرار الوضع الوظيفي للعاملين ، عكس الحال لو ظلوا مهددين أزمانًا طويلة بشبح الاتهام ، مما ينعكس أثره على مصلحة العمل وحسن سيره ، فضلاً عن أن مرور الثالين يوماً دون إقامة الدعوى التأديبية ينم عن إهمال وتصـــرف غير معقول من النيابة الإدارية ، لذلك فإنه يتعين اعتبار هذا الميعاد ميعاد سـوط ويجب على المحكمة التأديبية أن تقضـي به من تلقاء نفسها ( حكم المحكمة الإدارية العليا ، دائرة توحيد المبادئ ، جلسة 2015/5/2 - الطعن رقم 15280 لسنة 55 ق.ع )

وتابعت المحكمة قائلة : " ومن حيث إنه هديًا بما تقدم ، ولما كان الثابت من الأوراق ، أن رئيس الجهاز المركزي للمحاسبات قد اعترض على الجزاءات الموقعة على المطعون ضدهم لما نُسب إليهم من مخالفات في ضـوء تحقيقات النيابة الإدارية في القضية رقم 390 لسنة 2010 نيابة الثقافة ، وبتاريخ 2012/11/6 طلب رئيس الجهاز من النيابة الإدارية إحالة المطعون ضـــدهم إلى المحاكمة التأديبية ، وإذا لم تبادر النيابة الإدارية إلى إقامة الدعوى التأديبية ضد المطعون ضدهم بناء على طلب الجهاز المركزي للمحاسبات إلا بتاريخ 2012/12/10 أي بعد انقضاء الميعاد المقرر لإقامة الدعوى التأديبية وهو ثلاثون يومًا من تاريخ طلب الجهاز المركزي للمحاســـبات من النيابة الإدارية تحريك الدعوى التأديبية ، بحسـبان أن هذا الميعاد هو ميعاد سـقوط طبقًا لما اسـتقر عليه قضــاء المحكمة الإدارية العليا دائرة توحيد المبادئ على النحو المُشـار إليه ، الأمر الذي يتعين معه الحكم بعدم قبول الدعوى التأديبية لرفعها بعد الميعاد المقرر قانوناً ، وإذ ذهب الحكم المطعون فيه إلى ذات المذهب ، فإنه يكون قد صـــدر متفقًا وصحيح حكم القانون ، ويكون الطعن عليه غير قائم على سند صحيح من القانون جديرًا بالرفض " (201). وقد أكدت المحكمة الإدارية العليا قضــاءها الســابق بأحكامها المتواترة بعد ذلك ومنها حكمها في الطعن رقم

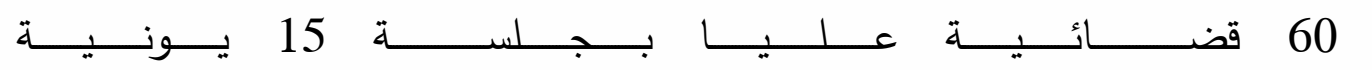
28714 (202) 2019

(201) حكم المحكمة الإدارية العليا في الطعن رقم 221 لسنة 60ق.ع ، بجلسة 2016/9/3 ، سلفت الإثارة إليه . (202) رددت المحكمة الإدارية العليا المبادئ السـابقة بثـأن اعتبار الميعاد المقرر للنيابة الإدارية لإقامة الدعوى التأديبية بطلب من رئيس الجهاز المركزي للمحاسـبات ميعاد سـقوط يترتب على فواته عدم قبول الدعوى التأديبية حيث جاء بحكمها في الطعن رقم 280714 فئل لسـنة 60 ق.ع بجلسـة 2019/6/15 بهذا الخصـوص " .... ولما كانت الحكمة التي تغياها المشـرع من جعل الميعاد المقرر لرئيس الجهاز المركزي للمحاسبات هو ميعاد سقوط أن هذا الميعاد مقرر لمصلحة الموظف وبالتالي فالجهاز إما أن يُعلن موافقته على قرار 


\section{الوسائل المستحدثة}

للفصل في الدعاوى الإدارية خلال مدة معقولة في النظام

القانوني الفرنسي

\section{شُبان أحمد رمضنان}

وعلى صــعيد الأحكام الصــادرة من المحاكم التأديبية بقبول الدعاوى التأديبية المُقامة من النيابة الإدارية بعد

المواعيد المحددة لرفعها من قبلها ، فقد انتهجت المحكمة الإدارية العليا النهج نفسـه حيث اسـتر قضـاؤها على إلغاء أحكام المحاكم التأديبية الصــــادرة بقبول الدعاوى التأديبية المرفوعة من النيابة الإدارية بعد مرور مدة الثلاثين يومًا المحددة لها لرفع تلك الدعاوى بطلب من رئيس الجهاز المركزي للمحاسـبات بثـأن اعتراضــه على قرارات الجزاءات الصـادرة في المخالفات المالية باعتبارها مدة سـقوط مقررة لمصـلحة العامل المحال للمحاكمة التأديبية ، وبالتالي فإن قبول المحاكم التأديبية لتلكم الدعاوى والفصــــل فيها ومجازاتها للمحالين أمامها يتعارض ومبدأ العدالة الناجزة في المجال التأديبي لكون هذا المســلك من قِبَلْ المحاكم التأديبية يُيـــهم في تراخي النيابة الإدارية في الإلتزام بالمواعيد المحددة لها لرفع تلك الدعاوى على النحو الذي يجعل المركز الوظيفي للموظف العام مهددًا لفترة طويلة بما ينعكس سلبًا على حقوقه الوظيفية كأثر لاستطالة فترة اعتباره محالاً للمحاكمة التأديبية ، فضلا عن فترة محاكمته فعليًا . ومن أحكام المحكمة الإدارية العليا بهذا الاتجاه حكمها في الطعن رقم 16907 لســنة 58 قضــائية عليا ، بجلسـة 18 فبراير 2018 (203). وحكمها في الطعنين رقمي 11250 لسـنة 57 قضـائية عليا ، 12363 لسـنة 57 قضـائية عليا بجلسـة 2 يوليه 2018 (204). وحكمها في الطعن رقم 41584 لســنة 60 قضـائية عليا بجلسـة 17 نوفمبر 2018 والذي جاء ببعض أسبابه بهذا الخصوص " .... ومن حيث استقر قضاء المحكمة الإدارية العليا على أن المشــرع قد اختص الجرائم ذات الطابع المالي بأحكام متميزة ، فلم يجعل قرارات الجهة الرئاســية بالتصــرف في

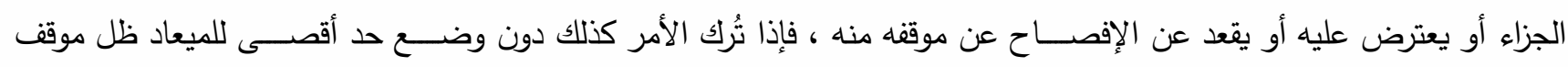
الموظف معلقًا تحت سطوة الاعتراض إلى أجل غير مُسـى وهي ذات الحكمة التي أوجب بسببها المشرع على الإعلى النيابة الإدارية إقامة

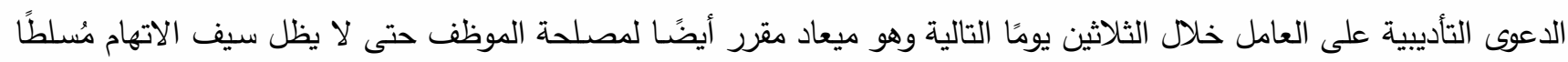

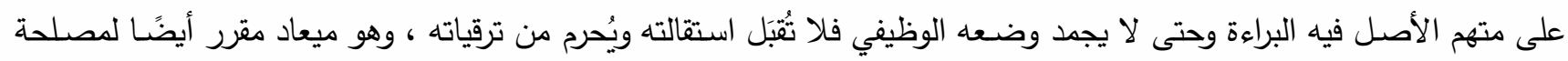

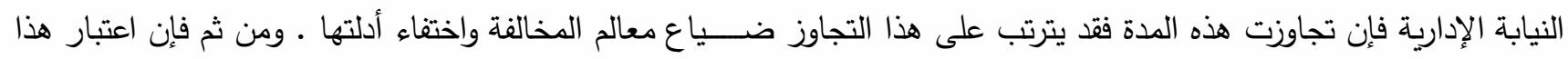

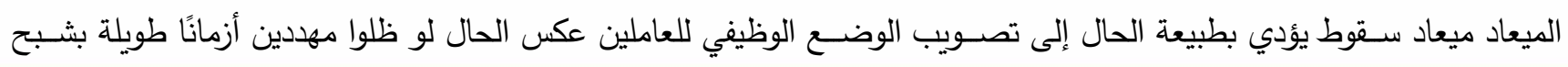

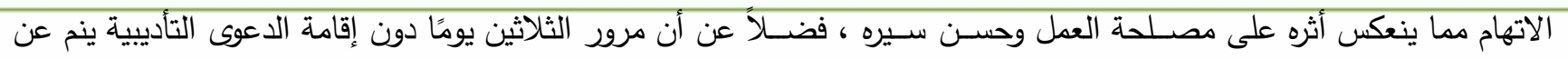

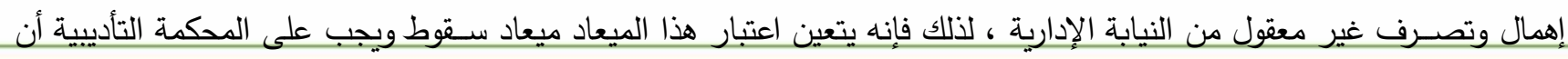
تقضي باه من تلقاء نفسها .... " . . . . = راجع حكم المحكمة الإدارية العليا في الطعن رقم 28714 لسنة 60ق.ع ع ، بجلسة 2019/6/15 حكم غير منشور • • (203) حكم غير منشور حمثم (204) • (204) حكم غير منشور 


\section{الوسائل المستحدثة}

للفصل في الدعاوى الإدارية خلال مدة معقولة في النظام القانوني الفرنسي خدادي مداري

\section{شعبان أحمد رمضنان}

التحقيق في هذه الجرائم نهائية ، وإنما نظم نوعًا من التعقيب عليها لرئيس الجهاز المركزي للمحاســبات ، فأوجب في القانون رقم 144 لســنة 1988 على الجهات الإدارية إخطار الجهاز المركزي للمحاسـبات بجميع القرارات الصــادرة منها في شـأن المخالفات المالية التي وقعت فيها ، وأعطى رئيس الجهاز المركزي للمحاسبات حق طلب تقديم العامل إلى المحاكمة التأديبية خلال ثلاثين يوماً من تاريخ ورود الأوراق كاملة إليه ، وأوجب على النيابة الإدارية باعتبارها

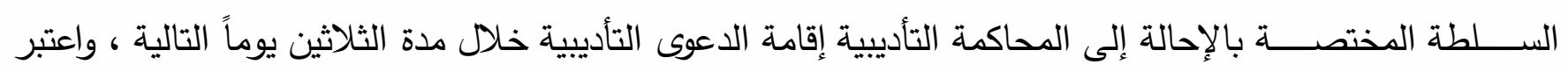
المشـرع العامل محالاً للمحاكمة التأديبية من تاريخ طلب رئيس الجهاز المركزي للمحاسـبات من النيابة الإدارية إقامة الدعوى التأديبية ضده ، ورتب على هذه الإحالة عدم جواز قبول استقالة الموظف المحال إلى المحاكمة التأديبية وعدم جواز ترقيته .

وتابعت المحكمة قائلة " وحيث إن الحكمة التي تغياها المشــرع من جعل الميعاد المقرر لرئيس الجهاز المركزي للمحاسبات هو ميعاد سقوط ، يُسقط حق الجهاز المركزي للمحاسبات في الاعتراض على قرار الجزاء بفواته

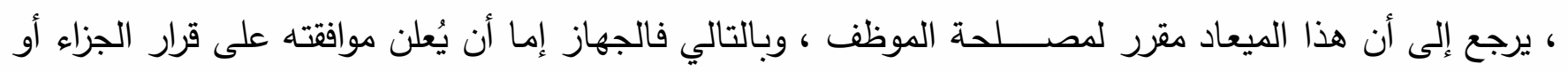

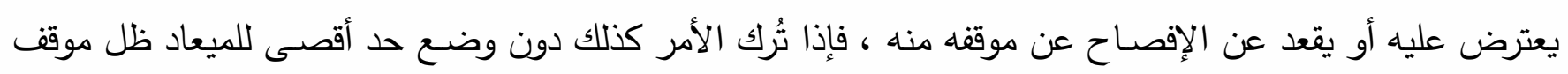

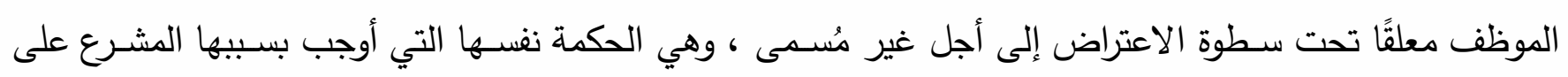

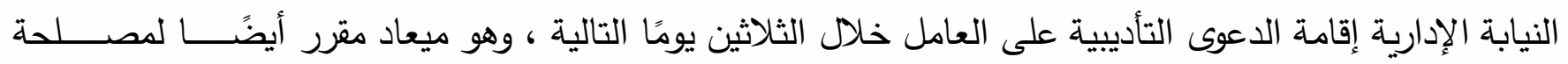
الموظف ، حتى لا يظل سيف الاتهام مسلطًا على متهم الأصل فيه البراءة ، وحتى لا يجمد وضعه الوظيفي فلا تُبَل

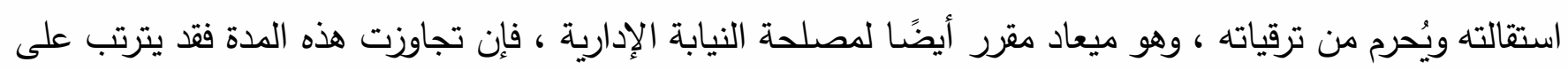

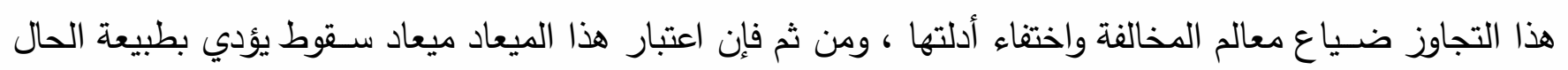
إلى اسـتقرار الوضـع الوظيفي للعاملين ، عكس الحال لو ظلوا مهددين أزمانًا طويلة بشـبح الاتهام ، مما ينعكس أثره في مصــلحة العمل وحسـن ســيره ، فضـــلاً عن أن مرور الثلاثين يومًا دون إقامة الدعوى التأديبية ينم عن إهمال وتصـرف غير معقول من النيابة الإدارية ، لذلك فإنه يتعين اعتبار هذا الميعاد ميعاد سـقوط ، ويجب على المحكمة التأديبية أن تقضي به من تلقاء نفسها ...

وأردفت المحكمة قائلة ... " ومن حيث إنـه وترتيبًا على مـا تقدم ولما كان الثابت من الأوراق أن النيابة الإدارية انتهت في قضـيتها رقم 189 لسـنة 2009 إلى التوجيه بمجازاة الطاعنة إداريًا فصـدر القرار رقم 269 لسـنة 2010 بمجازاتها بعقوبة الإنذار واخطر الجهاز المركزي للمحاســبات بذلك بتاريخ 2010/11/1 فاعترض رئيس 
الجهاز على هذا القرار بتاريخ 2010/11/28 وطلب من النيابة الإدارية إحالة الطاعنة وآخرين للدحاكمة التأديبية بتاريخ 2010/11/29 ومن ثم كان يتعين على النيابة الإدارية إحالة الطاعنة للمحاكمة التأديبية في موعد أقصـــاه 2010/12/28 ، وإذا أقامت دعواها رقم 86 لسنة 53 ق أمام المحكمة التأديبية لمستوى الإدارة العليا بإحالة الطاعنة وآخرين للمحاكمة التأديبية والصـادر فيها الحكم الطعين بتاريخ 2011/5/19 فمن ثم يكون قد سـط حقها في إقامة هذه الدعوى ، وإذ لم ينتهي الحكم الطعين إلى ذلك ، ودلف إلى موضـــوع الدعوى وما نســب إلى الطاعنة قاضــيًا بمجازاتها بخصم أجر شهر من راتبها فيكون قد صدر على غير سند يبرره مخالفًا لصحيح حكم القانون جديرًا بإلغائه فيما قضى به من مُجازة الطاعنة بخصم أجر شهر من راتبها والقضاء بعدم قبول الدعوى التأديبية " (205). وقد انتهت الإدارية العليا إلى الحكم بإلغاء حكم المحكمة التأديبية للأسباب التي أوردتها وأخصـها إقامتها من قِبلْ النيابة الإدارية بعد المواعيد المحددة لإقامتها بحسـبانها من مواعيد السـوط المقررة لمصـلحة الموظف العام على لــ النحو الذي يستوجب سـرعة إقامة الدعوى التأديبية حتى لا يظل وضـعه الوظيفي مهددًا بعدم الاسـتقرار إعمالاً لمبدأ العدالة الناجزة في مجال المحاكمات التأديبية .

وقد عادت المحكمة الإدارية وأكدت قضـاءها السـابق بعديد من أحكامها ومن بينها حكمها في الطعنين رقمي 29413 ، 29415 لسنة 60 قضائية عليا بجلسة 23 مارس 2019 (206). وحكمها في الطعن رقم 31422 لسنة 54 قضائية عليا بجلسة 18 مايو 2019 (207). وصـفوة القول أنه " يسـتخلص من أحكام المحكمة الإدارية العليا سـالفة الذكر تبنيها سـياسـة قضـائية مفادها تكريس العدالة الناجزة في مجال المحاكمات التأديبية عبر تفسيرها للنصـوص القانونية المتعلقة بمواعيد إقامة الدعوى التأديبية سـواء بطلب من رئيس الجهاز المركزي للمحاسـبات حال اعتراضـهـ على قرارات الجزاءات التأديبية الصـادرة بثـأن المخالفات المالية خلال ثلاثين يوماً من إخطاره بذلك ، أو تلك المحدة للنيابة الإدارية لإقامة الدعوى التأديبية خلالها - الثثلاثون يومًا التالية لطلب الجهاز المركزي - مُكيفة إياها على أنها مواعيد سقوط مقررة لمصلحة الموظف العام كضمانة له حتى لا يظل سيف الاتهام مسلطًا عليه لفترة طويلة ، وحتى يستقر وضـعه الوظيفي ، فضـلاً عن

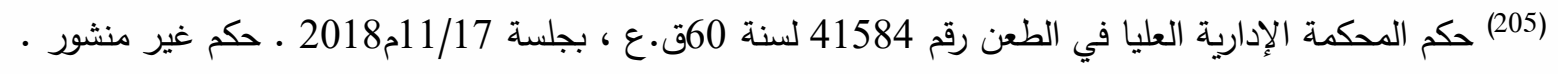

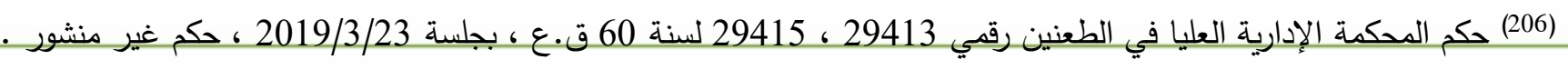

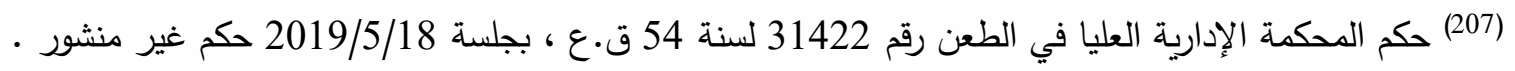




\section{الوسائل المستحدثة}

للفصل في الاعاوى الإدارية خلال مدة معقولة في النظام

القانوني الفرنسي

مصلحة العمل الإداري وحسن سيره على النحو الذي يقتضي سرعة إقامة الدعوى التأديبية والفصل فيها ، وهو بلاشك اتجاه محمود يصب في اتجاه تحقيق وتكريس العدالة الناجزة في المجال التأديبي • المطلب الثانى

إعفاء هيئة مفوضى الدولة من إعداد تقرير برأيها فى بعض الدعاوى الإدارية

تعد هيئة مفوضي الدولة أحد أعمدة القسم القضائى بمجلس الدولة المصري منذ صدور قانون المجلس الثانى رقم 165 لسنة 1955 , وما تلاه من قوانين لاحقه حتى صدور القانون الحالي رقم 47 لسنة 1972م , وقد أوضحت المذكرة الإيضـــاحية للقانون رقم 165 لســنـة 1952 دور الهيئة فى جملة أمور أظهرها ما يتعلق بتقديم معاونة فنية للمحكمة المختصـة تتعلق بتمحيص القضايا الإدارية تمحيصاً يضـئ ما أظلم من جوانبها ويجلو ما غمض من دقائقها برأي تتمثل فيه الحيدة لصـالح القانون وحده (208) عبر ما تضــعه من تقرير برأيها القانوني بشـأن موضـوع الدعوى الإدارية .

وطبقاً لنصــوص المواد 27 , 28 , 29 من قانون مجلس الدولة , وكذلك ما اســتقرت عليه أحكام المحكمة الإدارية العليا فإن إيداع تقرير هيئة المفوضـين قبل نظر موضـوع الدعوى يُعدُ إجراءً جوهرياً من النظام العام لأن من شان إيداعه أن تتاح الفرصه لطرفي الخصومة القضائية للتعقيب على ما ورد به من وقائع ومن رأي على النحو الذى تســتجلى منه المحكمة عناصــر المنازعة من جانبيها المادي والقانوني. الأمر الذى يجعل من إيداع هذا التقرير أحد مفترضـــات ومرتكزات طبيعة المنازعة الإدارية , والأسـسس التتظيمية التى تقوم عليها قواعد الإجراءات الإدارية أمام محاكم مجلس الدولة وكلها أمور تتعلق بالنظام العام للقضــاء الإداري لما يوفره من ضـمانة جوهريـا لصـالح طرفى المنازعة الإدارية أمام القضـاء الإدارى لتحقيق مرحلة تحضـيرها وتهيئتها للفصـل فيها بحيث يترتب على القضـاء فى موضـوع النزاع دون إيداع هذا التقرير بطلان الحكم لإهداره حق الدفاع لطرفى الخصـومة , فضـلاً عن مخالفته للنظام العام القضائى (209) .

(208) د. محمد فوزي نوبجي , القضـاء الإداري , المرجع السـابق , ص272, المستشـار / وليد محمود ندا , سلطات مفوضسى الدولة فى

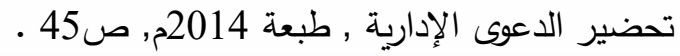

(209) حكم المحكمة الإدارية العليا فى الطعن رقم 4407 لسنة 45 ق. ع بجلسة 2002/2/16, وحكمها فى الطعن رقم 3057 لسنة 52 ق ع بجلسة 2005/11/18 مشار إليهما فى مؤلف المستشار / وليد محمود ندا , المرجع السابق ,صن4- 45- 48. 


\section{شعبان أحمد رمضنان}

وإذا كان الأصل المسلم به هو ضرورة قيام هيئة مفوضى الدولة أمام محاكم القسم القضائي بمجلس الدولة بإسـتثناء الدعاوى التأديبية - بإيداع تقرير برأيها القانوني فى موضـوع الدعوى الإدارية تمهيداً للفصل فيها على النحو

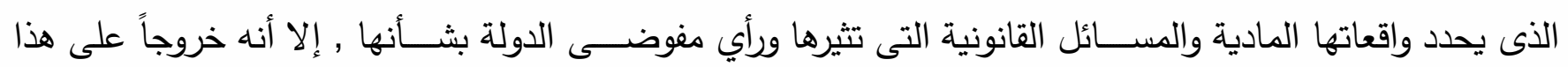

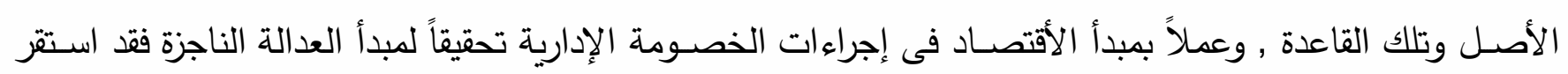
قضاء المحكمة الإدارية العليا على استثناء منازعات وقف تتفيذ القرارات والأحكام الإدارية من ضرورة إيداع تقرير من قبل هيئة المفوضين بشأنها , كما خرج المشرع المصري على هذا الأصل بدوره فى بعض القوانين المنظمة للإنتخابات الرئاسية والبرلمانية والمحلية كقانون مباشرة الحقوق السياسية رقم 45 لسنة 2014م , وقانون مجلس النواب رقم 46 لسـنة 2014م , وقانون الهيئة الوطنية للإنتخابات رقم 198 لسـنة 2017م (210) , وهو الاتجاه الذى باركته المحكمة الإداريـة العليا بأحكامها المتواترة بثـــان الطعون الانتخابية وهو مـا نوجزه فى فرعين يتعلق أولاهما بإعفاء هيئة المفوضــين من إعداد تقرير فى طلبات وقف تتفيذ القرارات الإدارية المطعون عليها بالإلغاء , ويتعلق الآخر بإعفائها من إعداد تقرير بشان الطعون الإنتخابية .

الفرع الأول : إعفاء هيئة المفوضـــين من إعداد تقرير فى طلبـات وقف تنفيذ القرار ات الإداريـة المطعون عليها

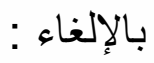

سـلك القضـاء الإداري المصـرى وعلى قمته المحكمة الإدارية العليا مسـلكاً يتفق وطبيعة الفصـل فى طلبات وقف تنفيذ القرارات الإدارية المطعون عليها بالإلغاء مفاده عدم إستلزام تحضير تلكم الطلبات من قبل هيئة المفوضين

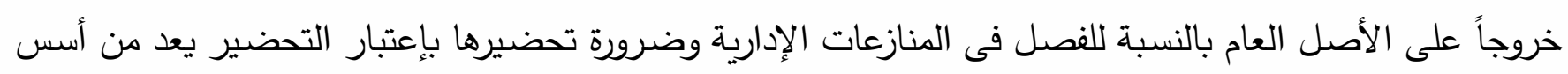
النظام العام للقضاء الإداري وأحد أهم قواعد الإجراءات الإدارية أمام محاكم مجلس الدولة .

وقد شيدت المحكمة الإدارية العليا مسكلها بهذا الصدد على حجة مفادها أن إجراء تحضير الدعوى من قبل هيئة المفوضـين وما قد يسـتغرقه من وقت قد يطول لا يتناسـب والطابع الخاص لطلبات وقف التنفيذ ذات الطبيعة العاجلة على النحو الذي يبرر إمكانية الفصـل فى تلك الطلبات دون إبــلزام إجراءات التحضــير إدراكاً لطبيعتها , وصـحيح النظر فى شـأنها. ذلك أن اسـتلزم إجراءات التحضـير بالنسـبة لطلب وقف التنفيذ يخالف طبيعته , ويفوت إتى غايته ويهدر ظروف الاستعجال وهى قوامه ومبرره(211).

راجع ما سبق بالطلب الثاني من المبحث الأول من هذا الفصل. (211) حكم المحكمة الإدارية العليا فى الطعن رقم 2170 لسـنة 29 ق •ع. بجلســـ 1987/3/21م , وحكمها فى الطعن رقم 270 لسـنة 


\section{الوسائل المستحدثة}

للفصل في الدعاوى الإدارية خلال مدة معقولة في النظام

القانوني الفرنسي

\section{شُبان أحمد رمضنان}

وقد تواترت أحكام المحكمة الإدارية العليا على اســتثناء طلبات وقف التنفيذ من إجراء تحضــيرها من جانب هيئة المفوضــين إعمالاً لمبدأ الاقتصــاد فى الخصــومة الإدارية , وتحقيقاً لفكرة العدالة الناجزة فى تلكم النوعية من المنازعات مراعاة لطبيعتها العاجلة , ومن ذلك حكمها فى الطعن رقم 950 لسـنة 35 قضـائية عليا , بجلسـة 12 من أكتوبر 1994 , وحكمها فى الطعن رقم 4449 لســنة 38 قضـــائية عليا , بجلســة 20 يونيه 1996 ,وحكمها فى الطعن رقم 2917 لسـنة 40 قضـائية عليا بجلسـة 4 ديسـمبر 2004(212) ـ وحكمها فى الطعن رقم 19668 لسـنة 61 قضــائية عليا , بجلســة 23 مارس 2019 والذي جاء بأحد أسـبابه فيما نحن بصـدده ....أن إيداع تقرير هيئة مفوضي الدولة قبل النظر فى موضوع الدعوي هو إجراء جوهري من النظام العام , لأن من شأن إيداع هذا التقرير أن تتاح الفرصة لطرفي الخصومة القضائية فى أن يعقبا على ما ورد به من وقائع ومن رأي قانوني من شأنه أن تستجلي به المحكمة بصــورة أدق مختلف عناصــر المنازعة من جانبها الواقعي والقانوني , الأمر الذي يجعل من إيداع تقرير هيئة مفوضـي الدولة أمر تفرضــه طبيعة المنازعات الإدارية التي تختص بها محاكم مجلس الدولة ويعد من الأسـس التظظيمية الرئيسـية التي يقوم عليها قواعد إجراءات نظر الدعاوي المذكورة والفصــل فيها وهي أمور كلها من النظام العام للقضاء الإداري , وعلى هذا المقتضي فإن الإخلال بهذا الإجراء الجوهرى يترتب عليه بطلان الحكم الذى يصدر فى الدعوى • ولا ينال من ذلك ما جرى به قضاء هذه المحكمة استثناء عن عدم التقيد بهذا الأصل إذا كانت المحكمة بصدد بحث طلب عاجل بوقف تتفيذ قرار مطلوب إلغاؤه , لأن مناط إعمال الاستثناء ألا تتجاوز المحكمة طلب وقف التنفيذ إلى الفصـل فى موضـوع الاعوى بحكم منه للخصـومة فيها , إذ يتعين عليها فى هذه الحالة الإلتزام بالأصـل العام المشار إليه وإلا وقع حكمها باطلاً....." (213)

الفرع الثاني : إعفاء هيئة المفوضين من إعداد تقرير بشأن الفصل فى الطعون الإنتخابية: تعد الطعون الانتخابية أحد أبرز تطبيقات مبدأ العدالة الناجزة السـريعة فى قضـــاء مجلس الدولة المصــري وعلى قمته المحكمة الإداريـة العليا نظراً للطبيعة الخاصـــة لتلك النوعية من الدعاوى , وهو الأمر الذي تبناه المشـرع

$$
32 \text { ق • ع , بجلسة 1989/6/24م. }
$$

= مشار إليهما فى د. عبد العزيز عبد المنعم خليفة , قضاء الأمور الإدارية المستعجلة , منشأة المعارف بالإسكندرية , طبعة سنة 2006

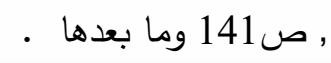
(212) مجموعة المبادئ التي قررتها المحكمة الإدارية العليا فى ربع قرن , الفترة من 1991/10/1 إلي 2016/9/30 , مجموعة المكتب

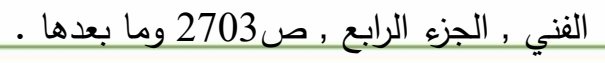
(213) حكم المحكمة الإدارية العليا فى الطعن رقم 19668 لسنة 61 ق •ع بجلسة 2019/3/23 ـ غير منشور . 
المصري عقب صدور الدستور الحالي لعام 2014م فى عدة قوانين أهمها قانون مجلس النواب لعام 2014م , وقانون مباشرة الحقوق السياسية عقب تعديله عام 2014م وقانون الهيئة الوطنية للانتخابات لعام 2017(214) والتى تضنيت جميعها نصوصاً صريحة بشأن الفصل فى الطعون الاتتابية على وجه السرعة , ودون إستلزام عرض الطعن على هيئة المفوضين لإعداد تقرير بشأنه .

والحقيقه أن المتتبع للإتجاهات الحديثة للمحكمة الأدارية العليا بشان الدعاوى والطعون الاتتابية يجد أنها قد أتجهت صــوب الإكتفاء بإبداء مفوض الدولة رأيه شـفاهة بصـددها فى جلســة المرافعة , مع إثبات ذلك فى محضـر الجلسة , دون إستلزام إيداع تقرير مكتوب , حتي قبل التعديلات التى تم إدخالها على قانونى مباشرة الحقوق السياسية ومجلس النواب , وكذا قبل صــدور قانون الهيئة الوطنية للإنتخابات , وهو بلا ريب اتجاه محمود يصــب في اتجاه تحقيق العدالة الناجزة , والفصل فى تلكم النوعية من الدعاوى والطعون خلال أجل قصير مراعاة لطبيعتها الخاصة . ومن أحكام المحكمة الإدارية العليا بهذا الخصـوص حكمها فى الدعوى رقم 2716 لسـنـة 28 قضـائية عليا بجلســــة 10 ديســـبر 2011م والذى جاء بصـــدـهـ فى وقائع الحكم أنه تم إيداع تقرير الطعن بثـــأنه بتاريخ 2011/11/17م , وتم تحديد جلســ 2011/11/21م لنظره , وفيها مثل طرفا الخصــومة وأبدى كل منهما دفاعه ,

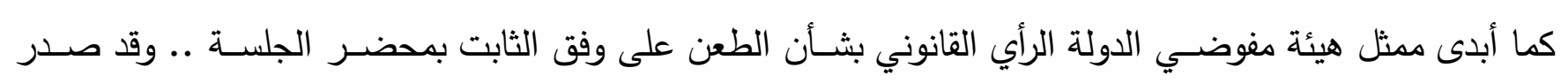
الحكم فيه بجلسة 10 ديسمبر 2011م (215) حيث لم يستغرق الفصل فيه سوى ثلاثة وعشرون يوماً من تاريخ إيداع الطعن , وكذلك حكمها فى الدعوى رقم 3420 لسـنة 58 قضـائية عليا , بجلسـة 24 ديسـمبر 2011م والذى جاء كذلك بواقعاته أنه بتاريخ 2011/11/24م تم إيداع تقرير الطعن المذكور حيث تم تحديد جلسـة 2011/12/3م لنظره أمام دائرة فحص الطعون , وفيها مثل طرفا الخصــومة وأبدى كل منهما دفاعه , وأبدى ممثل هيئة مفوضـــي الدولة

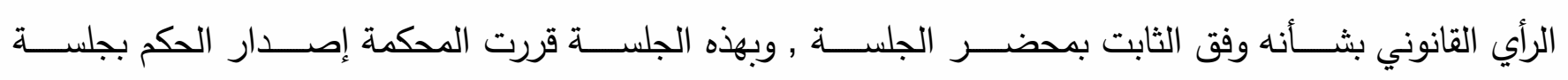

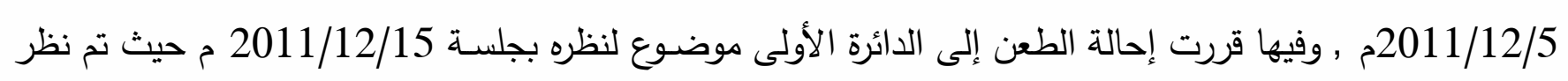
الطعن أمامها على النحو المبين بمضر هذه اللجسة , وفيها قررت المحكمة إصدار الحكم بجلسة 2011/12/24م

(214) (214) راجع ما سبق بالمطلب الثانى من المبحث الأول من هذا الفصل . (215) راجع هذا الحكم بدجموعة المبادئ القانونية التى قررتها المحكمة الإدارية العليا في شـأن الأحزاب السياسيـية والانتخابات الرئاسيـية والبرلمانية من أول يوليو 2011م إلى آخر ديسمبر 2016م , مجموعة الدكتب الفني , ص297. 


\section{الوسائل المستحدثة}

للفصل في الاعاوى الإدارية خلال مدة معقولة في النظام

القانوني الفرنسي

\section{شعبان أحمد رمضنان}

والمستفاد من الحكم السابق أن الفصل فيه لم يستغرق سوى شهر من تاريخ إيداع تقرير الطعن حتى صدور

حكم الإدارية العليا بشأنه , وكذلك إبداء مفوض الدولة لرأيه شفاهة بمحضر الجلسة .

وقد سـارت المحكمة الإدارية العليا فى الاتجاه ذاته بأحكامها المتواترة بعد ذلك مكتفيه بإبداء هيئة مفوضــي

الدولة لرأيها القانوني فى موضوع الدعوى شفاهة فى جلسة المرافعة , فضلاً عن فصل الدحكمة فى الدعوى على نحو لهو سريع فى غضون مدة لا تجاوز خمسة عشر يوماً من تاريخ إيداع تقرير الطعن قلم كتاب المحكمة , ومن ذلك حكمها فى الدعوى رقم 109886 لسـنة 61 قضـائية عليا بجلسـة 7 أكتوبر 2015م والتى تم إيداع تقرير الطعن بثـأنها قلم

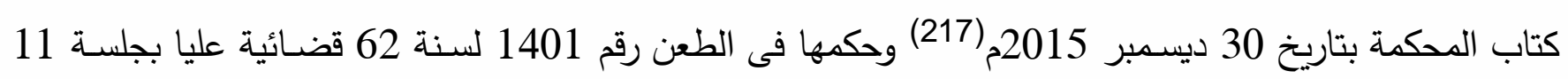
أكتوبر 2015م(218) , وحكمها فى الطعن رقم 45521لسنة 61 قضائية عليا بجلسـة 10 أبريل 2016م , والذى تم إيداع تقرير الطعن بثـــأنه بتاريخ 29 مارس 2016م , وقد جاء ببعض فقرات هذا الحكم المتعلقة بواقعاته أن ممثل هيئة مفوضي الدولة قد أبدى رأيه القانوني فى الطعن أثناء تداول نظره أمام دائرة فحص الطعون(219) .

وجملة القول أن المشرع المصـري , مؤيداً فى ذلك بما أستقرت عليه أحكام المحكمة الإدارية العليا , قد تبنى ســياســـة تثــريعية مفادها الاقتصـــاد فى إجراءات بعض الدعاوى والطعون الإدارية , كالدعاوى التأديبية والطعون الاتتخابية , تحقيقاً لمبدأ العدالة الناجزة على النحو الذي يكفل الفصــلـل فى تلك النوعية من الدعاوى والطعون خلال مدة معقولة ـ وهو بلا ريب اتجاه محمود يتطلب مزيداً من التوسع فيه بشأن بعض الدعاوى الإدارية الآخرى من خلال تبنى المشـرع لبعض الوسـائل التى اسـتحدثها المشـرع الفرنسى بتقنين العدالة الإدارية كالأخذ بنظام الدوائر الفردية , وحظر الطعن بالاســتئناف فى بعض الأحكام الإدارية , وهو ما نهيب بالمشــرع المصــري أن يحذو حذوه وصـــلاً للترضية القضائية التى يتغياها رافع الدعوى على نحو سريع بإعتبارها غاية الحق فى التقاضى ولُحمة سَداه .

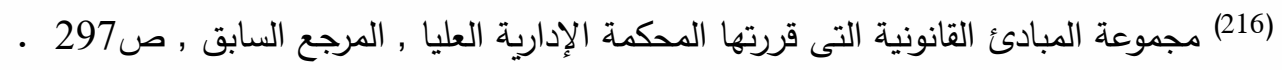
(217) راجع هذا الحكم بمجموعة المبادئ القانونية التى قررتها المحكمة الإدارية العليا فى شـأن الأحزاب السـياسية ولية والانتخابات الرئاسـية

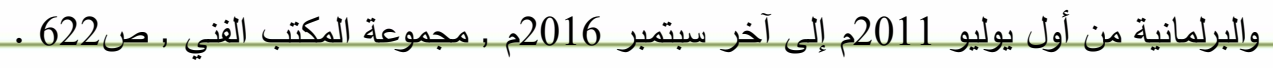

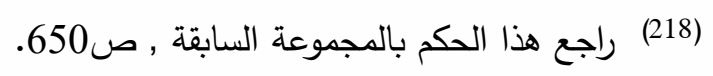

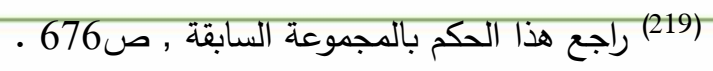




\section{الوسائل المستحدثة}

للفصل في الدعاوى الإدارية خلال مدة معقولة في النظام القانوني الفرنسي ملارك

\section{شعبان أحمد رمضنان}

\section{خاتمــة وتوصيــات}

تناولت الدراســة الماثلة موضــوع " الوســائل المسـتحدثة للفصـل فى الدعاوى الإدارية خلال مدة معقولة فى النظام القانوني الفرسي " وقد قسمنا دراستنا لهذا الموضوع لثلاثة فصول عرضنا فى الأول منها للفصل فى الدعاوى الإدارية خلال مدة معقولة فى النظام القانوني الفرنسـي من خلال التصــدي لتأصــيل فكرة العدالة الناجزة فى مجال المنازعات الإدارية عبر تحديد الأساس القانوني للمدة المعقولة اللازمة للفصل فى الدعاوى الإدارية فى النظام القانوني الفرنسي فى مبحث أول , ومضمون تلك المدة ومعايير تحديدها فى مبحث آخر .

وتتاولنا فى الفصـل الثانى وسـائل الفصـل فى بعض الدعاوى الإدارية خلال مدة معقولة طبقاً لتقنين العدالة الإدارية الفرنسـي وتعديلاته المختلفة بهذا الخصـوص حيث عرضــنا لأبرز تلكم الوسـائل والمتمثلة فى إعفاء المقرر

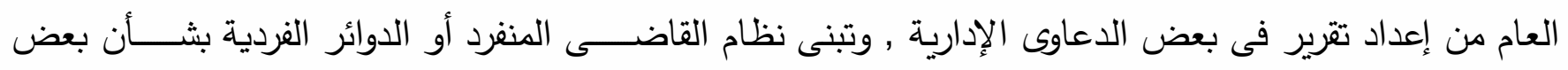

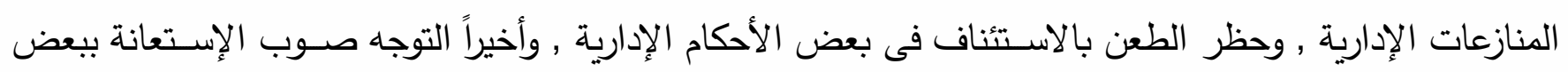
وسائل التقاضى الإكترونى فى مجال الدعاوى والطعون الإدارية وذلك فى أربعة مباحث على التوالي • وفى الفصـل الثالث والأخير تصـدينا لبيان مدى اعتناق القضـاء الإداري المصـرى لمبدأ الفصـل فى الدعاوى

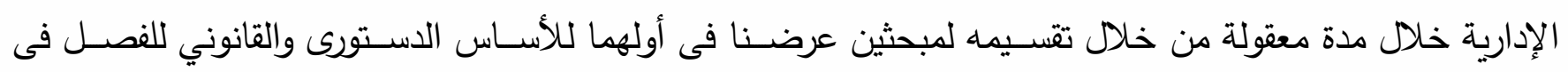
الدعاوى الإدارية خلال مدة معقولة فى النظام القانوني الدصــى , وكرســنا الآخر لأبرز تطبيقات القضــاء الإداري

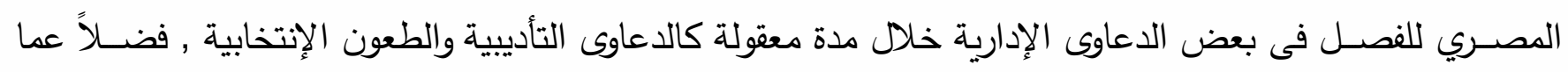
تبنته المحكمة الإدارية العليا بشأن الإكتفاء بإبداء هيئة مفوضى الدولة لرأيها شفاهة فى جلسة المرافعة بشأن موضوع الدعوى دون تطلب تقرير مكتوب بهذا الخصــوص , وهو الاتجاه الذى باركه وإعتنقه المشــرع المصــري فى بعض ترض التشريعات بعد صدور الدستور الحالى لعام 2014م وأبرزها قانون مباشرة الحقوق السياسية , وقانون مجلس النواب , وقانون الهيئة الوطنية للأنتخابات . لعدرئ وقد اسفرت الدراسة الماثلة عن عدد من النتائج والتوصيات يمكن إجمالها فيما يلى: أولا: نتائج الاراسة : 1_ــ أضحي الفصل فى المنازعات خلال مدة معقولة فى النظام القانوني الفرنسي أحد الحقوق ذات القيمة الدستورية على إثر صدور قرار المجلس الدستوري رقم 510 لسنة 2004 بتاريخ 20 يناير 2005 الذى أضفي عليه تلك 


\section{الوسائل المستحدثة}

للفصل في الدعاوى الإدارية خلال مدة معقولة في النظام القانوني الفرنسي ملارك

\section{شعبان أحمد رمضنان}

القيمة .

2ــــ أقر المشرع الفرنسي عبر تعديله لتقنين العدالة الإدارية بموجب المرسوم رقم 2005/911 بحق المتقاضين فى

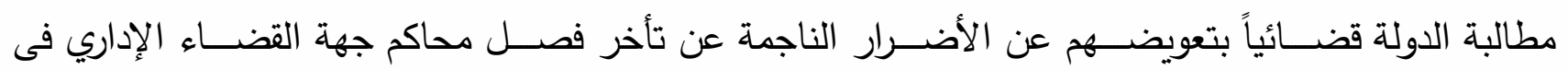
منازعاتهم الإدارية خلال مدة معقولة مع تخويله لمجلس الدولة اختصاصاً منفرداً بالفصل فى تلكم الدعاوى. 3ـ اعتناق المشرع الفرنسي لنظام القاضي المنفرد " الدوائر الفردية" للفصل فى بعض الدعاوى الإدارية , خلافاً للأصل العام فى تشكيل محاكم جهة القضاء الإدارى , اسفر إلى حد كبير طبقاً للإحصاءات الواردة بتقارير مجلس الدولة السنوية إلى تقصير أمد الفصل فى تلك المنازعات على النحو الذى يصب فى خانة تحقيق العدالة الناجزة الجيدة , وهو ما ينطبق كذلك على تبنيه لنظام حظر الطعن بالاســتئناف فى بعض الأحكام الإدارية , وإعفاء المقرر العام من إعداد تقرير فى بعض الدعاوى الإدارية .

4. عدم إعتناق القضاء المصري بجناحيه العادى والإدارى لمبدأ الفصل فى الدعاوى خلال مدة معقولة كأحد مفترضات

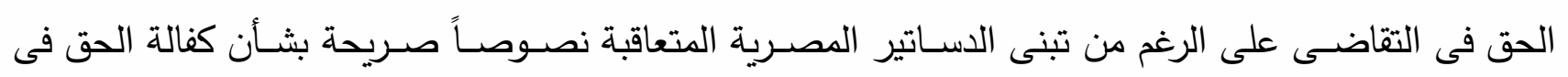
التقاضى وسرعة الفصل فى القضايا . 5. إضفاء المحكمة الدستورية العليا الطبيعة الدستورية على الحق فى محاكمة سريعة - أى الحق فى الفصل فى النزاع خلال مدة معقولة - لاسيـيا فى المجال الجنائي تحقيقاً للعدالة الناجزة , وفى غير المجال الجنائي حماية للحقوق والحريات التى يكفلها الدستور باعتبار الترضية القضائية الناجزة هي الغاية التي يرنو إليها رافع الدعوى.

6_ تبنى المشرع المصرى فى عدد من التشريعات فى مجال القانون العام - بعد صدور الدستور الحالى لعام 2014 - لفلسفة الفصل فى بعض الدعاوى والطعون الإدارية على نحو سريع مراعاة لطبيعتها الخاصة , ومن أبرز تلكم التشريعات قانون مباشرة الحقوق السياسية , وقانون مجلس النواب , وقانون الهيئة الوطنية للإنتخابات .

ثانيا: التوصيات:

1ـ نهيب بالمشرع المصري سرعة التدخل لتعديل قانون مجلس الدولة أو سن قانون تنظيم إجراءات التقاضى أمام جهة القضـاء الإدارى والذى طال إنتظاره لما يربو على نصف قرن على نحو يكفل بشكل صـريح الفصـل فى الدعاوى الإدارية خلال مدة معقولة من خلال تبسـيطه لإجراءات القاضـي , وتبنيه لبعض الوسـائل التى اسـتحدثها نظيره 


\section{شعبان أحمد رمضان}

الفرنسي بهذا الخصوص مثل نظام القاضي المنفرد , وحظر الطعن بالاستئناف فى بعض الاحكام الإدارية وإعفاء

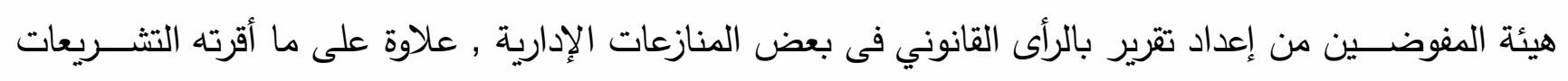
المنظمة للإنتخابات الرئاسية والنيابية.

2- نهيب بقضائنا الإداري , وعلى قمته المحكمة الإدارية العليا , أخذ زمام المبادرة بإرساء مبدأ الفصل فى الدعاوى والطعون الإدارية خلال مدة معقولة عملاً بنص المادة 97 من الدســتور الراهن لعام 2014م , كما نناشـــــها بالتوسع فى تبسيط إجراءات الخصومة تحقيقاً للعدالة الناجزة .

3ـ نهيب بالمحكمة الإدارية العليا التوجه صوب إرساء مبدأ مسئوولية الدولة عن تعويض المتقاضين عما يحيق بهم من اضــرار جراء تأخر محاكم جهة القضـاء الإدارى فى الفصـل فى بعض الدعاوى الإدارية على نحو غير مبرر ومتجاوز فيه , مع وضـعها لضـوابط تلك المسئوولية على نحو ما فعل مجلس الدولة الفرنسي بحكمه التاريخي فى قضــية Magiera وما تلاه من أحكام تصــب فى معينه باعتبار الفصـل فى الدعاوى خلال مدة معقولة يعد أحد المبادئ العامة الحاكمة لسير مرفق القضاء الإدارى , بل وأحد المبادئ الدستورية طبقاً للنظام الدستوري المصري. والله من وراء القصد وهو يهذي السبيل , ,, 


\section{الوسائل المستحدثة}

للفصل في الدعاوى الإدارية خلال مدة معقولة في النظام

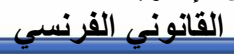

قائمــة المر اجـع

\section{شعبان أحمد رمضنان}

\section{أولاً - باللغة العربية: \\ (أ) - مؤلفات عامة ومتخصصة:}

1- د. أبو الوفا محمد أبو الوفا ، التنظيم القضائي ودور النيابة العامة في تحقيق العدالة الجنائية و الناجزة في القانون

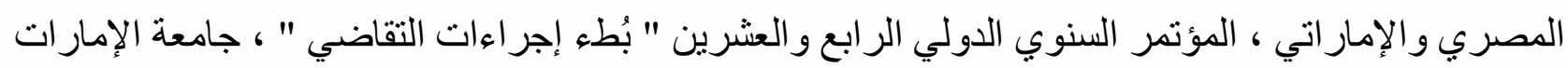

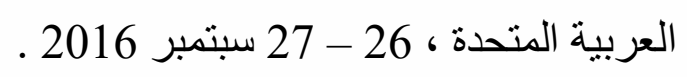

2- دـ. أحمد أبو الوفا ، القانون الدولي ، دار النهضة العربية ـ القاهرة ، الطبعة الرابعة ، سنة 2004 ـ 2010

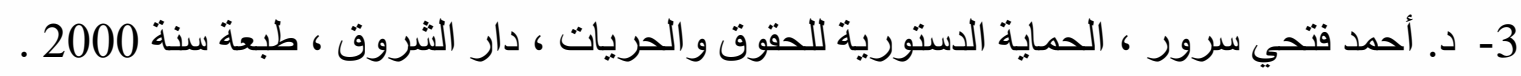

4- د. أسعد فاضل منديل ، التقاضي عن بُعد ، مجلة الكوفة للعلوم القانونية و السياسية ، المجلد الأول - العدد 21 ، سنة 2014 .

5- د. إسلام إبر اهيم شيحا ، الحق في محاكمة خلال مدة زمنية معقولة بين التأصيل و التفعيل ، مجلة الحقوق للبحوث

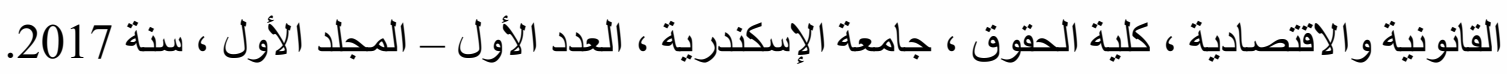

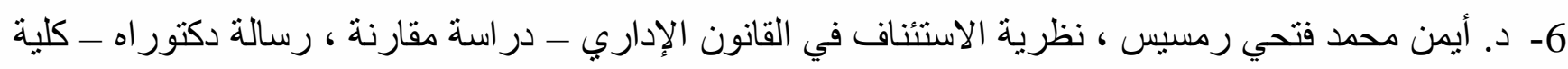
الحقوق - جامعة عين شمس ، سنة 2012 .

7- د. جرجس إسحاق ، نظام مفوض الدولة في مصر ، رسالة دكتور اه - كلية الحقوق - جامعة القاهرة ، سنة 2000

8- د. خالد ممدوح إبر اهيم ، الدعوى الإلكترونية و إجر اءاتها أمام المحاكم ، دار الفكر الجامعي ـ الإسكندرية ، طبعة سنة 2008 .

9- د. سيد أحمد محمود ، دور الحاسب الإكتروني أمام القضاء ، دار النهضة العربية ـ طبعة سنة 2008 ـ

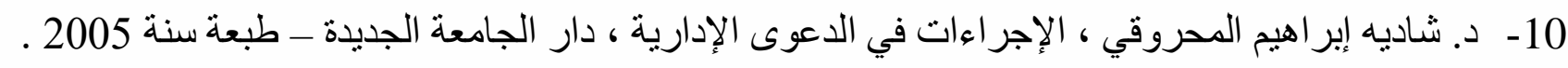

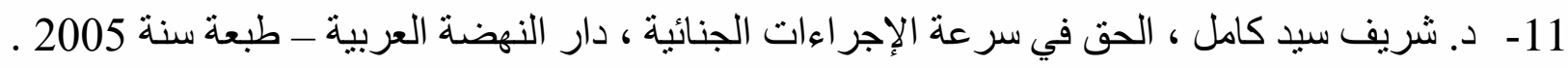
12- د. صفاء أوتاني ، المحكمة الإلكترونية " المفهوم و التطبيق " ، مجلة جامعة دمشق اللعلوم الاقتصادية و القانونية

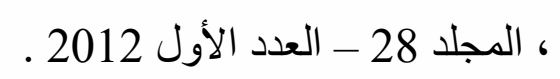

13- د. عبد الناصر علي عثمان ، استقلال القضاء الإداري ـ دراسة مقارنة ، دار النهضة العربية ، طبعة سنة

.2008

14- د. غنام محمد غنام ، حق المتهم في محاكمة سريعة ، دار النهضة العربية ، طبعة سنة 2002 ـ 2008 . 15- د. فتحية محمد قواري ، ضو ابط المحاكمة الجنائية خلال مدة معقولة ـ دراسة مقارنة ـ ، مجلة الاجتهاد 


\section{الوسائل المستحدثة}

للفصل في الاعاوى الإدارية خلال مدة معقولة في النظام القانوني الفرنسي خداري

\section{شعبان أحمد رمضنان}

القضائي ، جامعة محمد خيضر - بسكرة - الجزائر ، العدد 13 ، ديسمبر 2016 ـ

16- د. لقمان عمر حسين ، الاختصاصات الدستورية لإبر ام المعاهدات في الدولة الفيدر الية ـ در اسة تحليلية مقارنة

$$
\text { ، مكتبة زين - بيروت ، طبعة } 2016 .
$$

17- د. ليلى عصماني ، نظام التقاضي الإكتروني آلية لانجاح الخطط التنموية ، مجلة المفكر ، كلبة الحقوق و العلوم

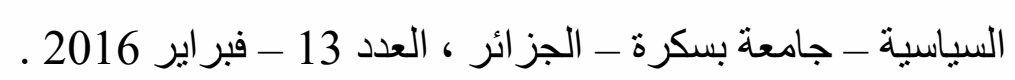

18- د. مجدي عبد الحميد شعيب ، آليات تمكين القضاء الإداري من الفصل في المناز عات في مدة معقولة تطور

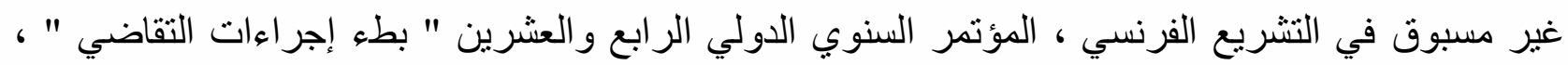

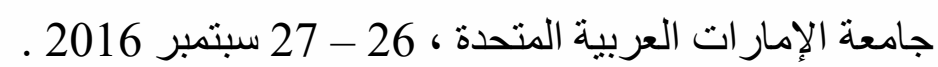
= الدور الإجرائي للمفوض في الدعوى الإدارية دراسة مقارنة بين النظامين المصري والفرنسي، بحثث منشور

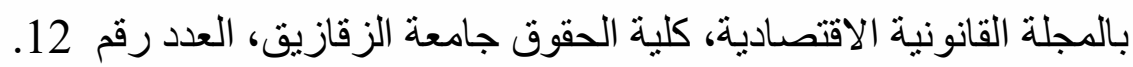
19- د. محمد باهي أبو يونس ، الحماية القضائية المستعجلة للحرية الأساسية ، دار الجامعة الجدية الجيدة - طبعة سنة .2015

20ـ د. محمد جابر محمد عبد العليم ، مفوض الدولة بين القضاء الإداري المصري و الفرنسي ، رسالة دكتور اه كلية الحقوق جامعة القاهرة ، سنة 2005 ـ

21- د. محمد فوزي نويجي ، القضاء الإداري ( مبدأ المشروعية ـ تنظيم مجلس الدولة ـ دعوى الإلغاء ) دار الفكر

$$
\text { و القانون - المنصورة ، طبعة سنة } 2016 .
$$

22- د. محمد محمد عبد اللطيف ، قانون القضاء الإداري ، الكتاب الأول ـ نظام القضاء الإداري ، دار النهضة

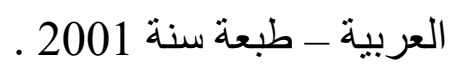

23- د. محمود سامي جمال الدين ، الوسيط في دعوى إلغاء القزارات الإدارية ، منشأة المعارف ـ الإسكندرية ،

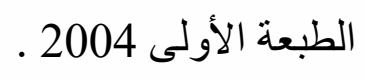

24- د. هادي حسين الكعبي ، جاسم محمد الكرعاوي ، " مفهوم التقاضي عن بُعد ومستلزماته " ، مجلة المحقق

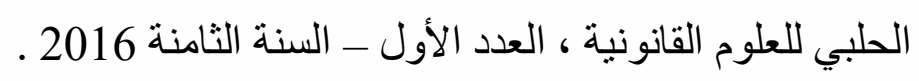

25- المستشار / وليد محمود ندا ، سلطات مفوض الدولة في تحضير الدعوى الإدارية ، بدون دار نشر ، طبعة سنة .2014

26- د. يوسف سيد سيد عو اض ، خصوصية القضاء عبر الوسائل الإلكترونية ، رسالة دكتور اة - كلية الحقوق جامعة عين شمس ، سنة 2012 ـ 


$$
\text { 3- 1- مجمو عة الموسو عة الحكام المحكمة الدستورية العليا. }
$$

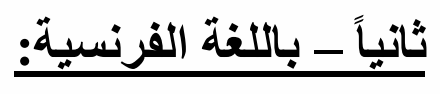

1- Anzil0ty (D.); Cours ds droit intermenational traduction français par Gidel. Paris 1926.

2- Auby (J.-M.) et Drago (R.) ; Traité de contentieaux administratif, T. 1, 2 ém. éd., L.G.D.J., 1975.

3- Boyer-Capelle (C.), Gestion des dossiers et qualité de la justice, La Revue française d'administration publique $\mathrm{n}^{\circ} 159,2016$.

4- Cassia (P.), " délai raisonable de jugement" in les Grands Arrets du contentieux Administrative, 3ém. éd., 2011

5- Chapus (R.); Droit du contentieux administratif, momtchrestien, 11 ém. éd., 2004.

$=$; Lecture du code de la justice administrative, R.F.D.Ad, 2000

6- Chevallier-Govers (C.), «Le président du tribunal administratif au secours de la célérité de la justice administrative », Gaz. Pa 1., 2000, D, pp. 1030-1047.

7- Corouge (E.); Le juge unique " Le contradictoire et les moyens relèves d'office " Gaz. Pal, 8 nov. 1997, no 311

8- Debbach (ch.); Contentieux administrative, Dalloze- paris, 1975

9- Delbez (L.); Les principes généraux de droit international public, 3ém. éd., 1964

10- De Guergue (M.); "Le double degré de juridiction " ; A.J.D.A., 2006.

11- De L'aubadere (A.); Venezia (CL.) ; Gaudement (Y.); Droit administratif. 17ém. éd., 
2002

12- Douchy-Oudot (M.), « Le souci d'efficacité de la justice, Propos introductifs », Gaz.

Pa 1., n²8,2004.

13- Drago (R.); Les cours administratives d' apple, R.F.D.A., no.. 2, 1988

14- Duverger (M.); Constitutions et Documents politiques, éd., P.U.F., 1987.

15- Fouletier (M.); La loi 30 juin 2000, relative devant le juridictions administrative, R.F.D.Ad. 2000 .

16- Forey (E.), «La dématérialisation de la justice et l'accès au juge », p. 456 s., in Donier Virginie, Lapérou-Scheneider Béatrice, L'accès au juge, Recherche sur l'effectivité d'un droit, Bruylant, 2013.

= «La visioconférence à l'épreuve du procès équitable », in « La visioconférence dans le prétoire », Les cahiers de la justice, $\mathrm{n}^{\circ}$ 2. 2011.

17- Gaia (P.), Ghevontian (R.) Melin - Soucramanien (F.), olive (E.), Roux (A.) ; Les Grandes Decision du conseil constitutionnel, ouvrage cree par favoreu (L.) et Philip (L.), 17 ém. éd. 2013

18- Garrido (L.); " La responsabilisation des acteurs du procés administratif : remède aux délais excessifs de jugement ou avatar ? ", Droit Administratif - Rev. mensuelle lexisnexis jurisclasseur, no 5, mai 2011, étude 9.

19- Gaudmet (Y.) ; Droit administratif, 2 lé. éd., L G D J, 2015

20- Gerbay (P.); Les effets d'apple en voie d'annulatian, D. 1993.

21- Givernaud (S.); Le droit á un délai raisonable de jugement sur un principe général de droit européen; A J D A, 2009.

22- Jean-Marc(P.) ; Poupeau, Diane (2015), « Télérecours, l'application qui bouscule les habitudes », AJDA, p. 1612 .

$=$ «La visioconférence à l'épreuve du procès équitable », in « La visioconférence dans le prétoire », Les cahiers de la justice, $n^{\circ} 2.2011$. 
23- Jouanneau (F.) « Télérecours, quel bilan deux ans après sa généralisation ? », Veille juridique-Alain Bensoussan Avocats, 28 octobre 2015 (http://www.alainbensoussan.com/telerecours-bilan/2015/10/28.

24- Labetoulle (D.) ; Le référé nouveau est arrivé. A.d., 2000

25- Lascombe (V.), michel et vandendriessche, Xavier, code constitutionnel et Des Droits Fondamentaux, 5 ém. éd., Dalloz - 2016.

26- La Tournere ; Essai Sur les méthodes juridictionnelles au consiel d'etat, 1964.

27- Lévy (D.) ; Devand que soulever la question prioritaire de constitutionnalité , la question prioritaire de constitutionnalité, sous la Direction de Dominique Rousseau, Gazett du palais, lextenso éd. 2010

28- Lombard (M.) ; responsabilité de l' Etat pour la durée excessive des procés administratif , Droit Administratif no 10, octobre 2002.

29- Magmom (X.); La question prioritaire de constitutionnalité pratique et contentieux, A jeur au 1er novembre. 2010.

30- Marcel (V.); Droit administratif, 9 ém. éd., 1966

31- Mari (C.); La commissaire des opèration de Baurle, 1991

32- Pacteau (B. ), Contentieux administratif, 7e édition refondue, Paris, P.U.F., 2005.

= vue de l'intérieur : La loi du 30 juin 2000 : une réforme exemplaire. R.F.D. ad. 2000 = Le juge unique dans les juridictions a dministratives, Gaz. Pal, 30 janr 1998

33- Patrice (S); Quel regard sur la jurisprudence du conseil constitutionnel sur le procès equitable, Nouveaux cahiers du conseil constitutionnel no 44 (Le conseil constitutionnel et le procès équitaule ) - Juin 2014

34- Peiser (B.); contentieux administrative, 12 ém. éd., Dalloz. 2000.

35- Perrot (R.) ; institutions judiciaires , 12 ém. éd., Montchrestien. 2006.

36- Pinault (M.); perspectives ou vertes par la loi de 1987, E.D.C.E., 1988, no 40.

37- Prouvez (J.-B.), «Efficacité, rapidité : un nouveau discours de la méthode pour le juge administratif d'appel », Procédures, $n^{\circ}$ 6, 2003.. 


\section{شعبان أحمد رمضنان}

38- Rousseau (ch.); Le droit international public, paris - dalloz, 3ém. éde, 1965.

39- Rusen (E.); " Prévenir des Arriérés dans la justice administrative ", colloque 7. Juin 2010, Rapport du conseil d' Etat de France Questionnaire.

40- Victore (H.) ; le commissaire du gouvernement et le resbect du contraditoire, Recueil Dalloz - 1999 , 19 ém. Charonique

41 - Weber (A.); " Le juge administratif unique, nécessaire à l'éfficacité de la justice " , RFAP, no 125. Janyaier. 2008. 
للفصل في الدعاوى الإدارية خلال مدة معقولة في النظام

$$
\text { شعبان أحمد رمضان }
$$


للفصل في الدعاوى الإدارية خلال مدة معقولة في النظام

$$
\text { شعبان أحمد رمضان }
$$


للفصل في الدعاوى الإدارية خلال مدة معقولة في النظام

$$
\text { شعبان أحمد رمضان }
$$


للفصل في الدعاوى الإدارية خلال مدة معقولة في النظام

$$
\text { شعبان أحمد رمضان }
$$

